Running head: SI ADMINISTRATION STAFFING AND SUPPORT

\title{
EFFECT OF SI ADMINISTRATION STAFFING AND SUPPORT ON SI PROGRAM OUTCOMES IN HIGHER EDUCATION
}

A Dissertation
presented to
the Faculty of the Graduate School
at the University of Missouri-Columbia
In Partial Fulfillment
of the Requirements for the Degree
Doctor of Education
KIRK A. SKOGLUND
Dr. Timothy J. Wall, Dissertation Supervisor
MAY, 2020




\section{SI ADMINISTRATION STAFFING AND SUPPORT}

The undersigned, appointed by the dean of the Graduate School, have examined the dissertation entitled:

\section{EFFECT OF SI ADMINISTRATION STAFFING AND SUPPORT ON SI PROGRAM OUTCOMES IN HIGHER EDUCATION}

presented by Kirk A. Skoglund

a candidate for the degree of doctor of education

and hereby certify that, in their opinion, it is worthy of acceptance

Dr. Timothy Wall

Dr. Nissa Ingraham

Dr. Leslie Galbreath

Dr. Kori Hoffmann 


\section{SI ADMINISTRATION STAFFING AND SUPPORT}

\section{DEDICATION}

First, this dissertation is dedicated to past and present tutors, SI leaders, SI mentors, and graduate assistants with whom I have worked. Your ideas, perspectives, and efforts have led me to where I am today and inspire me to continue working in this field. Your passion and enthusiasm for the work motivates me continually.

Second, I dedicate this dissertation to my parents and my family members. The value you placed on education inspires me to continue learning throughout my life. I recognize all the support you have given to me throughout my education, and I am so thankful for it.

Third, I would like to dedicate this dissertation to colleagues and mentors throughout my educational and professional career. There are too many of you to name, but if you are reading this, you are probably one of them. All of you have believed in me even when I did not believe in myself, provided continuous and unconditional support, and have always pushed me to grow.

Fourth, I would like to dedicate this dissertation to my fellow cohort XI members. The cohort model has provided me with an experience of a lifetime. I have learned so much from all of you, and the connections and friendships we have built during this journey have made it all worth it. 


\section{ACKNOWLEDGMENTS}

A huge acknowledgment goes to my mother, Tracy Skoglund. She spent countless hours looking up individual SI programs at different universities to find contact information for me to distribute my surveys. I could not have done it without her help. I would also like to acknowledge my committee members who have provided valuable feedback throughout this process. I probably owe my entire trajectory in higher education to Dr. Leslie Galbreath. I am eternally grateful that she believed in me early on in my undergraduate degree and always pushed me to grow. I would like to acknowledge my advisor, Dr. Timothy Wall, who has been with me during most of my graduate education, provided hours of feedback to me, and shaped my views on education and scholarly research. Dr. Nissa Ingraham and Dr. Kori Hoffmann are newer additions on my educational ride, but their contributions and feedback have been invaluable to me on my journey. Lastly, I want to acknowledge my friends who have supported me on this journey. Their continual support, encouragement, and understanding have been critical to my success. 


\section{TABLE OF CONTENTS}

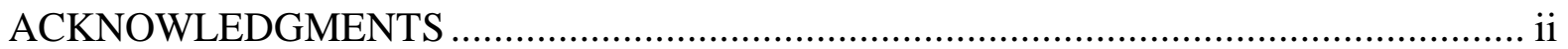

LIST OF TABLES ....................................................................................... vii

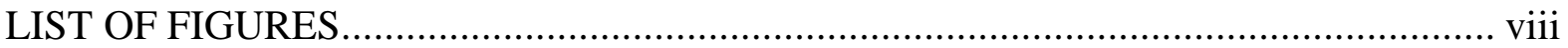

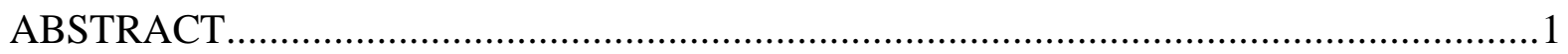

SECTION ONE - INTRODUCTION TO THE DISSERTATION-IN-PRACTICE ..............2

Introduction to the Background of the Study ........................................................2

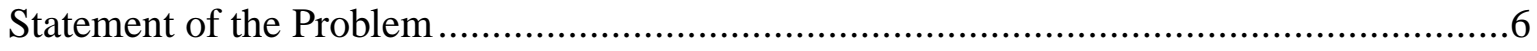

Purpose of the Study ......................................................................................... 7

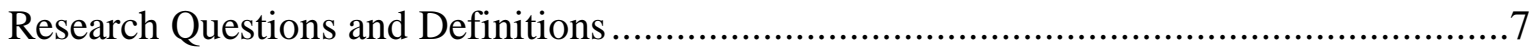

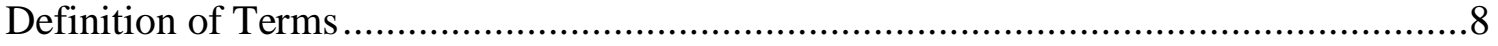

Research Questions ..................................................................................... 10

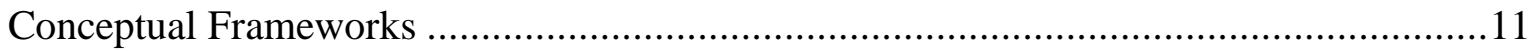

Higher Education and Learning Assistance .................................................... 11

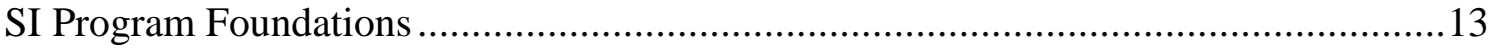

Staffing Considerations and Support............................................................... 16

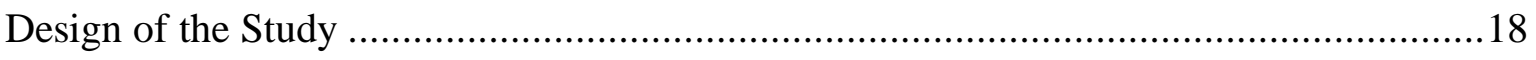

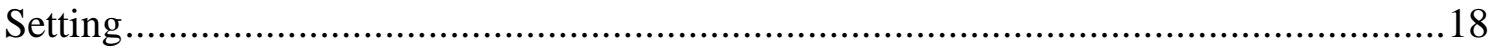

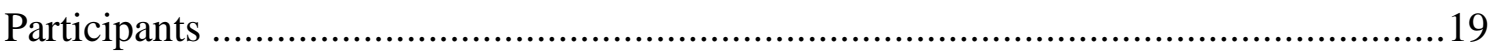

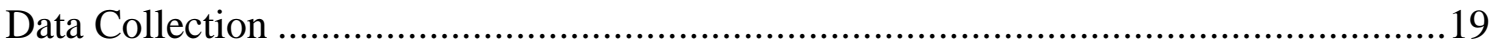

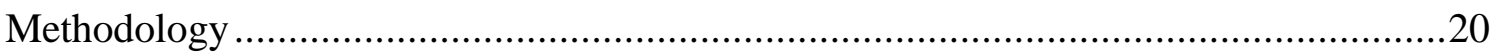

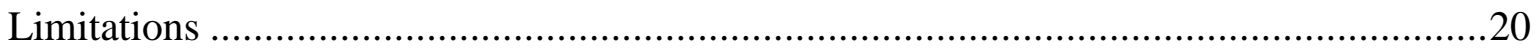

Delimitations, Assumptions, and Design Controls ..............................................22 


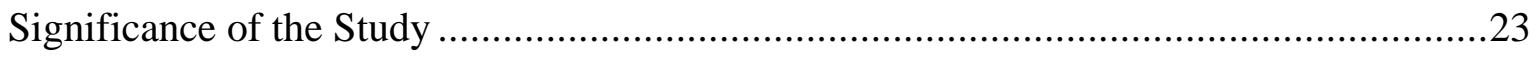

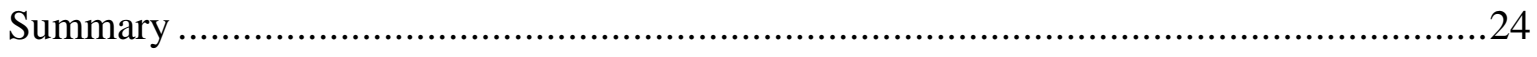

SECTION TWO - PRACTITIONER SETTING FOR THE STUDY .............................25

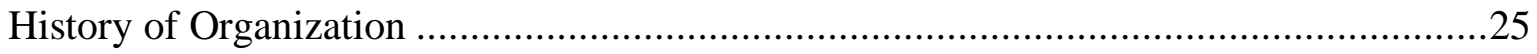

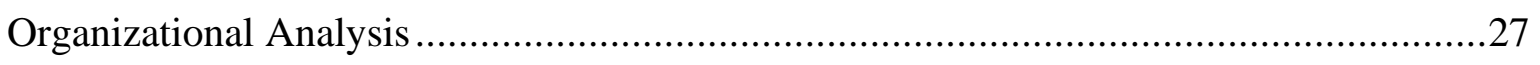

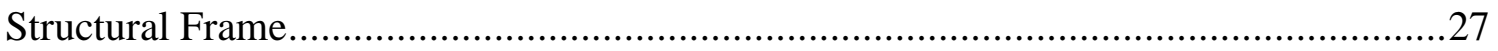

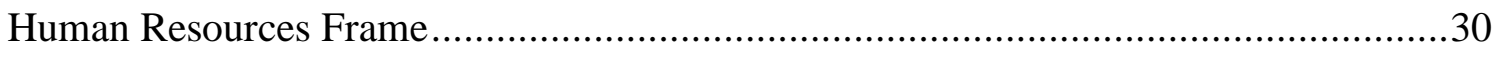

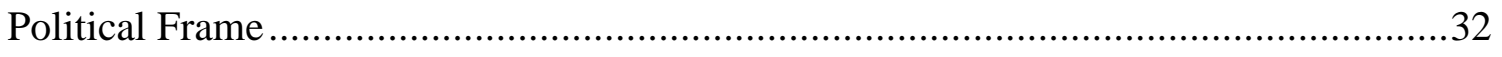

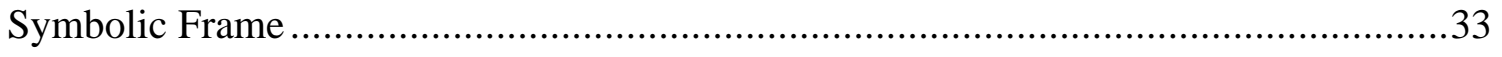

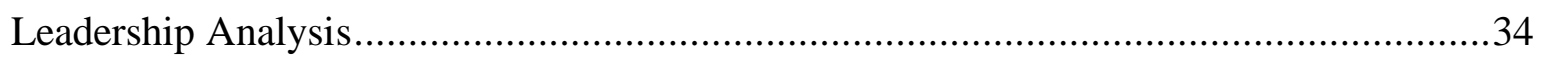

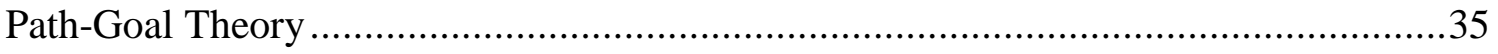

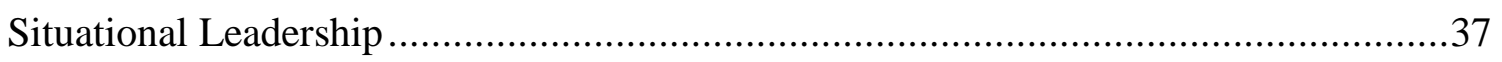

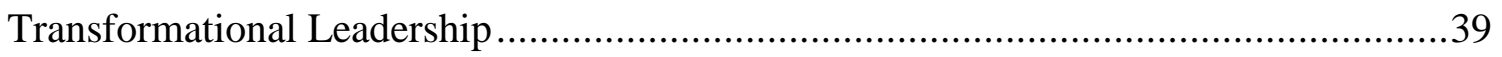

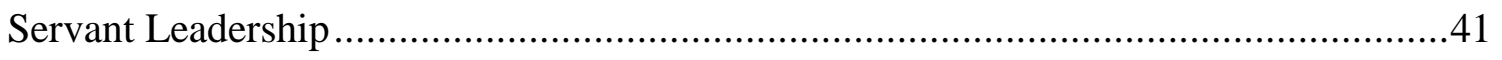

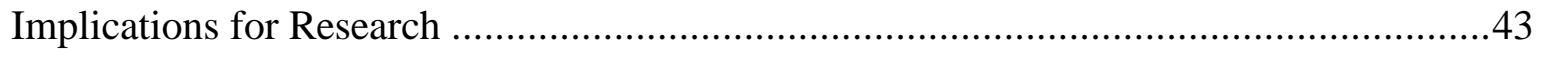

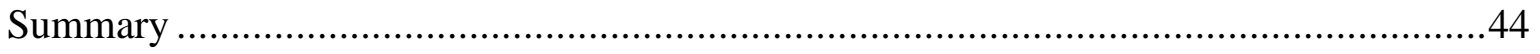

SECTION THREE - SCHOLARLY REVIEW FOR THE STUDY ...............................45

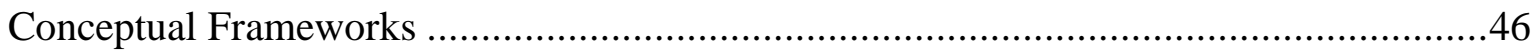

Higher Education and Learning Assistance......................................................46

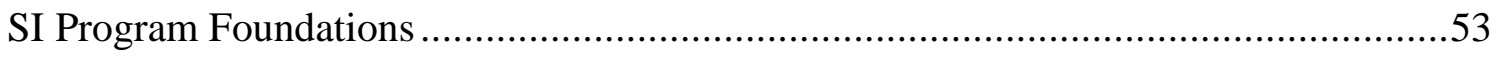

Staffing Considerations and Support .........................................................63

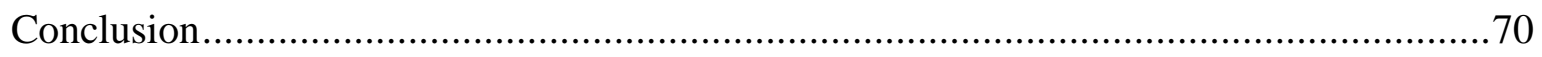

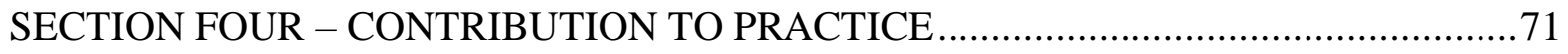




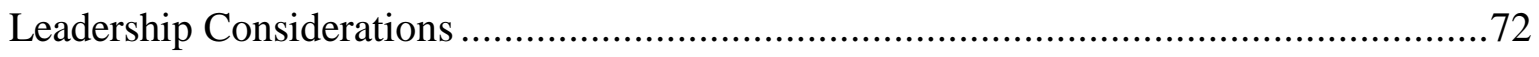

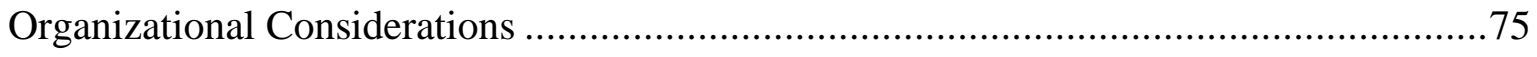

Supervisory Considerations....................................................................................

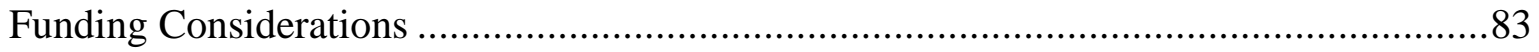

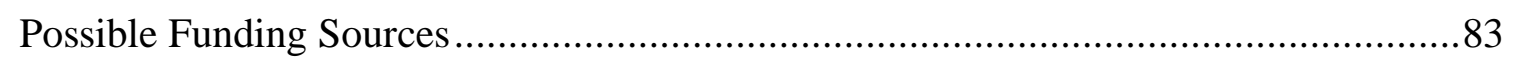

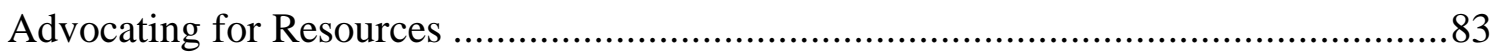

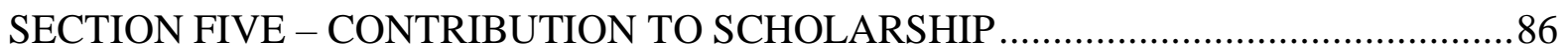

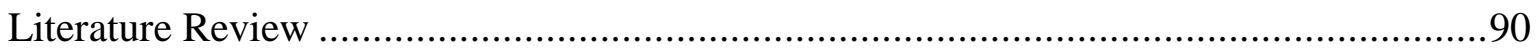

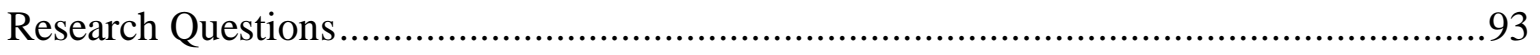

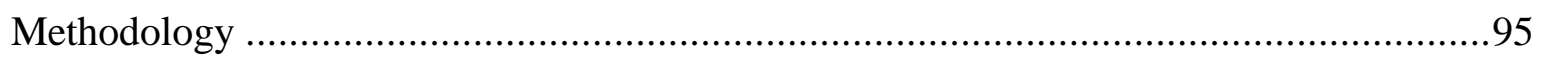

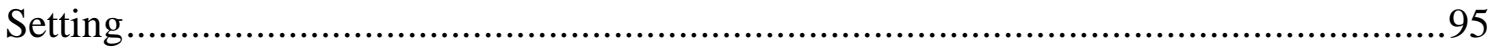

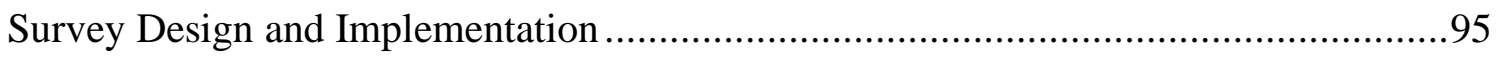

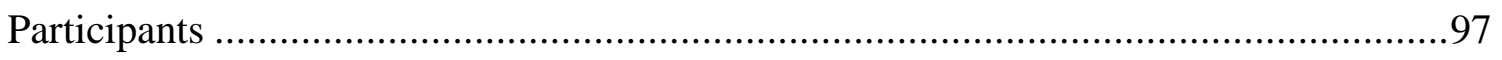

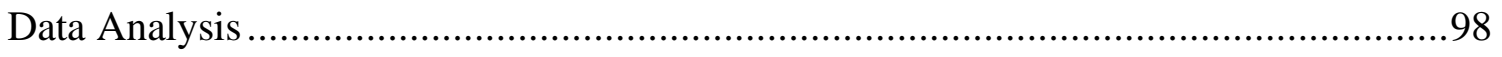

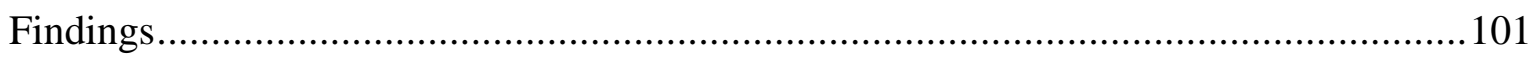

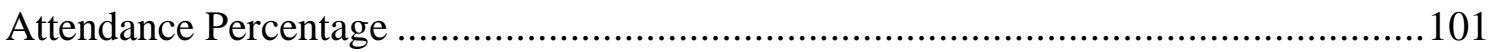

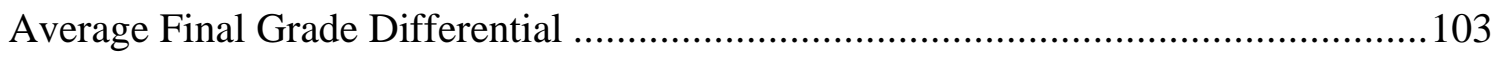

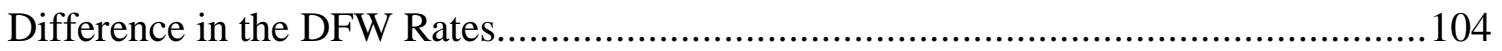

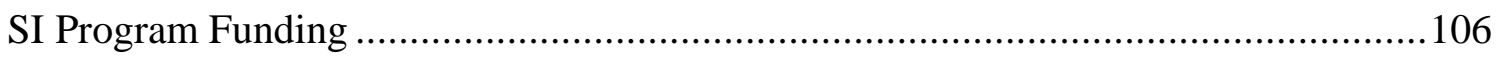

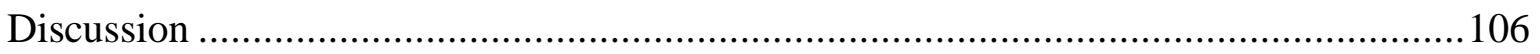

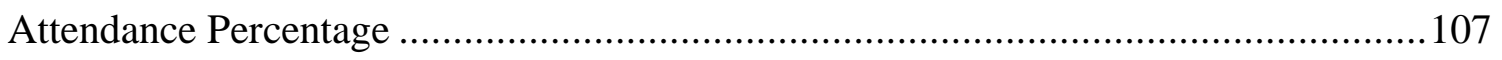

Difference in Average Final Grade ...................................................................... 108

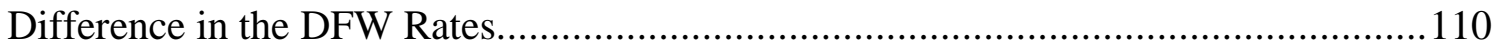




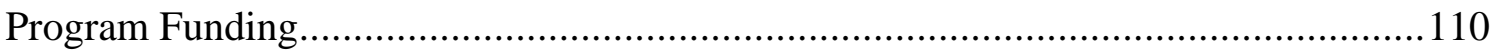

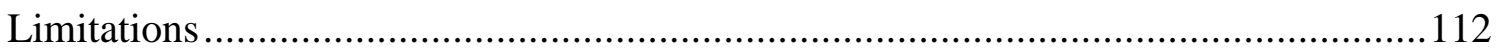

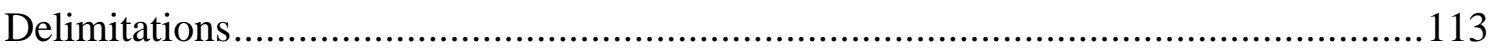

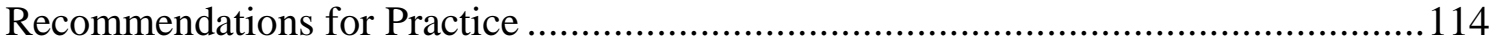

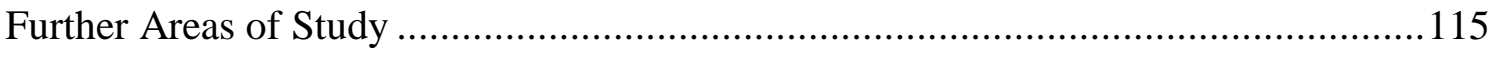

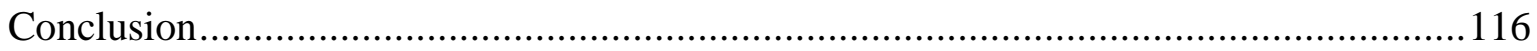

SECTION SIX - SCHOLARLY REFLECTION ...................................................... 118

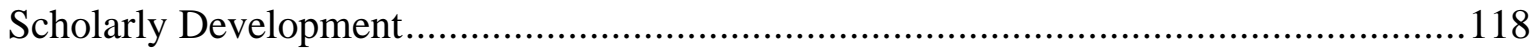

Practitioner Development............................................................................... 121

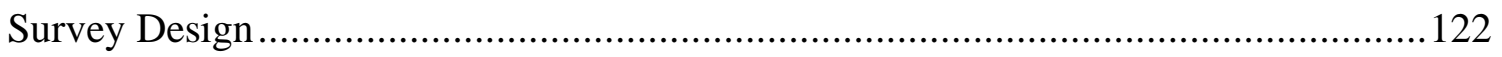

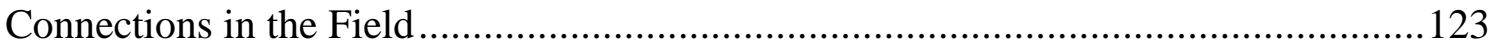

Reflective Practices ................................................................................... 124

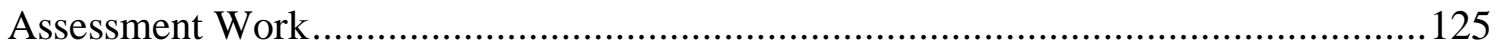

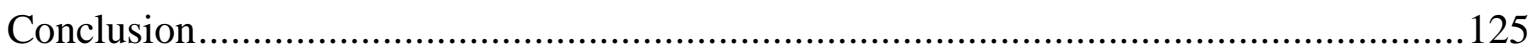

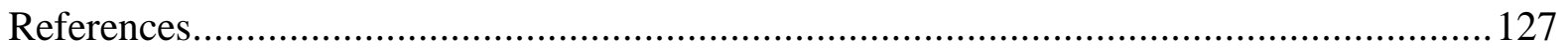

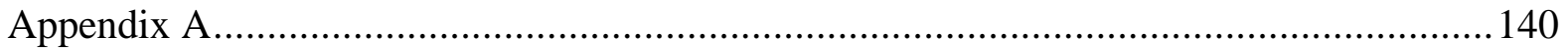

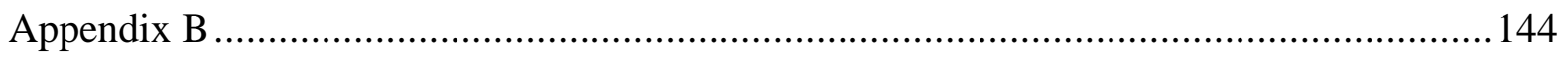

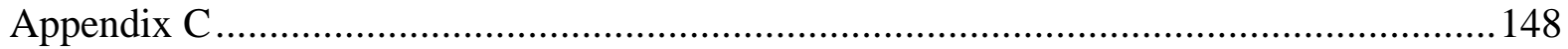

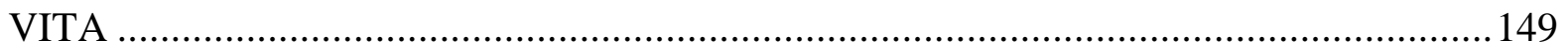




\section{LIST OF TABLES}

Table 3.1 - Eras in US Higher Education ................................................................ 47

Table 5.1 - Institutional Characteristics of the Survey Respondents .............................97

Table 5.2 - Descriptive Statistics of the Variables and SI Leaders ................................99

Table 5.3 - Coefficients for Regression Model for Attendance Percentage with Outliers

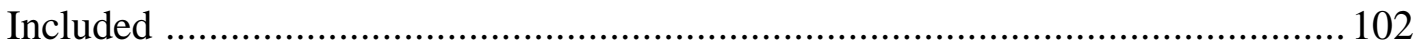

Table 5.4 - Coefficients for Regression Model for Attendance Percentage with Outliers

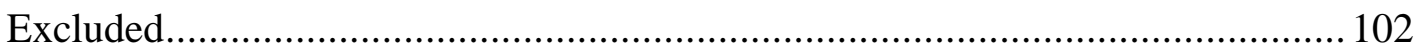

Table 5.5 - Coefficients for Regression Model for the Average Final Grade Differential with

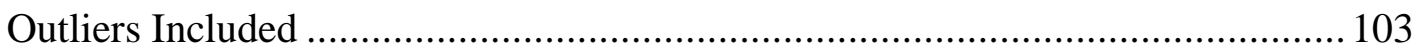

Table 5.6 - Coefficients for Regression Model for the Average Final Grade Differential with

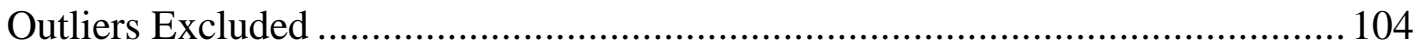

Table 5.7 - Coefficients for Regression Model for the Difference in the DFW Rates with

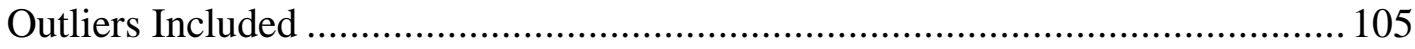

Table 5.8 - Coefficients for Regression Model for the Difference in the DFW Rates with

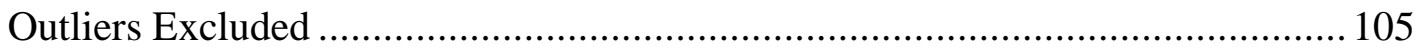

Table 5.9 - Pearson Correlations with Per SI leader Funding by Program Outcome ........ 106 


\section{LIST OF FIGURES}

Figure 1.1 - Key Individuals in SI Programs .....................................................

Figure 1.2 - SI Administrative Tenets and Program Outcomes....................................... 9

Figure 2.1 - SI Program Structure and Mintzberg's Five Parts of Organizations...............28

Figure 2.2 - The Situational Leadership Model ........................................................... 37

Figure 5.1 - SI Administrative Tenets and Program Outcomes................................... 94 


\begin{abstract}
Supplemental Instruction (SI) is an internationally recognized learning assistance program used in higher education to support traditionally challenging classes by offering regularly scheduled, peer-led, group study sessions for the students enrolled in the targeted course. This study explored the administrative hours spent on specific SI program constructs (training-related, observation of sessions, planning support, and administrative tasks) and program funding and their relationships with program outcomes (attendance rate for the program, the difference in the average final grades between SI session attendees and nonattendees, and the difference in the rate of Ds, Fs, and withdraws between the SI session attendees and non-attendees). This quantitative study collected data from SI programs at institutions across North America $(\mathrm{N}=63)$. Multiple linear regression and correlation were used to examine the relationships between the variables. The regression models and correlation analyses were statistically insignificant, except training-related hours per SI leader was significantly related to the attendance rates for the entire SI program. This result might suggest that training-related hours assist leaders in developing high-quality sessions, thereby increasing attendance percentage. This finding indicates that SI program administrators should enhance their training-related responsibilities per SI leader to increase attendance rates for the program. These findings were limited by small sample size and focus on supervisory constructs while ignoring other factors such as institutional characteristics that may influence program outcomes. Future studies should explore each supervisory construct individually while controlling for aspects of SI programs that may affect program outcomes and collect larger sample sizes.
\end{abstract}




\section{SECTION ONE - INTRODUCTION TO THE DISSERTATION-IN-PRACTICE}

Colleges and universities are being increasingly held accountable for student success (Dar, 2016) and increasing the affordability of a college education (Butler, 2016). The use of learning centers in higher education to aid underprepared students in America is commonplace (Arendale, 2004). Learning center programming often includes tutoring and academic support functions like Supplemental Instruction (SI) (Maxwell, 1997; Truschel \& Reedy, 2009). This study seeks to learn more about the relationship between administrative tenets of SI programs and funding with the program's outcomes. The results of this study provide benchmarks for SI program administrators on the hours to spend in certain areas and insight on what supervisory activities are related to program outcomes. The background of the study focuses on learning assistance programs and the development of SI programs. The next subsection includes the research questions. The conceptual frameworks of higher education, SI, and staffing considerations frame the study. Finally, the design and implications of this study are highlighted.

\section{Introduction to the Background of the Study}

There are several pressures facing colleges and universities today. Butler (2016) indicates that financial realities and academic readiness are barriers for students to access college. Arendale (2004) cites academic readiness and increasing enrollment as the catalyst for the expansion of learning assistance centers in higher education. Additionally, higher education institutions are being held accountable for student outcomes, like retention and graduation rates (Dar, 2016). The drop-out rate, another outcome, is cited as part of the development of learning assistance programs (Arendale, 2004). In order to support student achievement and access, learning assistance is a crucial strategy (Arendale, 2010). Huisman 
and Currie (2004) indicate that a need for more effective and efficient use of public funds is leading to more accountability from external bodies such as the government. Thus, it is critical for learning assistance programs to demonstrate their value in higher education.

There is a misperception of learning assistance as an unnecessary program by college administrators and the public, which creates a challenge for program administrators (Arendale, 2010). Arendale (2010) also cites increasing access and support for marginalized student populations as an added pressure for learning assistance programs. Moreover, Arendale (2010) discusses a lack of credible research to support learning assistance practices, which heightens these pressures. Thus, there is a clear and compelling need to study the efficiency and effectiveness of learning assistance program administration.

Christ (1971) as cited in Arendale (2004) says that learning assistance centers have six primary purposes: helping students with grades, a centralized tutoring service, a referral resource, a repository of materials to aid in studying, a trainer of tutors, and a place for faculty development. Maxwell's (1997) work updated this view of the learning assistance centers and describes fourteen functions of learning centers and added diagnostic testing, study skill programming, computer-assisted instruction, connecting with administrators, counseling, advising, evaluation, and Supplemental Instruction (SI). In a more recent view of the functions of learning centers, Truschel and Reedy (2009) found that tutoring services, including SI, were the top resources, in terms of frequency, provided in learning centers.

SI was developed in the 1970s to assist students at the University of MissouriKansas City (UMKC) in succeeding in traditionally challenging classes (Hurley et al., 2006). SI provides voluntary, regularly-scheduled sessions outside of a specific class led by peers for enrolled students to review course content (Martin \& Arendale, 1992c). The goals of SI 
programs are to increase graduation rates, reduce attrition rates for specific courses, and increase grades in targeted courses (SI, 2019b). This model of support has been adopted and used in over 2,000 institutions worldwide (Arendale, 2010).

SI programs consist of several individuals. The SI leaders, who are usually peers, assist students in learning challenging content through strategies that integrate how to learn and study the material during the out-of-class sessions (Hurley et al., 2006). The faculty of a targeted course and the SI supervisor are also critical components of an SI program. The supervisor helps plan the program, sets up SI leader training, helps plan and observe SI sessions, and conducts program evaluation. The SI faculty members need to be willing to work with SI leaders for the program to be successful (Hurley \& Gilbert, 2008a). Because of these responsibilities and if there is a large enough institutional enrollment, Ainsworth, Garnett, Phelps, Shannon, and Ripperger (1994) indicate that the SI supervisor should be full-time. Lastly, higher education administration plays a crucial role in providing the funding and support for SI programs. Figure 1.1 provides a visualization of the SI program structure and the key individuals. With the development of SI programs, program administrators are left with questions as it relates to program management.

The first is determining the level of supervision needed. Wilcox (2008) asserts that one supervisor cannot manage more than three or four SI leaders without some assistance but does not cite any evidence to support this claim. Given budget climates, such levels of supervision might be unrealistic for SI programs. Wilcox's (2008) reasoning for this number is that SI program supervisors have to observe SI leaders frequently, help with planning sessions, conduct and plan SI leader training, manage faculty relationships, and manage the program, including evaluation and logistics. Like the ideal ratio of SI leaders to supervisors, 
Wilcox (2008) does not suggest the ideal hours for most of the categories except for SI leader observations, which are addressed later.

Figure 1.1.

Key Individuals in SI Programs

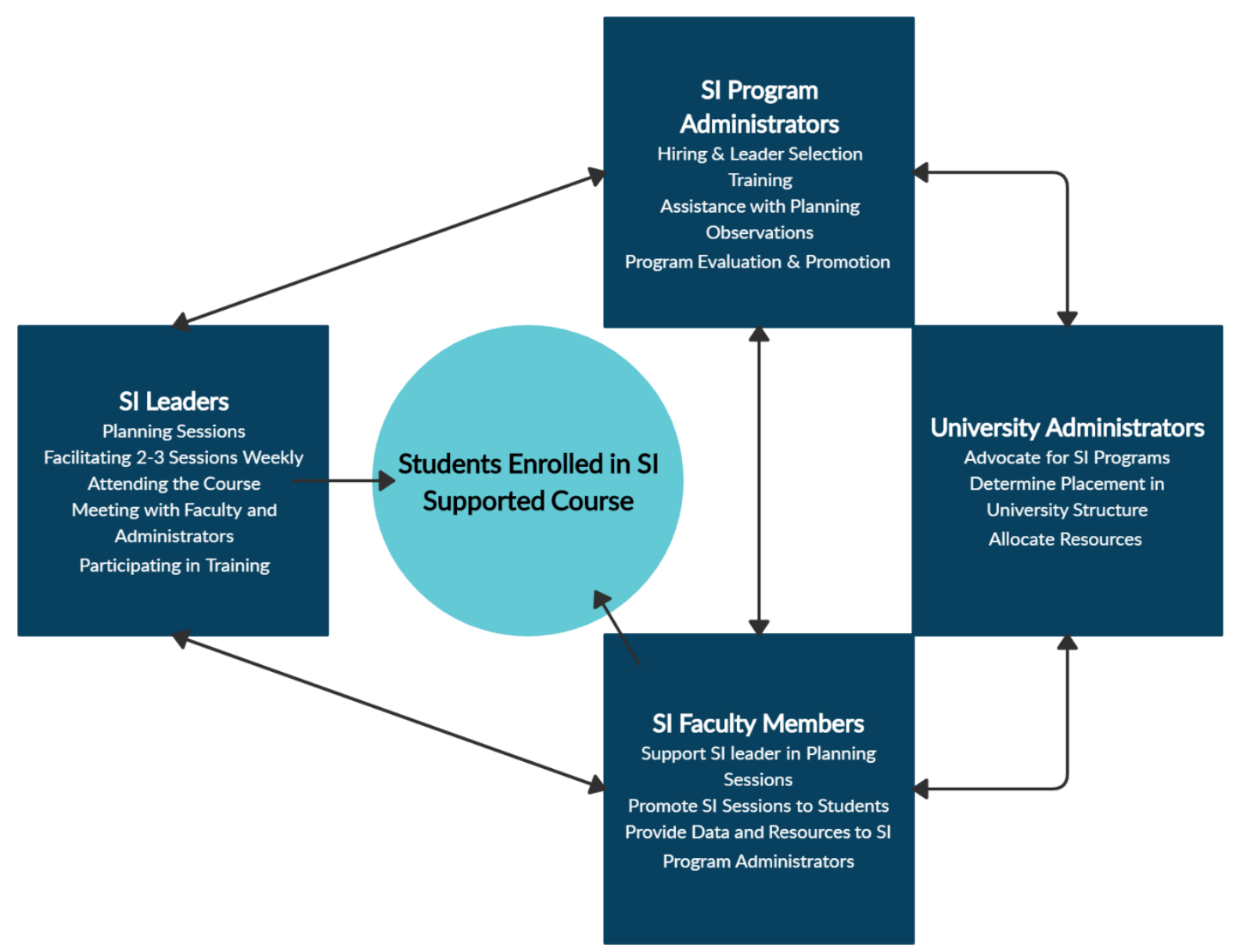

Furthermore, SI program supervisors also do not know how to prioritize the SI

responsibilities in their work. Consequently, there is a lack of knowledge on the impact of these administrative tenets on program outcomes. This study examines these tenets of SI programs and their influence on program outcomes. The information from this study assists in guiding SI program supervisors in their practice. 


\section{Statement of the Problem}

The widespread adoption of the SI model speaks to its efficiency and efficacy in promoting student success. There was a need to recognize SI programs that are following the core tenets of SI and regularly demonstrating positive outcomes of SI programs (SI, 2019a). In response to this, the International Center for Supplemental Instruction created an SI accreditation process to recognize and collect data from institutions that are accredited (SI, 2019b). The International Center for SI outlines that accredited programs demonstrate evidence in the following areas: a trained supervisor in the SI model, evidence of extensive and ongoing training, support through observation, planning of SI sessions, evidence of class attendance by the SI leader, and show a data trend similar to research findings (SI, 2019b).

The International Center has further specified these guidelines in a rubric, used to evaluate SI programs when they seek accreditation. This rubric guides programs on the number of session observations. At level one, for example, which is considered developing, the rubric indicates that programs should conduct three observations of all leaders, while the distinguished level indicates that programs should conduct ten or more observations for new SI leaders and eight for returning leaders (Curators of the University of Missouri, 2018). Additionally, the rubric recommends specific activities in pre-term training and at least eight hours of ongoing professional development and training for leaders at the distinguished level (Curators of the University of Missouri, 2018). However, there is not a mention of how much time should be spent assisting with faculty relationships, administrative tasks, and assisting leaders with planning. Additionally, the staff at the International Center for SI have discussed the potential relevance of program funding (J. Collins \& M. Cross, personal communication, August 8, 2019). Thus, there is a gap of knowledge in understanding how the SI 
administrative hours devoted to these areas — training/training preparation, observations, assisting leaders with planning, and general supervisory tasks such as data collection and faculty relations - and how program funding influences SI program outcomes. The problem is a lack of knowledge of the importance of these areas on program outcomes. These gaps in knowledge are problematic for SI programs that are seeking best practices to guide their work and when advocating for resources. This study adds additional research to this body of literature as it pertains to SI program administration and support.

\section{Purpose of the Study}

The purpose of this study is to gather data and information on administrator hours spent and program funding and their relationship to programmatic outcomes. More specifically, this study provides insights into the hours spent observing, assisting with planning, training-related activities, program administration, and program funding and their respective relationships with program outcomes. By learning more about the optimal practices and noteworthy influences on outcomes, SI program administrators can allocate their time, energy, and resources efficiently.

\section{Research Questions and Definitions}

This research uses data from a single semester or term from an institution's SI program. The dependent variables are SI program outcomes such as the percentage of students served, final grade differential between the students who attend SI and those who do not, and the difference in the rate of students who earn Ds, Fs, or withdraw from a course (DFW rates) of SI session attendees and those who do not attend any sessions. SI program administrators should know how many students are served to determine the benefit to the students (Hurley et al., 2006). Because participation in SI sessions is voluntary, the 
percentage of students served, as measured by the number of students who attend SI sessions, is one measure of program success. As SI programs have goals to positively influence grades and student learning, the average final grade differential between the students who attend SI sessions and those who do not is a standard SI program outcome (Hurley \& Gilbert, 2008a). Lastly, the difference in the DFW rates between SI session attendees and non-attendees is cited as a measure of retention within a course (Hurley \& Gilbert, 2008a), so it was included as a dependent variable in this study. Hurley and Gilbert (2008a) suggest that participation data, along with grade information, are essential to send to administrators and faculty for the continued success of a SI program.

The independent variables will consist of several constructs related to SI program supervision. The first variable is the average number of observations conducted per SI leader in a given term. The second variable is the average hours spent assisting with planning per SI leader each term. The third variable is the average hours of training, including preparation for training per SI leader during that term. The fourth variable is all other supervisory hours for an SI program on average per SI leader during that term. The fifth variable in the study is the average funding per SI leader. By studying SI programs on an institutional/program level, the results of this study guide practices in SI program administration. Figure 1.2 illustrates the potential relationships between the independent and the dependent variables.

\section{Definition of Terms}

Before discussing the research questions, it will be helpful to define the terms used throughout the study. Here are the definitions of some of the terminology used: 


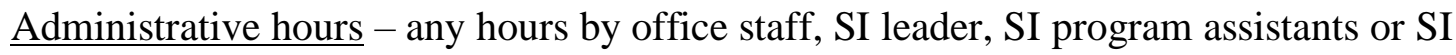

mentors, graduate assistants, or professional staff that are dedicated to SI program evaluation, faculty meetings, data collection, and tracking, report writing, room scheduling, emailing, etc. This figure does not include training, observations, or planning activities.

Difference in DFW rates - the difference between the rate of students who earn a D, F, or withdrew (DFW) from a course and attended at least one SI session and the DFW rate of the students who did not attend any SI sessions

Figure 1.2

SI Administrative Tenets and Program Outcomes

\section{Supplemental Instruction (SI) Program Adminstration}

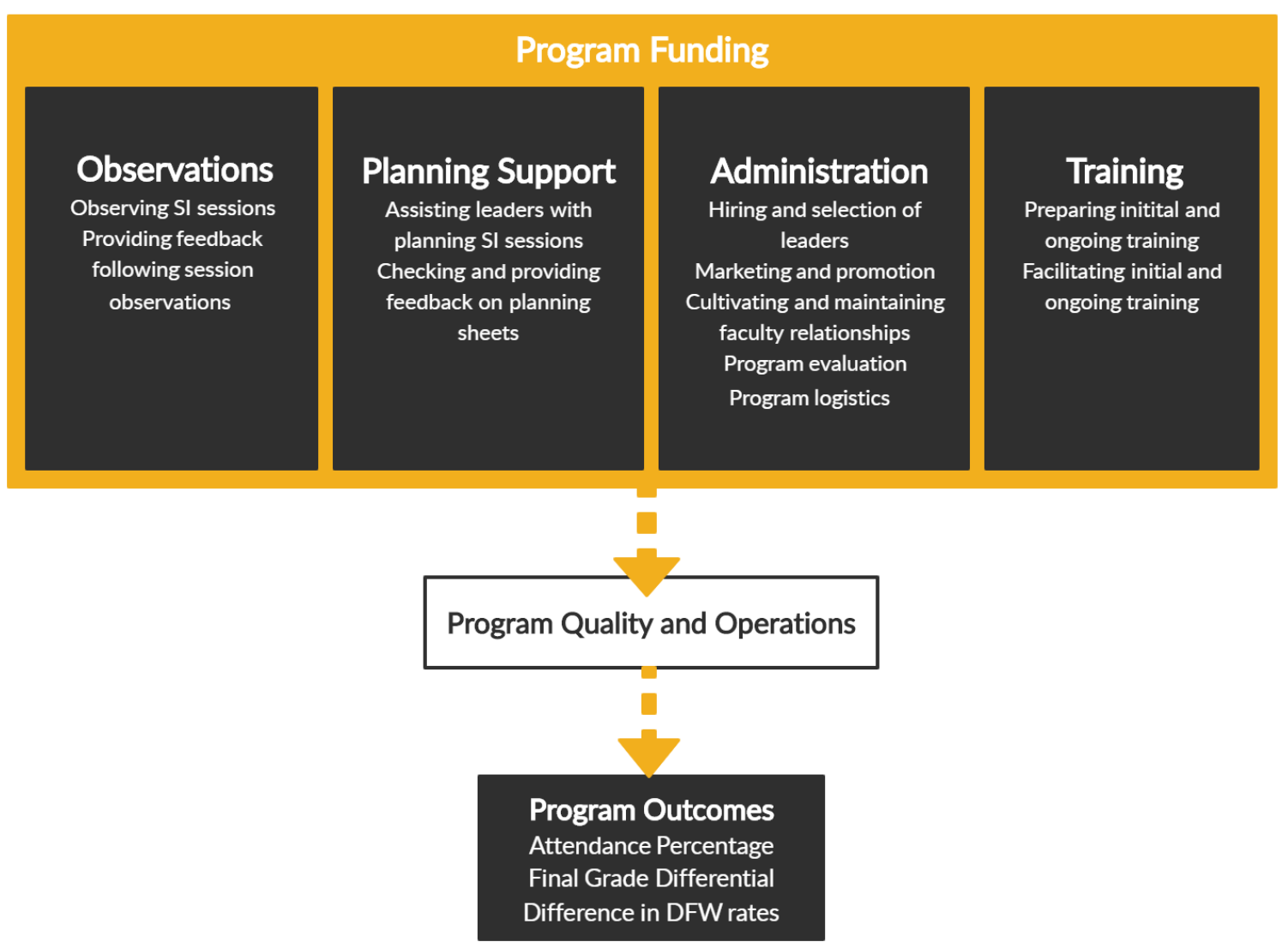


Grade differential - the difference in the average final grade of the entire SI program across all their courses for a given semester using a four-point scale $(4=\mathrm{A}, \mathrm{B}=3$, etc.) between the students who attend at least one SI session compared to the students who did not attend any SI sessions.

Observation hours - the approximate number of hours spent observing, preparing to observe, and debriefing with SI leaders following observations. These hours can include peer observations, observations by SI mentors or program assistants, and observations by professional or paraprofessional staff.

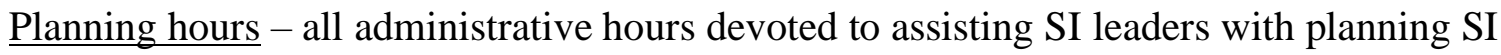
sessions.

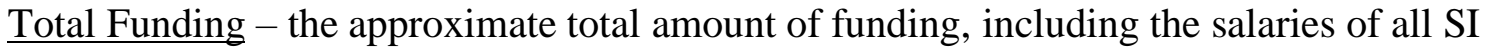
leaders and administrative staff and operational costs of the SI program.

Training hours - administrative hours planning and delivering training and/or professional development, including initial and any ongoing training. This figure includes the actual training time as well as time planning it.

\section{Research Questions}

1. What is the relationship between the observation hours per SI Leader, planning hours per SI leader, training hours per SI leader, administrative hours per SI leader, and funding per SI leader for an SI program and the percentage of students enrolled in an SI course that attend at least one SI session?

2. What is the relationship between the observation hours per SI Leader, planning hours per SI leader, training hours per SI leader, administrative hours per SI leader, and 
funding per SI leader for an SI program and the final grade differential between the students who attended SI sessions and the students who did not?

3. What is the relationship between the observation hours per SI Leader, planning hours per SI leader, training hours per SI leader, administrative hours per SI leader, and funding per SI leader for an SI program and the difference in DFW rates of the students who attend SI sessions and those who did not?

\section{Conceptual Frameworks}

The lenses of higher education and learning assistance programs, SI program foundations, and organizational staffing and support guide this study. Higher education and learning assistance provide the context and importance of SI programs. There is also a substantial body of literature that illustrates the gaps in knowledge as well as context for SI program administration. Lastly, organizational literature provides considerations for the administration of SI programs.

\section{Higher Education and Learning Assistance}

Higher education and learning assistance have a long history in the United States (US). According to Thelin (2011), higher education in the US was initially characterized by little governmental influence and emphasis on degree completion. Additionally, early US institutions did not have admission standards for students, and students were often admitted because of the financial need of the institution (Arendale, 2010; Church \& Sedlak, 1997; Thelin, 2011). A lack of accountability from the government created little need for formalized learning assistance systems. During this time, Arendale (2010) indicates that learning assistance programming was individualized tutoring before students attended college to prepare them for the coursework. 
As the $20^{\text {th }}$ century approached, the Morrill Act, which granted land for institutions to be built and often focused on fields such as agriculture and mechanics (Thelin, 2011), led to an increase in college enrollment and opportunity. This focus on agriculture and mechanics led to the increase of enrollment of students from backgrounds who generally were unprepared for college rigor (Arendale, 2010). Thus, Arendale (2010), Johnson (1997), and Cohen and Kisker (2010) indicate that academies prepared students going into higher education for writing, reading, and mathematics. According to Arendale (2010), some of the universities and colleges also began providing remedial coursework to prepare new students for the academic rigor of college. Learning assistance and higher education began to shift rapidly in the $20^{\text {th }}$ century.

In the mid- $20^{\text {th }}$ century, higher education began to shift towards mass access. There was a massive expansion of college enrollment partially due to the GI bill, which increased veteran access to higher education (Arendale, 2010; Cohen \& Kisker, 2010; Freeland, 1997; Thelin, 2011). According to Arendale (2010) and Cohen and Kisker (2010), the dramatic enrollment increase in higher education led to an increase in learning assistance and remedial coursework to prepare students academically. Arendale (2010) also posits that stigma related to learning assistance services also increased during this period as the more affluent students were more prepared for college-level work and did not need to take remedial coursework. With increased enrollment and value placed on education, higher education saw the expansion of consistent funding, expanded student affairs and services, and increased the use of standardized testing for admission decisions (Thelin, 2011). These all had a factor in influencing the growth of learning assistance in higher education. 
After 1970, there was a massive growth in learning assistance programs in higher education. Thelin (2011) indicates that there were increased concerns about retention and completion rates, which led to the expansion of student services. Arendale (2010) echoes this by indicating that learning assistance programs were expanded rapidly due to external pressures to increase student retention. Arendale (2010) indicates that the term "learning assistance" was first used in professional literature at this time and served to represent comprehensive academic support for students at all levels, not just students in need of remediation. During this period, learning assistance centers saw the rise of diversified programming in academic support (Arendale, 2010). Jacobs and Stone (2008) indicate that Supplemental Instruction (SI) was an alternative to traditional support systems such as tutoring and remedial courses. The idea of focusing on high-risk courses versus high-risk students was a shift that avoided the stigma that remedial classes and tutoring often have for students (Jacobs \& Stone, 2008; Martin \& Arendale, 1992c). With over 35 years of programming and dramatic expansion across the globe (Wilcox \& Jacobs, 2008), SI is firmly rooted in higher education. Thus, examining the administrative tenets of SI and program support as they relate to student outcomes adds to the body of literature in the field.

\section{SI Program Foundations}

SI was created in the 1970s, and several theories guide the program's functions. Martin and Arendale (1992c) cite the work of Jean Piaget and constructivism for the foundation of SI because the SI leader seeks to guide students through developmental levels and develop academic skills. Additionally, Martin and Arendale (1992c) discuss Edgar Dale's Cone of Experience to help SI Leaders plan their sessions, which provides the idea that leaders design activities to build upon concepts. McGuire (2006) discusses cognitivism, 
behaviorism, and constructivism viewpoints as foundations for session strategies and techniques. Zerger (2008) discusses more recent theoretical views to inform the SI model, including cognitive growth, constructivism, experiential learning, social interdependence theory, and critical theory. Zerger (2008) also says, "SI has borrowed from a multitude of learning theorists, and then adapted these ideas to work in conjunction with one another." (p. 26). Vygotsky's (1978) idea of the zone of proximal development which is "the distance between the actual developmental level as determined by independent problem solving and the level of potential development as determined through problem-solving under adult guidance or in collaboration with more capable peers" (p. 86) is a critical aspect of SI. Therefore, SI is designed to use several different theories of learning and development in conjunction with one another. Next, the various administrative components of SI programs are addressed.

Observations can significantly assist in the quality of the SI sessions (McDaniel, 2008). McDaniel (2008) suggests that observations help leaders develop vital skills that they learned in initial and ongoing training. Wilcox (2008) indicates the SI supervisor should observe the first three sessions, a session each week for the first half of the term, and every two weeks for the second half of the term. Wilcox (2008) does not cite any reasons why this high number of observations for a single SI Leader is essential and goes on to suggest that one supervisor cannot manage more than three or four leaders without some assistance. This level of supervision seems unrealistic.

Training is a critical element of SI programs. SI programs should conduct about eight to sixteen hours of pre-semester training for the SI leaders (McDaniel, 2008; Wilcox, 2008). This training should be under the direction of the SI program supervisor (Ainsworth et al., 
1994). The pre-semester training should prepare leaders to lead sessions, learn how to integrate study skills, teaching methods, theories of learning, and practice sessions (Martin \& Arendale, 1992c). SI leader training also includes a focus on collaboration (Wilcox, 2008) and facilitation skills (McDaniel, 2008). Beyond the pre-semester training, SI programs are encouraged to have ongoing training throughout the semester. These sessions help leaders add and refine strategies, address problems, and allow the leaders to support one another (McDaniel, 2008).

Effective planning is a required element of SI program certification (SI, 2019a), and McDaniel (2008) highlights how SI leader planning creates objectives for sessions and models effective strategies to learn. Zerger (2008) shares how SI sessions rely on cooperative learning strategies. Levi (2017) says that teams are more effective if they have positive social connections. Thus, for SI sessions to be successful, the SI leader must attend to the environment by creating a culture of respect and manage student behaviors. Additionally, the quality of the first few sessions could have a significant influence on the attendance of future SI sessions (Wilcox, 2008). Thus, adequate support for SI leaders as they plan is essential for successful sessions.

SI program administration involves several other tasks. The first is hiring and selection of the SI leaders. Some hiring criteria used include high grades in the targeted course and the ability to work well with others (McDaniel, 2008). Second, supervisors manage faculty partnerships, determine the placement of SI leaders, and promote SI to students to encourage attendance (Martin \& Arendale, 1992c; Wilcox, 2008). Third, SI program supervisors need to engage in ongoing program evaluation (Hurley et al., 2006). Lastly, supervisors manage all program logistics (Hurley et al., 2006). 
SI programs are relatively inexpensive to run. Wilcox (2008) suggests that the salary costs of the SI leaders are one of the most expensive components of a program. Additional costs include the time of the supervisor (Wilcox, 2008) and program supplies such as textbooks for leaders (Widmar, 1994). Theoretically, SI is efficient due to the group-based approach in that the program serves a large number of students (Wilcox, 1992; Zerger et al., 2006). The funding of the program may also influence the other administrative tenets because it provides resources to engage in them.

The components of SI program administration have not been well-researched. Arendale (2000) explored the implementation of SI programs by surveying the SI programs across the US. He explored the effect of administrative placement of SI program, SI supervisor involvement, SI leader training, and institutional involvement on the following outcomes: average attendance rate of the program, difference in average final grades, the difference in DFW rates, and satisfaction level with the program. Of these constructs, the only one that was not significantly related to the outcomes was administrative placement in institutions (Arendale, 2000). However, Arendale's (2000) research did not offer the optimal level of these administrative tenets nor a prioritization of these responsibilities.

\section{Staffing Considerations and Support}

The field of organizational analysis provides several considerations for administration in organizations. Bolman and Deal (2013) analyze organizations through frames. The first frame involves structure, and a key element in the structural frame is how labor is distributed (Bolman \& Deal, 2013). As indicated, Maxwell (1997) suggests that learning assistance programs include up to 14 different functions; thus, the allocation of those responsibilities is 
critical. This allocation raises two other structural considerations: span of control and coordination of activities.

The span of control is the idea that one supervisor can only supervise a specific number of individuals (Manning, 2009). This idea of the span of control is central to how many SI Leaders one supervisor can oversee. Given Wilcox's (2008) suggestions on SI supervisor activities, the span of control seems to be ideally four leaders per supervisor, but no reasons for this specific supervisory ratio are given. The span of control seems to be affected by complexity and responsibilities (Bell, 1967), the expertness of subordinates (Meyer, 1968), and the similarity of roles (Udell, 1967). Of these characteristics, the complexity of the job responsibilities seems to be closely related to the work of SI leaders and would suggest that the span of control would subsequently be lower for SI supervisors. Additionally, coordination also affects the supervisor. Bolman and Deal (2013) discuss two types of coordination: vertical and lateral. Vertical coordination is the idea of policies and procedures for a team, while lateral coordination is the organization of program activities with meetings and committees (Bolman \& Deal, 2013). These two types of coordination would affect the span of control in an SI program and potentially the effectiveness of the program supervision.

The human resources frame also provides insights into this problem. The human resources view of organizations believes that they should focus on the people in the organization first because a motivated workforce will benefit performance (Bolman \& Deal, 2013). Some basic human resource strategies include keeping employees, investing and empowering employees, and promoting diversity. Training and staff development is crucial for SI Leaders (McDaniel, 2008: Wilcox, 2008). Therefore, the human resources frame 
suggests that SI program supervisors need adequate time for hiring practices and staff development activities.

Organizational staffing and support are also political activities. When using the political frame, organizations can be viewed as a series of groups called coalitions that advocate for limited resources (Bolman \& Deal, 2013). Several researchers advocate for consistent program evaluation for SI programs to share with administrators and faculty (Hurley et al., 2006; Wilcox, 2008). This information is also used to advocate for continued funding and resources.

Another critical part of the political view of the organization involves power (Bolman \& Deal, 2013). SI program supervisors manage and coordinate the program and thus have power over operations (Martin \& Arendale, 1992c). French and Raven (1959/2005) discuss expert power as a type of power where expertise grants additional power and legitimate power, which is granted by authority or position. In SI programs, faculty members may have expert power over the content, while university administrators likely have legitimate power over budgets and funding. Both of these tensions influence the operations and support of SI programs.

\section{Design of the Study}

\section{Setting}

The study takes place using data from SI programs in North America. Since SI programs exist at all types of institutions, data was collected from public, private, four-year, and two-year institutions. 


\section{Participants}

The participants for this study are higher education institutions in North America with an SI program. The higher education institutions include public, private, four-year, and twoyear schools. At the time of writing, there are approximately 40 institutions that have an accredited SI program and over 1,000 institutions that have an SI program. The SI program supervisors for many of these programs were contacted for data.

\section{Data Collection}

The primary data collection was through a survey. A list of SI programs was generated through a list of institutions on the International Center for SI's website, which indicated which institutions had a trained SI supervisor. Each of those institution's websites was examined for program contact information. The survey was designed in Qualtrics, an online survey software program. The final version of this survey is included in appendix A. Fink (2017) indicates that surveys should include a definition of terms, avoid biased phrasing, focus questions on one thought, place easy to answer questions like demographics at the end, and send respondents a summary of the findings. The survey design includes these characteristics. Creswell (2014) indicates that using external auditors to review the project can increase validity; thus, this survey was shared with the International Center for SI and other SI program supervisors to review its validity and adjusted based on their feedback. The institutional data collected was observation hours, planning support hours, training-related hours, and general supervisory hours for a specific SI program for a specific term. Additionally, the funding for the specific term was collected. 


\section{Methodology}

The study takes a post-positivist worldview. This worldview believes that reality is objective and measurable (Creswell, 2014). Thus, the data collected was analyzed quantitatively to provide objective evidence of relationships. Field (2018) suggests analyzing data initially by looking at descriptive statistics, measures of central tendency, and spread of a distribution. These measures were used to examine the data initially.

Beyond descriptive measures, multiple linear regression was the main statistical procedure. Linear regression is used to predict a value based on multiple predictors (Field, 2018). Thus, linear regression was to analyze each research question as it illustrated the relationships between SI program administrative tenets and institutional outcomes. Another measure used was correlations, which addressed the strength of the relationship between constructs. Correlations provide information on the strength of a linear relationship (Miles \& Shevlin, 2001).

\section{Limitations}

There are several limitations to this study. The first involves the type of institution. Due to sample size constraints, this study was not able to control for the institutional type or characteristics such as selectivity or institutional size. These characteristics have the potential to affect the quality of students and thereby program outcomes and the percentage of students attending SI sessions. This study tries to mitigate this effect by using standardizing measures such as the percentage of attendees, difference in average final grades, and the difference in DFW rates. Additionally, Martin and Arendale (1992a) compiled data from over 1400 institutions, including two-year and four-year institutions, and found similar results in the 
differences in average grades and DFW rates among these different institutional types. This result suggests that not including institutional characteristics might have been warranted.

The second limitation involves the quality of activities of the SI program and the quality of the staff members involved in operations and administration. This study focuses on the average administrative time spent on specific activities, but the quality of those activities was not measured. Thus, the quality of training, observations, planning, and supervisory activities may have influenced program outcomes instead of the time spent. Additionally, the quality of the staff was not controlled. Thus, the supervisory staff or the SI leaders themselves may have varied in quality. However, this study seems to have encompassed a representative sample of programs and, subsequently, a representative sample of the quality of supervisors and leaders.

Third, this study's survey did not constitute a random sample, an experimental design, and likely lacked sufficient controls. Creswell (2014) indicates that a random sample increases the odds of having a representative sample, which allows for generalization to the population. This study relied on volunteer response to the survey. As such, there is a possibility of systematic bias in the study's participants. By not randomly sampling the participants, a study is generally considered quasi-experimental (Creswell, 2014). This study does not manipulate a specific independent variable to see its effect on the dependent variables and, thus, cannot be classified as a true experiment. Miles and Shevlin (2001) suggests that multiple linear regression can be used to determine how a specific independent variable affects the dependent variable while controlling for the other independent variables in the regression model. This study used the various administrative tenets of SI programs to see how they affected program outcomes. This control process, through the inclusion of 
variables, would suggest that including enough independent variables into a regression equation will allow researchers to determine a specific independent variable's effect. However, this study was limited by the sample size collected, which limited the number of independent variables included in the study. Thus, there may be other controls that should have been included in the study.

The fourth limitation involves adherence to the SI model. Many institutions adapt the SI model by requiring attendance, offering extra credit, or modifying aspects of the model that could affect program outcomes. When starting an SI program, it is encouraged to think through institutional adaptations, and many institutions have been successful in changing the model (Wilcox, 2008). Participant data points were removed in the study if they described program deviations that would have directly influenced program outcomes (e.g., offering extra credit). Still, other program adaptations may be affecting program outcomes more than the administrative tenets.

Fifth, the study did not explore other crucial elements of the SI model. For example, faculty play a role in the success of an SI program, but the effect of the faculty and their support were not included. Similarly, the quality of support from university administrators or even structural placement within the university were not examined.

\section{Delimitations, Assumptions, and Design Controls}

There are two main delimitations of this study. The first delimitation of this study is the focus on higher education institutions in North America. Only North American higher education institutions were included in the results, and other international institutions were excluded or discouraged from completing the survey. Thus, the results are only able to be applied to North American institutions and programs. Also, there are cases of SI programs 
that operate in secondary schools, but these were excluded from this study. Second, hours reported from the institutions included in the study could have included hours from full-time professional staff or part-time staff such as SI mentors. The delimitation is that these hours were treated as if they are of the same quality.

There are a few assumptions, biases, and design controls that are implemented in this study. The first assumption was that the administrative tenents are specifically related to the stated outcomes. Arendale (2000) found that aspects of these tenets are related to these outcomes, but not these measures precisely. The next assumption was that SI programs that follow the International Center model are similar enough to be compared and grouped. The author is an SI program supervisor; thus, there is a vested interest in the success of administration on SI program outcomes. To reduce the effect of this bias, methods and processes were checked by the researcher's advisor and dissertation committee. The only design control was focusing on North American SI programs.

\section{Significance of the Study}

From a practitioner standpoint, this study provides further understanding of the optimal administration of SI programs. The results of this study offer guidance regarding administrative hours for SI programs and how those hours affect program outcomes. The results of this study guide practice recommendations for SI program administrators.

This work also has scholarly significance for higher education and learning assistance. First, the study builds upon the work of Arendale (2000) when he examined the implementation of SI programs through a national survey of SI programs and explored the relationship and impact of program constructs, structural placement of the SI programs, and satisfaction of administration with program outcomes such as average final course grades, 
percent of students earning a D, F, or withdrawing, percent of students participating in SI, and administrator satisfaction. In his study, Arendale (2000) found positive relationships with program activity constructs (SI supervisor involvement, SI leader involvement, SI leader training, and institutional involvement). This study focuses on the administration and supervisory component to discover how those elements influence the success of a program's operations.

Second, this study provides a template for other studies to model when studying program administration. If programs or services have specified administrative tenets and a clear connection between those tenets and program outcomes, this study provides a framework to assess those administrative tenets. This methodology has clear implications for other learning assistance programming such as tutoring, but also other higher education programming such as peer mentoring, service learning, developmental education, leadership programming, and other student affairs programming.

\section{Summary}

Higher education institutions have undergone significant changes in the US over the last 200 years. Institutions are drawing in higher enrollments (Thelin, 2011), with more underprepared students (Arendale, 2010), while experiencing financial burdens and being held accountable for student outcomes (Dar, 2016). Learning assistance programs such as Supplemental Instruction help institutions positively affect student outcomes such as retention and graduation, but examining the administrative structure for efficiency is crucial. This study seeks to understand the optimal levels of supervision for SI programs. Data was collected from SI programs across North America on an institutional level. The results of this study influence SI program administration and practices related to program staffing. 


\section{SECTION TWO - PRACTITIONER SETTING FOR THE STUDY}

Supplemental Instruction (SI) was created to support students in high-risk courses.

Due to the evidence of its success in reducing course attrition and in improving student's grades, SI programs rapidly expanded around the world (Arendale, 2000). Furthermore, SI program supervisors receive training from certified trainers through the International Center for SI (Wilcox, 2008). The consistent training and organization of SI programs suggest that SI programs are standard organizations with similar goals and processes. What follows is a brief history of SI along with a description of program goals, followed by an analysis of SI programs as an organization, and concluding with an analysis of the leadership of programs.

\section{History of Organization}

Supplemental Instruction (SI) is a learning assistance program designed to reduce student attrition in professional schools within the University of Missouri - Kansas City (UMKC) (Hurley \& Gilbert, 2008a). Initially, SI was implemented in the school of dentistry, and then other professional schools at UMKC (Hurley \& Gilbert, 2008a). In 1981, the US Department of Education acknowledged SI programs as an exemplary educational practice (Hurley \& Gilbert, 2008a). From there, UMKC began expanding the model and training other institutions, public and private, in SI (Arendale, 2000). Since its inception, the International Center has trained over 1,500 individuals in the SI model (UMKC SI, 2019).

In the United States, learning assistance programs originated through individualized support to prepare students for collegiate level coursework (Arendale, 2010). The Morrill Act and GI bill increased college enrollment significantly (Thelin, 2011), which drove enrollment of students who needed academic assistance to prepare students for college (Arendale, 2010). Arendale (2010) discusses how many colleges began offering remedial coursework for 
students entering college who were unprepared for academic work. Deanna Martin, who was charged with supporting students who were struggling at a UMKC professional school, examined traditional models of learning assistance, which focused on high-risk students and reimagined a focus on high-risk courses (Martin \& Blanc, 1981). By focusing on high riskcourses versus high-risk students, SI attempts to avoid the stigma that was associated with other support programs such as tutoring and remedial courses (Arendale, 1994). Furthermore, SI programs are cost-effective. Supporting students through SI is a more economical service, because the program delivers resources in a group format versus one-on-one, and SI helps institutional budgets because it assists in retaining students (Zerger, Clark-Unite, \& Smith, 2006).

SI leaders are peers who have been successful in challenging courses. They attend the targeted class, model good student behaviors, and lead collaborative learning sessions each week for individuals in the class (SI, 2019b). Challenging courses are typically defined as a course with a $30 \%$ or higher rate of Ds, Fs, and Withdrawals (W) — DFW rates — from a course (Martin \& Arendale, 1992c). The SI leader attends the targeted course to be able to take notes and do the assigned readings and assignments (Hurley et al., 2006), which allows them to plan their sessions directly aligned with the material in the class (Martin \& Arendale, 1992c). There are several reasons SI has been effective. SI is proactive, attached to specific courses, and the program design supports good student behavior on the part of SI leaders with a high level of interaction in SI sessions (Martin \& Arendale, 1992c). SI programs have programmatic goals to increase student retention and improve grades in targeted courses while increasing graduation rates (SI, 2019b). 


\section{Organizational Analysis}

Organizational literature provides a framework to view SI programs. Bolman and Deal (2013) discuss analyzing organizations through four interrelated frames or frameworks: structural, human resources, political, and symbolic. Each frame adds to the discussion of SI programs and their operation. The following sections use each frame to explore SI programs and provide context.

\section{Structural Frame}

The structural frame views organizations in terms of roles and responsibilities. According to Mintzberg (1979/2005), there are five basic parts of an organization: the operating core, the middle line, strategic apex, technostructure, and apex. Mintzberg (1979/2005) suggests that the operating core is where the bulk of the work related to the product of an organization occurs, the middle line and strategic apex provide the management and leadership, the support staff directly supports the work of the operating core, and lastly, the technostructure provides specialized tasks and analysis for the organization. The operating core of a university would include the professors and students. SI generally supports courses that are perceived to be challenging (Martin \& Arendale, 1992c; Wilcox, 2008), so this work would most closely align with the support structure of the organization. See Figure 2.1 for an illustration of this model.

Core processes. Several structural imperatives, such as core processes, information technology, size, and age, affect how organizations structure themselves (Bolman \& Deal, 2013). SI supervisors are trained at UMKC or by a certified trainer in the core processes of an SI program (Martin \& Arendale, 1992c; Wilcox, 2008). This training supports the consistency of structure and philosophy. These core processes include 1) key individuals, 2) 
training and development of SI leaders, 3) SI session strategies and techniques, and 4) ongoing monitoring through program evaluation (Hurley \& Gilbert, 2008a; Martin \& Arendale, 1992c).

Figure 2.1

SI Program Structure and Mintzberg's Five Parts of Organizations

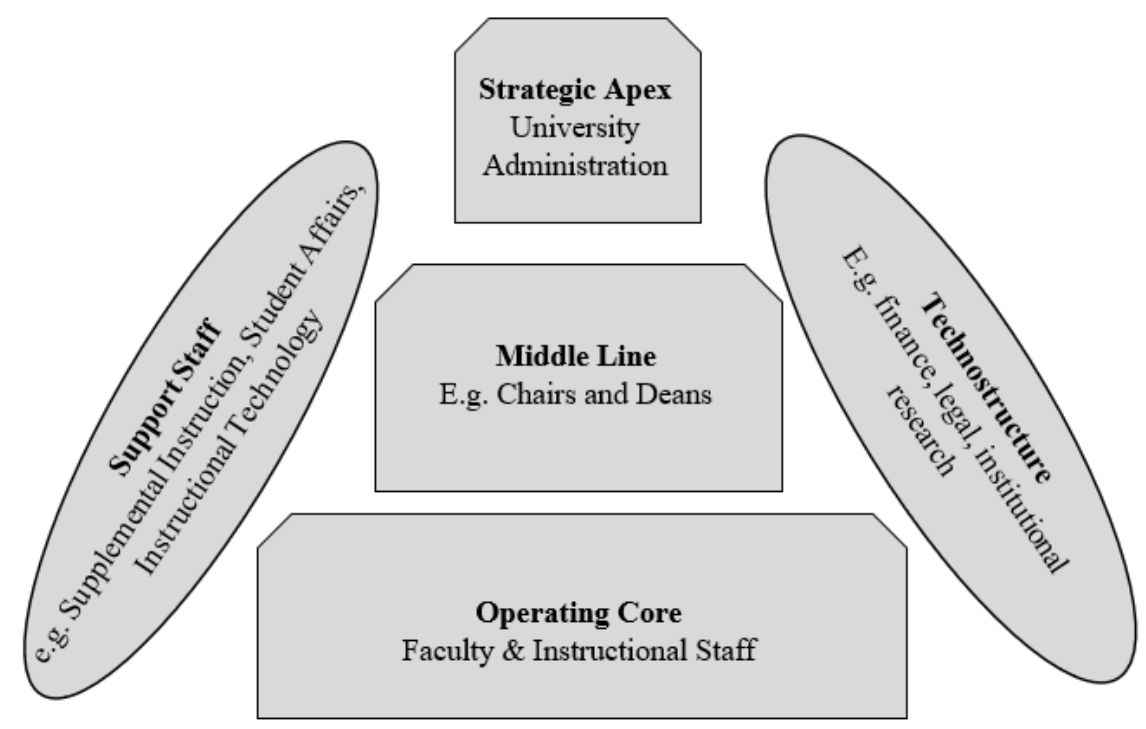

Additionally, the size and age of a program affect an SI program. Wilcox (2008) suggests that new SI programs start small and build in flexibility and complexity and that SI program supervisors cannot manage more than a few employees without some permanent administrative assistance. As technology has developed, SI programs have explored using technology to facilitate learning and serve distance education students (Painter et al., 2006), but there is little discussion on how technology can be used for SI program administration. Lastly, the workforce of SI programs has high turnover. An SI program can only expect 50\% of the SI leaders to return any given semester, which may be due to the training requirements, class attendance, and graduation of student staff (McDaniel, 2008). Thus, the high potential 
turnover rate heightens the need for SI program supervisors to focus on training and staff development as well as coordination activities.

Structural dilemmas. Some other structural dilemmas include excessive autonomy versus interdependence and an organization that is too loosely or too tightly bound (Bolman \& Deal, 2013). Loose coupling would imply that parts of an organization are connected, but changes in one do not dramatically affect the others, while tight coupling suggests that changes in one part, affect the other parts of the system (Weick, 1978/1983). According to Bolman and Deal (2013), too much autonomy makes individuals feel alone in carrying out their work versus too much interconnection can result in too much coordination. Wilcox (2008) suggests that SI program supervisors spend eight to sixteen hours training SI Leaders every term, observe and debrief from SI leader sessions every week for the first half a term and every other week for the second half, and help SI leaders plan their sessions by designing activities and planning instructional strategies. These responsibilities raise questions about the level of autonomy of the SI Leaders. SI program administrators also have responsibilities related to marketing SI, program evaluation, program logistics, and maintaining connections with faculty and administration (Hurley et al., 2006). Too much support and interconnection could be overwhelming for the supervisor, but not enough coordination or support could result in dissatisfaction and poor performance of the SI leaders. Weick (1978/1983) discusses loosely coupled systems in educational contexts and suggests that they can result in lower coordination, decentralization, increased autonomy for tasks, and lower consistency.

In contrast, tightly coupled system systems can be too rigid and limit flexibility, adaptations, and creativity (Bolman \& Deal, 2013). Wilcox (2008) discusses this dilemma with new SI programs, as he indicates that new SI programs who rigidly adhere to the model 
can squash creativity and innovation. Hurley and Gilbert (2008) discuss some of the more common and consistent program elements, including facilitation strategies, active learning techniques, and training and development for SI leaders. These common elements allow for flexibility while maintaining quality through consistency across SI programs.

Additionally, the structural frame consists of coordination activities such as vertical coordination, which includes authorities and rules and lateral coordination, such as meetings and committees (Bolman \& Deal, 2013). SI program supervisors are responsible for the daily management of the SI program (Hurley \& Gilbert, 2008a) and are responsible for designing the policies and procedures of the SI program. Additionally, supervisors must contend with issues and questions from the leaders, which involves a significant amount of time (Wilcox, 2008). Another critical aspect of an SI program is ongoing training and development

(Wilcox, 2008). These ongoing sessions are a notable example of lateral coordination, but the literature recommends few other consistent coordinating activities.

\section{Human Resources Frame}

The human resources (HR) frame consists of the basic idea that people are the crucial element of organizations (Bolman \& Deal, 2013). The first key idea of a human resources strategy is training and development (Bolman \& Deal, 2013). As SI leaders are generally students and part-time, the training of SI leaders is critical for SI programs (McDaniel, 2008; Wilcox, 2008). Given that an SI supervisor can high turnover in their student staff (McDaniel, 2008), training becomes ongoing and is a crucial element of every semester. Additionally, sound hiring practices is a key human resources strategy (Bolman \& Deal, 2013). SI leaders should have course instructor approval, strong content knowledge, and the ability to relate well and collaborate effectively (Wilcox, 2008). Additionally, SI leaders 
should have strong social skills and high grades (Ainsworth et al., 1994; McDaniel, 2008) and to be focused on assisting struggling students (Stout \& McDaniel, 2006). These practices suggest that SI programs have a strong and robust selection process for leaders.

Some other human resources strategies include promoting from within, investing, and empowering employees (Bolman \& Deal, 2013). Martin and Arendale (1992c) indicate that many SI programs are beginning to use SI program assistants to help supervise and support SI leaders. This position aligns with the strategy of promoting from within. Additionally, SI programs are intentionally designed to support the investment and empowerment of the employees. Wilcox (2008) describes the importance of holding SI leaders to high expectations, which will often result in more productivity. As mentioned before, significant efforts go into the training of SI leaders. SI program supervisors generally spend five to ten hours prepping for eight to sixteen hours of leading SI leader training every semester (McDaniel, 2008). This work suggests that successful SI programs invest in their employees. The last human resources strategy includes rewarding, protecting position, reducing employee turnover, and having diversity on the team (Bolman \& Deal, 2013). One of the critical responsibilities of an SI program supervisor is to observe and debrief with SI leaders (McDaniel, 2008). McDaniel (2008) indicates that this observation process can improve SI sessions and is an investment in the SI Leader, which may lower turnover. Levi (2017) indicates that diversity on a team can support team success, but the literature on administering SI programs does not include the importance of recruiting diverse leaders. Consequently, this might be an area of growth for SI programs in the future. 


\section{Political Frame}

The political frame of organizations assumes that organizations are political bodies which consist of coalitions of groups representing different interests (Bolman \& Deal, 2013). When starting an SI program, there are several possible coalitions, including college administrators, faculty members, and students (Wilcox, 2008). According to Wilcox (2008), faculty members can feel defensive when asked to take on an SI leader because they feel it is a critique of their teaching. Conversely, administrators seek cost-efficient solutions that help students succeed and stay at universities. Students have the most apparent agenda - they seek support to improve their opportunity to be successful in a challenging course. All of these demands and concerns pull SI programs in different directions.

Another aspect of the political frame is allocating resources (Bolman \& Deal, 2013). Some pressures in allocating resources include top-down pressure from authorities (Bolman \& Deal, 2013). Wilcox (2008) suggests that college administrators tend to like SI programs because they are cost-effective, and faculty members also feel the additional support of an SI leader removes work from their plate. Furthermore, SI program supervisors also put topdown pressure on the staff as they conduct observations, which are like performance evaluations (McDaniel, 2008). Besides top-down pressure, there is also bottom-up pressure in organizations when allocating resources (Bolman \& Deal, 2013). An example of this bottom-up pressure is from students. SI courses are chosen because of a high DFW rate (Martin \& Arendale, 1992c) and because students perceive them as difficult (Wilcox, 2008). For courses that do not have that perception, even if the DFW rate may otherwise indicate it, SI program intervention may be less successful (Hurley \& Gilbert, 2008a; Martin \& Arendale, 1992c). 
Power also plays a role in organizations (Bolman \& Deal, 2013). French and Raven (1959/2005) outline several types of power, including reward, coercive, legitimate, referent, and expert power. Three of these types_-legitimate, referent, and expert power — play a role in SI programs. In SI programs, the SI program supervisor has legitimate power. The SI program supervisor is deemed responsible for managing and coordinating the program (Martin \& Arendale, 1992c). Several individuals in an SI program could be described as having referent power. Given the prestige of faculty members, they may have this type of power more so than others in the SI program, but referent power could exist with the SI program supervisor or even an experienced SI. Wilcox (2008) suggests that the hiring process should include recommendations from instructors of the targeted course. Thus, the faculty generally hold the expert power in SI programs as it pertains to the content while the SI program coordinator holds expert power when deciding on programmatic changes with the program.

\section{Symbolic Frame}

The symbolic frame of organizational analysis focuses on how individuals make meaning of the organizational activities (Bolman \& Deal, 2013). Bolman and Deal (2013) describe how a vision can turn "an organization's core ideology, or a sense of purpose into an image of the future" (p. 250). The consistent training SI program administrators receive and the training SI leaders replicate this vision. Wilcox (2008) indicates that UMKC should train SI program supervisors in the particulars of the model. This training can add to the consistent vision of the SI program and its goals. Additionally, training for SI leaders also includes an overview of the SI model and history of the SI model (Wilcox, 2008) as well as focus on learning theory, teaching methods, study strategies, problem-solving, and mock sessions 
(Martin \& Arendale, 1992c). These consistent elements in training help align the visions of SI programs across the world.

Stories and specialized language are hallmarks of the symbolic frame. They continue the values and ideals of the organization (Bolman \& Deal, 2013). As mentioned earlier, SI training for leaders should include the history of the organization (Wilcox, 2008), which might be described as a story. On an international scale, there are few stories that regularly shared among the SI programs, but such stories could exist in individual programs. SI training also focuses on group facilitation techniques and three key strategies: redirection of questions, checking for understanding, and wait time (Hurley \& Gilbert, 2008a; McDaniel, 2008). This specialized language is used consistently across programs and added to the program's effectiveness in various contexts.

The next aspect of the symbolic frame is considering the culture of an organization (Bolman \& Deal, 2013). Schein (1993/2005) indicates that culture is a set of shared underlying assumptions and repeated patterns, and Bolman and Deal (2013) describe culture as the lessons learned from experiences. SI program supervisors learn these shared experiences at the UMKC training workshop (Wilcox, 2008). Additionally, SI training consists of similar topics every semester (McDaniel, 2008). These repeated experiences create a specific SI culture that permeates different universities and programs.

\section{Leadership Analysis}

Four leadership theories guide this analysis of SI programs. The first theory used is the path-goal theory, first defined by House and Mitchell (1974), which suggests that a leader's role is to enhance the performance of a team by focusing on member satisfaction and motivation (Northouse, 2016). The second theory is situational leadership, which describes 
how leaders should act based on the context of the situation (Blanchard et al., 1985). Third, transformational leadership is used to analyze SI program leadership. Transformational leaders help others reach their potential and motivate them to get there (Bass \& Riggio, 2006). Lastly, servant leadership theory — a model that suggests leaders should serve those with whom they work — provides insight for SI program administration. First, we discuss Path-goal theory in the context of SI program administration.

\section{Path-Goal Theory}

Path-goal theory suggests that a leader's effectiveness is dependent on how they influence their followers' motivation, performance on tasks, and satisfaction (House \& Mitchell, 1974). Leader behavior will enhance subordinate goal-oriented performance if the leader increases motivation, task skills, guides, remove obstacles, and provides resources (House, 1996). Path-goal theory consists of three parts: leadership behaviors, follower characteristics, and task characteristics (Northouse, 2016). In SI programs, the followers are generally students, and McDaniel (2008) indicates that SI programs should expect to lose up to $50 \%$ of the student staff from semester to semester, which makes this follower population transient. Additionally, the tasks SI leaders complete include planning, modeling good student behaviors such as using resources, asking questions, and facilitating sessions to enhance student learning (Hurley \& Gilbert, 2008a). These tasks require creativity and autonomy.

According to Path-goal theory, the leadership behaviors should change based on the follower and task characteristics (Northouse, 2016), and that if the leadership style complements the environmental factors, performance will increase (House \& Mitchell, 1974). There are four leadership behaviors: directive, supportive, participative, and 
achievement-oriented (House \& Mitchell, 1974). Directive leadership is generally the most effective when the task and procedures are unclear (House \& Mitchell, 1974). This leadership style applies to SI programs most when assisting SI leaders with planning sessions or troubleshooting sessions when observing.

The participative leadership style is most impactful when control of specific tasks can be given to the followers (House \& Mitchell, 1974). This type of leadership style may be useful in SI programs when helping leaders plan, so supervisors can give the SI leader autonomy to determine what would be the most useful in the session. Additionally, participative leadership is evident in larger SI programs that use more experienced SI leaders to observe and assist with observations, training, and planning. According to Martin and Arendale (1992c), many SI programs are using program assistants to lead these functions. These program adaptions are great examples of using participative leadership in SI programs. Supportive leadership tends to be the most useful when the task is stressful, or the task is not satisfying (House \& Mitchell, 1974). The tasks of leading SI sessions rarely are unsatisfying nor especially stressful, but there are some logistical elements of SI programs that might fit this description. For example, SI programs are expected to track attendance, and many SI leaders are responsible for managing this task. This task can be unsatisfying, so supportive leadership in these cases might involve making it easier and communicating a job well-done.

Achievement-oriented leadership involves challenging subordinates to strive for higher performance in non-repetitive and unclear tasks (House \& Mitchell, 1974). In SI programs, SI leaders are continually challenged to improve session performance through 
observations and improved planning (McDaniel, 2008). Thus, achievement-oriented leadership may be useful for SI program performance.

\section{Situational Leadership}

Situational leadership provides insight into the ideal supportive and directive behaviors needed by a leader, given a subordinates' level of competence and commitment (Blanchard et al., 1985). Leaders adjust their behaviors depending on the development level of followers (Blanchard et al., 1985). In SI programs, SI supervisors are working with several student staff members at any given time and need to be able to adjust their leadership behaviors. These behaviors exist on a continuum of high to low supportiveness and high to low directiveness while the development level of followers consists of their competence and commitment (Blanchard et al., 1985). These leadership styles illuminate the administration of SI programs. See figure 2.2 for an illustration of this model based on Blanchard et al. (1985).

Figure 2.2

\section{The Situational Leadership Model}

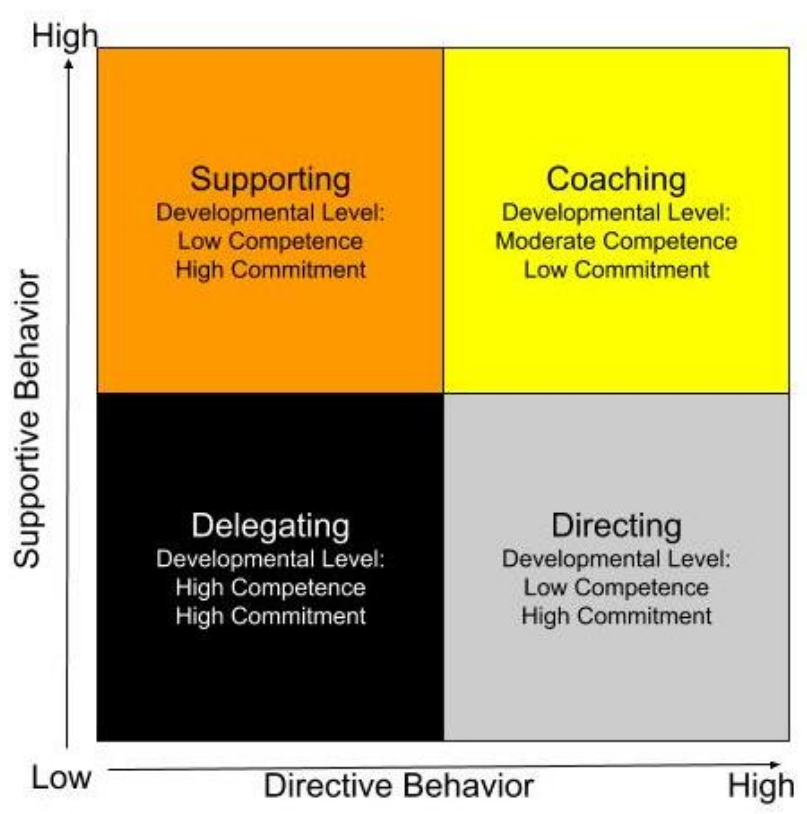


The directive style consists of low supportive and highly directive behavior for a developmental level of low competence but a high commitment on the part of the follower (Blanchard et al., 1985). According to Blanchard, Zigarmi, and Zigarmi (1985), this style of leadership should work well for individuals who are enthusiastic and committed but lack experience, and therefore, possess limited competence. In an SI program, SI supervisors are tasked to help SI leaders plan their first sessions along with conducting several observations early in the semester (McDaniel, 2008). This type of work provides the opportunity for directive behavior by the SI supervisor if it is needed by the SI Leader when the leader is initially less competent than later in the semester. However, there is not a way to gauge SI leader commitment. Length of time in an SI leader position may provide evidence of competence and commitment. Thus, another leadership style would be better for more experienced and mature SI leaders.

The next leadership style within the situational leadership framework involves coaching. Coaching involves high directive and supportive behavior on the part of a leader (Blanchard et al., 1985). This leadership style is best for individuals at a developmental level where they have moderate competence and limited commitment (Blanchard et al., 1985). In SI programs, coaching often comes during observations and debriefs. SI observations are typically heavier during the beginning of the semester to offer additional support and guidance and then taper off at the end of the semester (McDaniel, 2008). This process provides the opportunity for coaching when it is needed to build commitment and competence in the SI Leader role. Additionally, SI leaders are supported with planning sessions early in the semester, and this tapers off as needed (Wilcox, 2008). Again, this provides an environment for support and feedback as needed for coaching. 
The third leadership style is supporting. The supportive leadership style involves highly supportive leadership behavior and limited directive behavior for higher levels of commitment but lower levels of competence (Blanchard et al., 1985). As SI leaders gain experience, the number of observations and planning support decreases, but SI programs strive to do some team-building during training (McDaniel, 2008). These elements increase the amount of support for SI leaders. Additionally, the International Center for SI encourages participation in an SI Leader appreciation week that happens at the end of September, which can help provide recognition and support (UMKC SI, 2019).

The last leadership style is delegating. The delegating style is for individuals with high competence and commitment levels, and consequently, support and direction from the leader are lower (Blanchard et al., 1985). SI leaders primarily work autonomously; consequently, this style of leadership is used. Thus, SI program supervisors must work with their SI programs to build strong commitment and competencies in the leaders early so that they need minimal support and direction later in their tenure. The next leadership frame is transformational leadership.

\section{Transformational Leadership}

Transformational leadership provides a useful lens through which to view SI programs. Transformational leadership strives to increase motivation and maximize follower potential (Northouse, 2016). Bass and Riggio (2006) suggest that there are four key components of transformational leadership: idealized influence, inspirational motivation, intellectual stimulation, and individualized consideration. These four components influence aspects of SI programs. 
The first component, idealized influence, involves striving to be a role model, having a strong sense of vision, working to influence others, and the ability to take risks (Bass \& Riggio, 2006). Kouzes and Posner (2012) also discuss modeling the way and inspiring a shared vision in their model of transformational leadership. During SI leader training, SI supervisors are asked to model active learning strategies so they can be a role model for the SI leaders (McDaniel, 2008). SI programs generally give SI leaders a sense of the big picture, as training generally includes the history and goals of the SI program (Wilcox, 2008) as well as the theory that is a foundation of the program (Martin \& Arendale, 1992c). While the SI administration literature includes little, if any, discussion on influencing others, McDaniel (2008) discusses the importance of team building in SI leader training, and those positive team relationships have the potential to create influence. Lastly, idealized influence involves the ability to take risks. Wilcox (2008) indicates that new SI programs should strive to be adaptive so that they can adjust to an institution's uniqueness.

The second component of transformational leadership is inspirational motivation. According to Bass and Riggio (2006), inspirational motivation involves communicating expectations and motivating followers around the future. In SI leader training, administrators are expected to include expectations for the role, including data collection and evaluation (McDaniel, 2008). Jacobs, Stout, and Stone (2008) discuss the future of SI programs, including international adaptations of the model, involving SI in distance education, and using SI as a means for social justice and lifting marginalized groups. In guiding SI program administrators in motivating followers around the future, little attention is given in the SI literature. 
The third component of transformational leadership involves intellectual stimulation. Intellectual stimulation is the process wherein leaders challenge processes, present innovative ideas, and encourage others to take risks (Bass \& Riggio, 2006). Intellectual stimulation is a key idea for SI program supervisors. In the observation process, SI supervisors should strive to offer specific feedback to provide tailored training (McDaniel, 2008). Within in this observation process, leaders of SI programs challenge processes and brainstorm creative solutions. Similarly, SI sessions suffer if there is inadequate planning (McDaniel, 2008). McDaniel (2008) suggests helping SI leaders plan several of their early sessions and to have the session plans checked by the supervisor or mentor. This process provides the opportunity for processes to be challenged and for feedback to be given.

The last aspect of transformational leadership is individualized consideration. Individualized consideration involves the leader considering follower needs, offering ongoing development, and addressing individual differences (Bass \& Riggio, 2006). SI supervisors are expected to provide initial and ongoing training for SI leaders and observations to provide feedback (McDaniel, 2008). These processes allow SI program supervisors to provide continuous training and feedback and account for individual differences between SI leaders. Wilcox (2008) suggests that SI program administrators cannot adequately supervise more than three to four leaders without some assistance. Therefore, in SI programs with larger numbers and fewer supervisors, it may be challenging to attend to follower needs.

\section{Servant Leadership}

The last leadership model used to explore SI programs is servant leadership. This theory of leadership was created by Robert Greenleaf, whose ideas were based on the 
assumption that leadership is in crisis, education does not prepare one for leadership, and values are continually evolving (Greenleaf, 1996). Greenleaf (1996) suggests several strategies of a servant leader such as goal-setting, prioritization, listening, communication, strong values, personal growth, managing stress, embracing imperfections, and accepting all. Greenleaf's ideas have been explored more recently, Liden, Panaccio, Meuser, Hu, and Wayne (2014) researched six characteristics of servant leaders: a desire to serve others, emotional intelligence, moral maturity, prosocial identity, self-evaluation of one's worth, and low narcissism. These characteristics manifest themselves in several ways in SI program administration.

The first two characteristics are the desire to serve others and possess emotional intelligence. The desire to serve is where leaders are generally selfless and altruistic and possessing emotional intelligence allows servant leaders to empower followers and be more empathetic (Liden, Panaccio, Meuser, Hu, \& Wayne, 2014). As SI is an academic support program designed to assist students in high-risk classes (Hurley et al., 2006), leaders of these programs generally focus on serving student needs and helping them be successful.

Additionally, SI programs can help students feel connected, assist marginalized populations, and assist distance education students (Jacobs et al., 2008). Thus, it seems SI programs are trying to adapt to and serve changing student needs. SI administrators have vital roles that involve hiring, training, and selecting SI leaders, working with faculty and campus partners, and providing feedback to the SI leaders on their performance (Wilcox, 2008). These responsibilities suggest that SI program administrators need to have emotional intelligence.

The next characteristic of servant leaders involves moral maturity and a prosocial identity (Liden et al., 2014). Moral maturity is having moral ideals, moral action, and belief 
in morality, and a prosocial identity is a strong desire to help others as part of the core identity (Liden et al., 2014). These two characteristics probably vary among leaders of SI programs. Ideally, SI program supervisors are well-trained in the SI model by UMKC and serve as a role model (Wilcox, 2008). This pattern of training would suggest that trained SI program supervisors will align with the SI model, believe in the model's ideals, and carry out the model using good judgement. This potential consistency lends itself to the moral maturity, action, and belief in morality. SI program supervisors also are likely to have a prosocial identity as the program focuses on supporting students, which aligns with this idea.

The last two characteristics of servant leadership are core self-evaluation, which is how the leader understands themselves as a competent individual and low narcissism (Liden et al., 2014). Attending the SI supervisor workshop provides SI program administrators with the skills and grounding in the model (Wilcox, 2008). Attendance to this workshop and participation in conferences and professional development around SI programs can help SI program administrators feel more competent and assured in the model. Additionally, the international SI leader center offers an SI program accredited (SI, 2019a), which can add to the competence of a supervisor who leads a program that is accredited. As for low narcissism, this would vary from SI program to SI program and leader to leader. Again, SI program goals are to support students and high-risk courses, which makes the likelihood of narcissism unlikely.

\section{Implications for Research}

There are several implications of this research in the practitioner setting. The first is guiding practice. The study seeks to understand how the amount of supervision in SI programs influence the outcomes of the program. These results guide program administrators 
on structuring the activities and practices of SI programs. This research aids program supervisors in leading SI programs effectively and enhancing the leadership of program administrators.

This research also builds upon the scholarly research of SI and adds to the significant body of literature around SI programs. This research also provides possible other ways of assessing learning assistance program operations, including leadership and organizational effectiveness. By designing assessments aligned with organizational structures, learning assistance professionals can better understand what works and what does not. This type of research, in an era of accountability, is critical for higher education and learning assistance scholars.

\section{Summary}

SI program literature offers several suggestions on how to organize and lead SI programs effectively. Some vital organizational considerations involve maintaining flexibility within the organizational structure and solidifying human resources practices such as training, promoting from within, and support, which also adds to the culture of the program. SI program supervisors need to be acutely aware of the power dynamics at their respective institutions, particularly with SI program faculty and administrators. SI program administrators have several leadership considerations. The first is to maintain flexibility to provide additional support and guidance to SI leaders that need additional support. The second is to consider how to inspire, motivate, and create a vision of the future for the program, and the third is to align actions and program activities with values consistent with SI programs and their purpose. These leadership activities and organizational considerations help SI program administrators effectively manage their programs. 


\section{SECTION THREE - SCHOLARLY REVIEW FOR THE STUDY}

With more and more students attending college (Baum et al., 2013), postsecondary institutions are being held more accountable for student success. Additionally, Huisman and Currie (2004) indicate that the need for effective and efficient use of public funds has also led to more governmental accountability. Moreover, there is also pressure for colleges to make the cost more affordable (Butler, 2016). Some researchers have suggested removing some student services to keep costs low (Haveman \& Smeeding, 2006), which would include learning assistance programs such as Supplemental Instruction (SI). Thus, these programs need to illustrate their efficiency and effectiveness. Besides efficiency and effectiveness, there is also increasing levels of accountability for student outcomes.

Colleges and universities are increasingly being held accountable for student outcomes (Alexander, 2000; Dar, 2016). Increasing enrollment and decades of research on what helps students succeed in college have barely affected completion rates (Tinto, 2012). The focus on outcomes like the drop-out rate of students has been one of the reasons the number of learning assistance programs has increased in the United States (Arendale, 2004). Thus, college learning assistance programs should be evaluated for their efficiency and usefulness.

Supplemental Instruction (SI) is a learning assistance program designed to reduce attrition in high-risk courses (Martin \& Arendale, 1992c). The success of SI on influencing grades, retention rates, and graduation rates is well documented (see Arendale, 2000; Blanc, DeBuhr, \& Martin, D. C., 1983; Bowles, McCoy, \& Bates, 2008; Buchanan, Valentine, \& Frizell, 2019; Congos \& Mack, 2005; Congos \& Schoeps, 1993; Etter, Burmeister, \& Elder, 2001; Gattis, 2000; Guarcello et al., 2017; Kochenour et al., 1997; Meling, Mundy, Kupczynski, \& Green, 2013; Ogden, Thompson, Russell, \& Simons, 2003; Oja, 2012; Price, 
Lumpkin, Seemann, \& Bell, 2012; Ramirez, 1997; Skoglund, Wall, \& Kiene, 2018). Wilcox (2008) suggests that SI program supervisors can only adequately supervise up to four SI leaders without additional assistance but provides no supporting evidence. Arendale (2000) found that SI supervision was a critical construct in the success of SI programs but again did not deliver the ideal level of supervision. Thus, there is a gap in knowledge regarding the influence of administrative hours of an SI program on SI program outcomes. The findings of this study inform SI program supervisory practices.

\section{Conceptual Frameworks}

Three conceptual frameworks guide this study and its findings. The first is higher education and learning assistance programs. This framework puts the administration of the SI programs into the historical and organizational context. The second framework is the literature surrounding SI because, since its inception in the 1970s, SI has been thoroughly researched. The last framework focuses on staffing considerations and support for organizations. This framework focuses on organizational staffing and support.

\section{Higher Education and Learning Assistance}

Significant events and influences have marked higher education in the US. Cohen and Kisker (2010) discuss six eras of higher education in the US, as shown in table 3.1. These eras marked changes in learning assistance programming, trends in American society, and degrees of accountability and financial constraints in higher education. This subsection addresses the evolution of learning assistance in higher education across these eras.

In the first two eras, higher education was marked by little student preparation for college and little accountability for higher education institutions. The formulation of external boards of trustees provided early aspects of accountability for higher education (Church \& 
Sedlak, 1997; Thelin, 2011), which was a model based on Scottish higher education (Cohen \& Kisker, 2010). At this time, there was also little emphasis on finishing degrees as students often attended school for one or two years (Thelin, 2011). Furthermore, admission standards at the time were almost nonexistent if the applicant could pay (Cohen \& Kisker, 2010;

Thelin, 2011).

Table 3.1

Eras in US Higher Education

\begin{tabular}{cc}
\hline Name of the Era & Approximate Timeframe \\
\hline Colonial Era & $1636-1789$ \\
Emergent Nation Era & $1790-1869$ \\
University Transformation Era & $1870-1944$ \\
Mass Higher Education Era & $1945-1975$ \\
Consolidation Era & $1976-1993$ \\
Contemporary Era & $1994-2009$ \\
\hline
\end{tabular}

Learning assistance in this period in higher education mostly involved tutoring outside of the institution and before admittance to prepare students for the rigor for college, and because of the need, there was little stigma associated with the service (Arendale, 2010). As higher education in the US expanded in the 1800s, there was also the inclusion of academies, which also served to help prepare students for college coursework (Arendale, 2010; Cohen \& Kisker, 2010). Often these academies were college-like or provided education to students at the elementary and secondary education level (Church \& Sedlak, 1997). While higher education up until this point was primarily religious-based, other factors began to also drive the growth and change of higher education programming (Cohen \& Kisker, 2010).

Higher education and learning assistance seemed to undergo significant changes from the mid-1800s until 1945. The Morrill Act of 1862 provided incentives to states to create 
institutions of higher learning, many of which had a focus on agriculture and mechanics because of stipulations in the Morrill Act (Thelin, 2011). While it took many years, the Morrill Act eventually led to consistent state funding to these institutions, which also increasing state oversight of these institutions (Johnson, 1997). There was also a massive expansion of institutions designed for African Americans and women during this era (Cohen \& Kisker, 2010); thus, expanding the original design of American higher education. The increase in the availability of higher education led to the rise of enrollments and to increases in extracurricular activities, student affairs programming (Thelin, 2011), and specialized administrative roles such as admissions, registrars, and librarians (Brubacher \& Rudy, 1997). Beyond increased opportunities for postsecondary education, higher education's potential for social mobility also contributed to rising enrollments (Thelin, 2011). The influx of students led to the usage of admissions exams to make decisions swiftly for student placement as well as admissions decisions (Thelin, 2011).

During this era, the use of admissions standards broadened, and institutions also began using the prior academic performance of students to judge suitability for college admission (Cohen \& Kisker, 2010). According to Arendale (2010), the increased use of admission standards led to the need for learning assistance programs to support students who were admitted but still not successful. Thelin (2011) indicates that high drop-out rates were an issue during this period as those rates conflicted with the collegiate ideal marketed to the public. For underprepared students, additional preparatory departments were created to offer courses in colleges and universities to remediate students academically (Arendale, 2010; Cohen \& Kisker, 2010; Johnson, 1997; Thelin, 2011). Because students were generally unprepared, colleges and universities also began to push secondary schools to improve 
preparation for college-level work requirements (Cohen \& Kisker, 2010). During this period, the lack of governmental regulation led to external bodies being created to keep higher education accountable (Thelin, 2011).

The landscape of higher education and learning assistance programs changed dramatically during the period from 1945 to 1970 . After World War II, the GI bill provided returning veterans with funds to pursue postsecondary learning, which resulted in booming enrollments (Cohen \& Kisker, 2010; Freeland, 1997; Thelin, 2011). This unprecedented public investment in higher education and corresponding high demand for postsecondary offerings necessitated increased utilization of standardized testing for admissions, and because many new enrollees were academically unprepared, there were also high attrition rates in the first and second years (Cohen \& Kisker, 2010; Thelin, 2011). The increase in students, particularly non-traditional students such as part-time or older students returning to school, which was a result of the GI bill, led to an increased demand for support services for those students, such as learning assistance programs (Arendale, 2010). Arendale (2010) also posits that the Civil Rights Act led to an increase in programs that strived for equity and supported underrepresented populations, which often supported learning assistance programming. Remedial and developmental education for college students was typical in this era (Cohen \& Kisker, 2010). Cohen and Kisker (2010) identify SI as an academic support program that developed during this era. Additionally, institutional accountability for the investment of public funds through the GI Bill and other state aid programs led to the increased usage of accreditation boards for oversight purposes (Cohen \& Kisker, 2010). These influences and trends, along with public concern for student outcomes, led to significant changes in learning assistance in higher education. 
After the 1970s, higher education began to feel the pressure of accountability. Thelin (2011) indicates that colleges and universities were financially uncertain, so there was a trend towards consumerism in hopes of attracting students, and key federal policies such as portable financial aid, which allowed students to travel with their financial aid packages made competition for students fierce among colleges and universities. The massive increase in enrollment growth (Thelin, 2011) led to governmental bodies having more influence on how higher education was spending their money (Alexander, 2000). Additionally, concern was growing and would continue to grow in the subsequent eras about the length of time it took to get a degree as well as the large enrollment in remedial programming despite a stronger high school curriculum (Cohen \& Kisker, 2010). These pressures led to state activities and accreditation bodies, calling for significantly augmented accountability from higher education institutions for a wide array of activities and measures of success (Cohen \& Kisker, 2010). These trends pushed higher education in a direction that valued efficiency and programming that focused on student success.

The changes that pushed higher education towards greater accountability in also led to the growth of learning assistance programs after the 1970s. According to Thelin (2011), there was an expansion of student services and significant gaps in the academic preparation of the incoming students, which led to resources being allocated to support services. There was also an increasing concern about retaining students (Thelin, 2011) and reducing time to degree (Alexander, 2000). This attrition rate and lower completion rate made learning assistance programs a significant policy issue (Arendale, 2010). This period was ripe for the expansion of learning assistance programs in the US. 
After the 1970s, learning assistance trends changed. Before this era, learning assistance programs centered around tutoring and remedial coursework for students entering college (Arendale, 2010). Supplemental Instruction (SI) was part of the changing learning assistance program trends. SI was created in the 1970s by Deanna Martin to reduce student attrition in the professional schools at the University of Missouri - Kansas City (UMKC) (Hurley \& Gilbert, 2008a). Three things differentiated SI from other learning assistance models at the time: 1) it focused on high-risk courses versus high-risk students, 2) it was nonremedial, and 3) it was cost-effective (Hurley \& Gilbert, 2008a).

During this time, the cost of higher education increased, and that financial burden was shifted to students and their families, and student expectations of the college experience increased to include more amenities and higher career placement rates after earning a degree (Cohen \& Kisker, 2010). Furthermore, greater calls for accountability and significant budget crises facing many states and universities led to greater accountability for student outcomes (Cohen \& Kisker, 2010). Additionally, Supplemental Instruction programs, which focus on reducing attrition and increasing graduation rates, aligned well with policy goals regarding completion and increasing student retention. SI also aligned well with the key student development and retention models and theories at the time, which are elaborated on in the following paragraphs, and sought to address issues of student attrition and degree completion.

Chickering and Reisser (1993) outlined a model for college student development to guide higher education practitioners that included seven vectors. These seven vectors are developing competence, managing emotions, moving through autonomy towards interdependence, interpersonal relationships, developing identity, developing purpose, and 
developing integrity (Chickering \& Reisser, 1993). Congos (2002) drew parallels with SI programs to Chickering and Reiser's model by noting vector alignment to the SI program features. These features included that SI programs expanded student-faculty contact, encouraged cooperation among students in SI sessions, encouraged active learning in sessions, allowed students to get prompt feedback from the SI leader, focused on time-ontask by providing structured study time, allowed courses to maintain high expectations while providing support, and respected diverse abilities and knowledge through inclusion in SI sessions (Congos, 2002). Additionally, Chickering and Reisser (1993) explored the notion that support programming should influence their student development vectors to help students navigate the college or university setting. Given the alignment of SI with the vectors and that one of the main goals of SI is to assist students in earning higher grades, persisting, and operating independently through study skill development (SI, 2019b), SI seems to fit the description of support programming that Chickering and Reisser (1993) described.

Additionally, SI programs are cited for developing a sense of community among the students who attended sessions and foster cognitive skill development (Martin \& Arendale, 1992b). This community-building may help students who participate in SI develop interpersonal relationships and manage their emotions and assist students in developing independence. It is unclear; however, how SI might influence the vectors related to developing identity, purpose, and integrity.

Tinto (1987) developed a theory of student departure that helps understand why students leave an institution. Tinto (1987) suggested that pre-institutional student characteristics such as academic performance and intent, and two interrelated institutional systems - academic and social integration - affects a student's decision to stay in or leave an 
institution. Essentially, if the student experiences positive integration in social areas and academics, the student will be more likely to persist. Martin and Arendale (1992b) suggested that framing SI in Tinto's theory has the potential to assist students in the academic and social aspects of the institutions. Widmar (1994) mentioned how SI supports retention and performance and works across institutional types, courses, and programs.

Tinto (2012), more recently, suggested four conditions of student success, which includes support, assessment and feedback, high expectations, and involvement. SI provides support, feedback, and high expectations for students enrolled in challenging courses. Wilcox (1992) and Widmar (1994) noted that SI programs assist in maintaining high institutional academic standards by supporting students in reaching those standards. Furthermore, SI can also help students be involved in campus (Martin \& Arendale, 1992b). Astin (1985) suggested that students need to get involved in higher education to be successful and that there is a relationship between student learning and involvement. Involvement is loosely defined as how much energy the student invests in their college experience, both academically and socially (Astin, 1985). Additionally, Astin (1985) suggested that higher education programming and services could be evaluated on the basis of whether they increase student involvement. As noted earlier, Martin and Arendale (1992b) claimed that SI programs facilitate student involvement, and Hurley, Jacobs, and Gilbert (2006) also contended that SI promotes integration into the culture of the campus. Thus, SI programs seem to be aligned with Astin's work with student involvement.

\section{SI Program Foundations}

Since its inception, SI has been expanded to universities and colleges internationally and validated as an "exemplary educational practice" by the US Department of Education. 
(Hurley \& Gilbert, 2008a, p. 2). The courses that SI supports are ones that are deemed highrisk and defined as a course with $30 \%$ or more students who earn Ds, Fs, or withdraw (DFW rate) from the course (Hurley \& Gilbert, 2008a). Generally, the focus for these courses is on the first-year of college (Hurley \& Gilbert, 2008a; Martin \& Arendale, 1992b). Essentially, a student who has successfully completed the identified course is hired to be the SI leader, and that person holds voluntary, regularly scheduled, outside-the-class-time, study sessions for the students enrolled in the targeted course (Martin \& Arendale, 1992c) Additionally, that SI leader will attend that course again, take class notes, and be an active participant in the class (Hurley \& Gilbert, 2008a). These study sessions center on small group activities designed to be collaborative (Hurley \& Gilbert, 2008a), and these sessions also integrate study skills

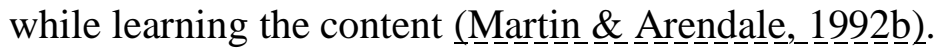

Theoretical underpinnings. Several different theoretical models inform the SI model. The theoretical foundation of SI is Jean Piaget's work and theories related to constructivism because SI was designed to help students build new understanding through discussion (Zerger, 2008). McGuire (2006) suggests cognitivism, constructivism, and behaviorism as other theoretical underpinnings of SI programs. For example, SI session facilitation techniques are based heavily on ideas in cognitivism (Zerger, 2008). Another concept that informs SI is Vygotsky's idea of the zone of proximal development in the field of constructivism. The zone of proximal development is the space between development levels that a person can bridge with the help of a more competent individual (Vygotsky, 1978). In SI sessions, collaboration with peers is a crucial element, and the SI Leader can help students bridge that gap of knowledge through carefully worded questions, well-crafted discussions, and engaging activities. Lastly, Edgar Dale's cone of experience helps SI 
Leaders plan SI sessions because it focuses on getting students to engage and experience the material in more meaningful ways (Martin \& Arendale, 1992c).

SI programs also focus on ideas related to student retention and success. Tinto's (1987) theory of student departure indicates that social and academic integration affect a student's departure decision from an institution. Martin and Arendale (1992b) suggest that SI programs affect both the social and academic integration of students. Martin and Arendale (1992b) also note that SI aligns with Alexander Astin's thoughts on student involvement. According to Astin (1985), the more a student is involved on campus, the more likely they are to stay enrolled. Therefore, SI session attendance can be considered as involvement. Lastly, Hurley and Gilbert (2008a) and Hurley, Jacobs, and Gilbert (2006) discuss the dependency cycle - where students come to depend on a teacher or authority figure for answers - as it relates to SI sessions and suggests that SI strategies help break students out of this dependency cycle.

The SI Leader, SI supervisor, and course faculty member are three key players in an SI program (Hurley \& Gilbert, 2008a; Martin \& Arendale, 1992c). The SI leader is the student who has been deemed competent in the targeted course material, trained extensively by the SI supervisor, attends the course again, and uses strategies to guide student learning during sessions (Hurley \& Gilbert, 2008a). The SI leader should be scheduled for about ten to fifteen hours each week for training, attending class, holding sessions, and planning sessions (McDaniel, 2008; Wilcox, 2008). The SI faculty member needs to be willing to have an SI Leader sit in their class, encourage SI session attendance, and be willing to meet with the SI leader occasionally (Hurley \& Gilbert, 2008a). If an SI faculty member is not supportive of the SI program, then the SI intervention will not be as successful (Wilcox, 
2008). The International Center for Supplemental Instruction generally trains the SI supervisor by means of a supervisor workshop (Wilcox, 2008). A program supervisor is generally full-time, plans programming, interviews and hires SI Leaders, plans and leads training, observes sessions, conducts program evaluation, and fosters relationships with faculty members and institution administrators (Hurley \& Gilbert, 2008a).

Outcomes of SI programs. Attendance at SI sessions is generally voluntary for students enrolled in the targeted course. However, some institutions have been successful in requiring SI session attendance or incentivizing attendance (Wilcox, 2008). Regardless, an SI program will only be able to influence student grades and persistence with participation by the students. Arendale (2000) included participation rate as an outcome of SI programs when he analyzed the effects of program tenets on program outcomes. Arendale (2000) found that SI supervisor involvement was significantly related to SI program participation and recommended further study in the SI supervisor construct. In the administrative responsibilities, many SI program supervisors are responsible for program evaluation (Hurley et al., 2006), and this can evaluation can be used to promote the program and increase SI session attendance. For example, Hurley, Jacobs, and Gilbert (2006) provide an analysis of first exam grades as it relates to SI session attendance to encourage students to participate in more sessions. Thus, attendance percentage for SI programs is an outcome for programs.

Two other common outcomes of SI programs are the difference in the average final grades between the SI session attendees compared to the non-attendees and the difference in DFW rates between those two groups (Wilcox, 2008). The difference in average grades is seen as a measurement of student learning while the difference in DFW rates between the students who attend SI sessions and those who do not is seen as a measurement of attrition 
for that course (Hurley \& Gilbert, 2008a). Methods of calculating these values are described in detail in the SI supervisor workbook provided by the International Center for SI (Curators of the University of Missouri, 2019). Thus, these two figures provide another set of common outcomes for SI programs.

The influence of SI programs on student outcomes is well-researched. Several studies found that SI attendance was positively related to increased grades in the targeted course (Arendale, 2000; Blanc et al., 1983; Buchanan et al., 2019; D. H. Congos \& Mack, 2005; Etter et al., 2001; Gattis, 2000; Guarcello et al., 2017; Meling et al., 2013; Price et al., 2012). Additionally, some studies found that SI attendance was positively related to an increase in GPA (Kochenour et al., 1997; Oja, 2012; Ramirez, 1997). Some research showed that SI relates to increases in knowledge and learning skills. For example, Gattis (2000) found that SI attendance in an introductory chemistry course led to increases in learning in subsequent chemistry courses. In another study, it was shown that students at a university in Hong Kong increased their learning competence and skills after using SI (Ning \& Downing, 2010).

The relationship between SI attendance and student retention is not as clear. Oja (2012) did not find a relationship between SI session attendance and persistence to the following fall term using binary logistic regression. Bowles and Jones (2004) controlled for the academic characteristics of the students but found no relationship with retention and SI session attendance. However, Ogden, Thompson, Russell, and Simons (2003) found that SI attendance significantly impacted the retention of conditionally-admitted students but not traditionally-admitted students. Ramirez (1997) required at-risk students to attend SI sessions and found that it significantly and positively affected their retention. Lastly, Skoglund, Wall, and Kiene (2018) found an improvement in fall to fall retention of first-year students utilizing 
SI who had under a 3.5 high school GPA. Therefore, the results are unclear on whether SI session attendance is a significant contributor to student retention

Others have studied the relationship between SI session attendance and graduation rates. Bowles, McCoy, and Bates (2008) controlled for high school GPA and found an increase in the probability of graduating within four years by approximately $10 \%$ if a student attended SI sessions. Buchanan, Valentine, and Frizell (2019) found an increase in graduation rates of SI session attendees, but this effect did not extend to minorities or nontraditional students. The influence of SI programs on graduation rates needs additional research. Generally, it seems research has illustrated that SI programs have been successful in supporting students.

SI program administration. One of the first areas of responsibility for SI program supervisors is hiring and selection of SI leaders. Ainsworth, Garret, Phelps, Shannon, and Ripperger-Suhler (1994) describe hiring criteria for SI leaders such as high grades, interpersonal skills, and possible prior experience as a tutor. In the community college context, Zaritsky and Toce (2006) include studying student academic patterns, transcripts, and calling references in the hiring process. Additionally, students that are hyper contentfocused or unsympathetic to struggling students will probably not make good SI leaders (Stout \& McDaniel, 2006). SI leaders should also have instructor approval (Wilcox, 2008), high grades (McDaniel, 2008), and strong interpersonal skills (McDaniel, 2008; Wilcox, 2008). Managing this hiring process requires a concentrated effort on the part of the supervisor. Additionally, once SI leaders are hired, program supervisors have an important role in the SI leader training. 
Training for SI leaders includes initial and ongoing training. According to Wilcox (2008), SI program supervisors should expect to hold training for eight to sixteen hours each semester and have five to ten hours of preparation time for that training. When developing a training course for SI leaders, Lipsky (2006) included topics such as the role of an SI leader, collaborative learning, active learning, critical thinking and problem-solving, assessing learning, and diversity. Zaritsky and Toce (2006) included topics related to learning theories, situations, and facilitation strategies as part of training for their community college SI leaders. Training should consist of pre-term training and ongoing training. The pre-term training should ready leaders to facilitate sessions and include a basic understanding of learning and study skills (Martin \& Arendale, 1992c). Wilcox (2008) also included an emphasis on planning SI sessions in pre-term training. Hurley, Jacobs, and Gilbert (2006) also recommend ongoing training, or leaders may resort to just reteaching or re-lecturing. This ongoing training could include topics such as problem students or specific session strategies (McDaniel, 2008). Additional crucial responsibilities of SI program supervisors are observations and assistance with planning.

Observations of SI sessions typically take more time than most supervisors expect (Wilcox, 2008). McDaniel (2008) discusses how observations provide an opportunity to provide feedback and training as well as ensure the quality of SI sessions. These observations and debriefing are similar to employee performance evaluations, which are valuable experiences for SI leaders (Stout \& McDaniel, 2006). Wilcox (2008) suggests observing the first few sessions of the term, weekly for the first half of the term, and biweekly for the remainder of the term. Session planning is a crucial responsibility of the SI leader and should be thoroughly completed (Hurley et al., 2006). Hurley et al. (2006) also 
note that leaders should work with supervisors and faculty members to plan sessions. Thus, assistance with planning is an essential element of supervisory responsibilities.

Besides observations, hiring, and training, there are many other administrative functions of SI programs for which the supervisor is responsible. One example is SI program evaluation. SI program evaluation should be completed every semester and include metrics on the number of students served, lowering the DFW rate in the targeted course, and increasing student learning (Hurley et al., 2006). Ainsworth et al. (1994) echoed the need for evaluation and assessment. Wilcox (2008) also suggests that assessment of SI programs leads to greater credibility with administration as well as an understanding of the performance of the operation. Additionally, SI program supervisors need time to market SI to students, build instructor partnerships, and determine courses to support with SI (Martin \& Arendale, 1992c; Wilcox, 2008). SI supervisors also assist with scheduling and ongoing supervision of the entire program (Hurley et al., 2006). These responsibilities are significant, but the cost of SI programs is generally low.

The most costly aspect of an SI program is the salary of the SI leader (Martin \& Arendale, 1992c; Wilcox, 2008). There are several ways to fund SI leader salaries, including work-study funds, grants, departmental funding, or alternative methods such as course credit (Martin \& Arendale, 1992c). Wilcox (2008) shares that considering alternative forms of compensation might be more beneficial than paying SI leaders hourly because of the time associated with managing the payroll of the leader. Other costs include supplies for the leaders such as books and copying (Widmar, 1994) and release time or salaries for administrative personnel (Wilcox, 2008). As programs expand, using SI student assistants 
who are more experienced SI leaders and help with the supervision of SI leaders can be an effective way to keep costs low (Martin \& Arendale, 1992c).

Supplemental Instruction is considered a low cost and efficient program. There is no limit to the number of students served because of the group-based approach (Wilcox, 1992; Zerger et al., 2006). Additionally, SI is claimed to save money because it helps retain students to graduation (Wilcox, 1992). Congos (2001) illustrates how SI has a significant return on investment due to the retention of students versus other methods of maintaining enrollment, such as recruitment costs. While this figure is likely out-of-date, Widmar (1994) suggests there was a $\$ 1.50$ return for every dollar invested in an SI program due to increased student success and persistence. Based on these, it is clear that SI is seen as a low cost and efficient program.

Overall, there is not a lot of guidance on SI supervision Figure 1.2 in section one illustrates the core administrative tenets of SI program supervisors. The responsibilities noted earlier for SI program supervisors often include seven to eight hours per week per course for the first three weeks in making class presentations and handing out materials (Wilcox, 2008). Some ongoing activities for supervisors after the start of the terms are observations of staff, meeting with faculty members, ongoing training, and being available to assist with planning SI sessions (Wilcox, 2008). Because of these responsibilities, Wilcox (2008) suggests that one supervisor can only adequately supervise three to four SI leaders beyond which the supervisor would need assistance. However, there is no empirical research support for this breakdown. Given the current financial demands on higher education, such supervision levels seem impractical. 
When exploring the importance of SI program components, little research has been performed on how the components connect to SI program outcomes. Jones (2013) explored the use of multiple SI leaders in a single introductory accounting class, even though the typical leader to course ratio is one-to-one and found positive effects on grades suggesting that multiple SI Leaders do not harm the program outcomes. However, Jones's (2013) study does not make clear what the ideal class enrollment to SI leader ratio is nor how supervisory levels can vary. Wilcox (2008) proposes an adequate program staffing ratio of 20 leaders supervised by three SI mentors (SI program assistants who help supervise) plus an SI supervisor. However, this ratio is not supported by research evidence.

The most extensive study to-date on program features and their relationship with program outcomes was Arendale's (2000) dissertation. Arendale (2000) assessed SI programs across the United States in the following areas: general background information about the SI program such as administrative location, SI program outcomes, and SI program activities (training, observation, class attendance, and session activities). Arendale (2000) used administrative satisfaction with the program, attendance rate, the average final grade differential between the students who attended SI sessions and between those who did not attend, and the difference in DFW rates of the students who attended SI compared to those who did not as the dependent variables. Arendale (2000) found that SI supervisor involvement, SI leader involvement, and SI leader training were essential components for SI program success. However, Arendale's (2000) study did not define the level of supervision needed nor the optimal level of supervision. Arendale (2000) recommends that more national studies be conducted and that researchers include institutional and student characteristics and further study SI program constructs such as supervision. 


\section{Staffing Considerations and Support}

The field of organizational analysis supports the conceptual pillar of staffing considerations and support. First, the administration and structure of organizations affect the power dynamics and the structure of a program. Second, support for programs in organizations is inherently political when competing for resources. Next, support is also affected by the structure and culture of an institution. Fourth, training and development is a common strategy for organizations to improve effectiveness. Lastly, the supervision of SI leaders involves issues of coordination of activities and navigating power dynamics. These considerations are addressed more fully in the following subsections.

Administration and structure. When considering organizations from a structural perspective, there are two fundamental tensions: differentiation and integration (Bolman \& Deal, 2013). Both of these play a role in staffing considerations. Differentiation is about how different responsibilities are parceled out among individuals in an organization (Bolman \& Deal, 2013). Mintzberg (1979/2005) describes five basic parts of organizations that define responsibilities: the operating core, the technostructure, the middle line, the support team, and the strategic apex. Given that the operating core of higher education institutions is teaching and conducting research, SI programs either fit within this structure or within the support structure of the organization. See figure 2.1 in section two for a visual representation of these five basic parts.

Organizations can group units in several ways, such as function, process, or geographical region (Bolman \& Deal, 2013), and SI programs are mostly grouped by the process-learning support. Differentiation can also depend on hierarchical relationships within the structure. Carzo and Yanouzas (1969) empirically studied flat and tall 
organizational structures by examining the communication chains of an organization with four hierarchical levels with a smaller number of direct reports for each person on each level (tall organizational structure) and an organization with one level with a high number of direct reports for the person on that level (flat organizational structure). Carzo and Yanouzas (1969) found no effect on decision time but found superior performance in a tall structure, which they suggested resulted in more orderly decisions and communication processes. Thus, it may be better for SI programs to exist in taller structures. Martin and Arendale (1992c) note that many SI programs were beginning to implement assistant SI supervisors to help the main supervisors in the task of supervising SI leaders. Thus, SI programs may function better with a taller organizational structure that involves such assistants.

Another determinant in organizational structures is also the span of control. The span of control is the number of people one person can supervise (Manning, 2009). The concept of span of control has been sporadically researched over the decades. Udell (1967), in a study of marketing firms, found that the span of control is negatively affected by the dissimilarity of the jobs of supervisors and subordinates and positively affected by the amount of supervision needed. In a study of determinants of span of control, Bell (1967) looked at the complexity of subordinate and supervisor job responsibilities, which include discretion, responsibility, types of tasks, and closeness of supervision needed. Bell (1967) found that when subordinate jobs were complex, it was difficult for supervisors to oversee more than a few employees; thus, the complexity of the supervisor's role decreased span of control.

Meyer (1968) studied the role of expertise on the span of control in public organizations and found that as the expertise required to complete a role increased, the span of control of their supervisor increased as well. Meyer (1968) speculated that this was due to 
the competence that expertise gave the subordinates, which required less supervision. In SI programs, Wilcox (2008) suggests that one supervisor can only adequately supervise up to four SI leaders before needing some assistance. If this ratio is accurate, it might suggest that SI leaders do not have enough expertise to complete their role independently or, as noted in the preceding paragraph, that SI leader responsibilities are complex and require close supervision. Consequently, SI program supervisors would have less span of control and Wilcox's (2008) suggestion would be supported.

In a more recent span of control study, Meier and Bohte (2000) explored the idea of how the span of control in K-12 schools (the administrator to teacher and teacher to student ratio) affected student performance. They found that while other aspects of the organization, such as resources of the school, affected performance more, the span of control was still significant (Meier \& Bohte, 2000). These findings suggest that a lower ratio of administrators to SI leaders and additional program resources could result in improved program outcomes.

The power of the individuals also influences the administration and support of programs within the organization. French and Raven (1959/2005) describe several aspects of power. One of which is legitimate power, which is the power granted through a higher authority (French \& Raven, 1959/2005). In a structure of SI programs, legitimate power belongs to the SI supervisor, but also to the person to whom the SI program reports. Thus, having an SI program supervisor reporting to someone relatively high in the organizational chart may increase their legitimate power, which in turn could help in advocating for resources.

Additionally, since SI programs are designed to work closely with faculty, it might be ideal for the SI program to report on the academic affairs side to a dean or provost to add 
legitimate power to the SI programs with the same people to whom faculty report. This extra power would assist in improving faculty relationships and, thereby, program outcomes. However, Arendale (2000) explored the relationship between SI program administrative location such as academic affairs or student affairs and program outcomes and did not find a significant relationship between the two constructs.

Another consideration for administrating programs is integration. Integration is the idea of coordinating activities within an organization and deals with people's behaviors (Bolman \& Deal, 2013). There are two types of coordination: lateral, which is organizing across different parties, and vertical coordination, which is mostly top-down direction from administration (Bolman \& Deal, 2013). Bolman and Deal (2013) suggest that too much vertical coordination can stifle initiative and creativity and is better when operations are simple and clear, but lateral coordination is more effective when the task at hand is complex. In SI programs, there needs to be a careful balance struck between lateral and vertical coordination methods. The next section addresses organizational considerations for program support.

Support for programs. Support for organizations is a highly political process. Organizations consist of coalitions that represent different interests or ideas (Bolman \& Deal, 2013). Between these coalitions, there is a conflict for scarce resources (Bolman \& Deal, 2013). SI programs, including broader learning assistance programs, are one such coalition in an organization. Thus, funding for SI programs is a result of competition with other programs at an institution. Subsequently, the literature on SI programs describe ways to advocate for resources. Both Congos (2001) and Widmar (1994) claim a significant return on investment in SI programs in terms of increased revenue for the college or university. Others cite the 
group-based format of SI to promote the efficiency of the program (Wilcox, 1992; Zerger et al., 2006).

Support for programs is also influenced by the structure and culture of the organization. As suggested earlier, organizations consist of coalitions competing for scarce resources (Bolman \& Deal, 2013). Thus, if an SI program is placed within a unit with fewer programs to compete with for resources, this might improve its support. Moreover, funding and support relate to the culture of the organization. According to Schein (1993/2005), organizational culture is "a pattern of shared basic assumptions that the group learned" (p.364-365). Additionally, organization and team culture are the "shared values, beliefs, and norms of an organization" (Levi, 2017, p. 283). Thus, if an organization establishes SI as part of the culture or espouses values that align with the SI model with a student-focused approach, funding and support for SI programs might be easier to attain.

Training and Development. A key strategy of organizational effectiveness is hiring and selection of employees. Bolman and Deal (2013) suggest that an organization should be selective and understand what it is seeking in prospective employees. Collins (2001) explored factors that allowed organizations to transform from good to great, one of which included making sure that the team composition was ideal and that individuals were in the positions that suited their abilities, talents, and the organizational needs. Hiring requirements for SI leaders often look for high grades (Ainsworth et al., 1994; McDaniel, 2008; Zaritsky \& Toce, 2006), a student-focused demeanor (Stout \& McDaniel, 2006), and interpersonal skills (McDaniel, 2008; Wilcox, 2008). After selection, training is the next human resource strategy for organizations. 
Training is a critical strategy for many organizations (Bolman \& Deal, 2013). Arendale (2010) indicates that one best practice of learning assistance programs is ongoing training and professional development for all personnel in the program. Kathman and Kathman (2000) discuss challenges for training student employees in academic libraries, which include high turnover, other responsibilities of the supervisor, and training time/content. These all apply to SI program supervisors as well. The conceptual framework that Kathman and Kathman (2000) developed for training includes pre-employment activities (job description, performance outcomes, culture, and work environment), orientation (what is needed to learn, e.g. necessary knowledge about services), specific training including computer instruction, follow-up training, evaluation of training (continuous improvement). Wilcox (2008) indicates that evaluation and training preparation is a significant aspect of a supervisor's role, so these responsibilities need to be included in a supervisor's workload. Lastly, Bolman and Deal (2013) suggest that learning needs to occur on the job and in the classroom. Thus, a critical aspect of SI program supervision is ongoing feedback and development of staff.

Supervisory Activities. By attending to human needs, an organization can better motivate the employees to do their work and increase organizational performance (Bolman \& Deal, 2013). Given that SI leaders are often part-time employees, an SI supervisor must be able to attend to student employee needs and motivations. One possibility in SI programs, given lean budgets, is downsizing. Bolman and Deal (2013) caution that downsizing can hurt morale and is usually only useful when technology and management allow for greater efficiency. 
Staff development is critically important. Bolman and Deal (2013) suggest that progressive organizations empower employees, give autonomy, and provide feedback, and Wilcox (2008) suggests that a critical component of SI program supervision includes observing sessions and giving detailed, constructive feedback. Martin and Arendale (1992b) indicate that SI programs that implement assistant SI supervisors use those staff members to help observe and provide feedback to the SI leaders themselves. Additionally, staff development involves creating a team environment. Levi (2017) suggests that cultivating a successful team focuses on group processes and organizational context. Lozada and Johnson (2019) found that creating a team environment in SI programs can assist in transformational learning on the part of the SI leader. This finding suggests that a critical component of SI program supervision is also developing a team atmosphere.

Structurally, a key responsibility of organizations is to coordinate the activities of the program (Bolman \& Deal, 2013). One such coordination in SI programs could be planning. Supervisors are recommended to help SI leaders plan for sessions early in the semester (McDaniel, 2008). Thus, supporting SI leaders in the planning process is a critical supervisory element. This planning support process also helps reduce ambiguity, which, according to Bolman and Deal (2013), is a standard structural tension in an organization. The planning process also raises questions of power dynamics. As suggested earlier, SI program supervisors may have legitimate power due to their position, which means SI leaders will likely lean towards following the perspective or direction of the supervisor. However, SI leaders also work with their faculty members to plan sessions. Faculty members may have expert and referent power. Expert power is where expertise grants the individual power while referent power is prestige or desired association (French \& Raven, 1959/2005). 
Thus, if there is a conflict in the planning process between the supervisor's and a faculty member's desires, there may be a power struggle or series of struggles among constituent groups. Thus, a part of SI supervision might be working with SI leaders to navigate this dynamic.

\section{Conclusion}

Higher education is under considerable scrutiny. Not only are postsecondary institutions being held accountable for increasing student outcomes (Dar, 2016), institutions are also being asked to make college more affordable (Butler, 2016). Learning assistance programs are a vital element in helping students be successful in higher education (Arendale, 2004), and SI is a strategy that has shown positive outcomes. Arendale (2000) shows that SI supervision is a critical importance in SI programs, but in today's budget climate, it is essential to understand how efficient SI program administration can be. Staffing considerations involve the structure, span of control, coordination activities, and training and staff development. Understanding optimal patterns of SI programs will help program administrators better align their programming and advocate for resources. 


\section{SECTION FOUR - CONTRIBUTION TO PRACTICE}

The International Center for Supplemental Instruction (International Center) based at the University of Missouri - Kansas City will be interested in this research and the findings given their role of mentoring and assisting SI programs across the globe. The International Center provides training multiple times of the year to SI program supervisors and potential supervisors across the world, so this information would assist them in this training. The International Center has indicated that research on the optimal administrative tenets would be useful information to have (J. Collins \& M. Cross, personal communication, August 8, 2019).

In their SI program supervisor training, the International Center provides a workbook/handbook for each participant. In this handbook, a few pages describe best practices for SI program supervisors, but it is mostly potential job descriptions. Thus, this section provides additional SI supervisory guidelines and best practices. This section provides critical considerations for supervisors based on past writers on SI programs such as Deanna Martin, David Arendale, F. Kim Wilcox, and Amelia McDaniel. In addition, this section insert also contains guidance on leadership and organizational considerations for SI program supervisors. If the International Center chooses to add this section or a modified version of this section, it would widely disseminate information for program supervisors, because this workbook is shared with SI supervisor training participants. This section insert will be sent to the International Center following the dissertation defense for their potential inclusion, review, and modifications.

An annotated version of the section insert is included. Text in red provides additional context on the literature supporting those recommendations while writing in black will be the text of the actual section insert. 


\section{LEADING \& SUPERVISING AN SI PROGRAM}

This section provides SI program supervisors further guidance from the literature on leadership, organizational analysis, and SI program descriptions. The discussion around leadership uses three theories on leadership, and the discussion on organizations views them through a specific framework. Following these discussions, the next section explores supervisory considerations and offers recommended staffing level considerations based on the research and past discussion on these areas. Lastly, insights on funding programs and advocating for resources are provided.

This introduction outlines what to expect in this section. First, during the writing process for section two of this dissertation, I found reflecting on SI programs through leadership and organizational lenses provided new insights into SI program supervision. Therefore, I have included small literature reviews of some of the content from that section, along with other leadership and organization considerations and applied them to SI programs. Second, there was considerable guidance on recommended ratios/levels of certain supervisory activities from the writers on Supplemental Instruction. So, I wanted to include a portion that describes those recommendations and contains the benchmarking results and findings from my study. The findings and summarized descriptions make references to earlier sections in the handbook. Lastly, the literature on SI program funding and support was described to provide recommendations for supervisors to consider when funding their program.

\section{Leadership Considerations}

\begin{tabular}{|l|l|}
\hline Theory \& Description & $\begin{array}{l}\text { Considerations for Program Leaders } \\
\text { This portion speculates how the leadership theory in the left-hand } \\
\text { column could be applied to SI program supervision. This } \\
\text { information is partially based on the reflective process engaged in } \\
\text { section two. }\end{array}$ \\
\hline $\begin{array}{l}\text { Path-Goal Leadership } \\
\text { This leadership theory } \\
\text { suggests that leaders } \\
\text { can be effective if they } \\
\text { influence their } \\
\text { followers' motivation, } \\
\text { performance, and } \\
\text { satisfaction (House, } \\
\begin{array}{l}\text { 1996) and consists of } \\
\text { leader behaviors, } \\
\text { follower } \\
\text { characteristics, and task } \\
\text { characteristics } \\
\text { instructions and is most useful when tasks and procedures are } \\
\text { unclear (House \& Mitchell, 1974). Potentially useful for } \\
\text { supervisors when: } \\
\text { Assisting SI leaders with planning sessions. }\end{array} \\
\text { - An SI leader needs significant improvement in their } \\
\text { performance. }\end{array}$ \\
$\begin{array}{l}\text { For setting expectations for logistical program elements such } \\
\text { as sign-in sheets, attendance tracking, etc. }\end{array}$ \\
$\begin{array}{l}\text { Supportive leadership is where the leader provides support to the } \\
\text { followers and is particularly useful when the task is stressful and }\end{array}$ \\
\hline
\end{tabular}




\begin{tabular}{|c|c|}
\hline & $\begin{array}{l}\text { unsatisfying (House \& Mitchell, 1974). Potentially useful for } \\
\text { supervisors when: } \\
\text { - Asking subordinates to complete menial tasks such as } \\
\text { attendance tracking, submitting payroll, etc. } \\
\text { - An SI leader is facing challenging situations in sessions, in } \\
\text { their SI class, or with their SI faculty member. } \\
\text { Participative leadership is where the leader gives greater } \\
\text { participation to followers and helpful when control and autonomy } \\
\text { are given to the followers (House \& Mitchell, 1974). Potentially } \\
\text { useful for supervisors when: } \\
\text { - Giving greater responsibility for session planning to leaders. } \\
\text { - Using SI program assistants to help supervise and mentor other } \\
\text { SI leaders in the program. } \\
\text { - Building relationships and partnerships with faculty and other } \\
\text { campus stakeholders. } \\
\text { Achievement-oriented leadership helps followers strive for higher } \\
\text { performance in non-repetitive and unclear tasks (House \& } \\
\text { Mitchell, 1974). Potentially useful for supervisors when: } \\
\text { - Observing sessions and providing leaders with feedback. } \\
\text { - Guiding SI program assistants in improved performance of } \\
\text { leaders. } \\
\text { - Developing initial, ongoing, and individualized training for SI } \\
\text { program staff. }\end{array}$ \\
\hline $\begin{array}{l}\text { Situational Leadership } \\
\text { Leadership depends on } \\
\text { a follower's } \\
\text { competence and } \\
\text { commitment level } \\
\text { (Blanchard et al., 1985) } \\
\text { and consists of both } \\
\text { directive and } \\
\text { supportive behaviors } \\
\text { (Northouse, 2016). }\end{array}$ & $\begin{array}{l}\text { Leadership Style } \\
\text { Directive Style, which is high directive and low supportive } \\
\text { leadership behaviors for followers with low competence levels } \\
\text { (Blanchard et al., 1985). Potentially useful for supervisors when: } \\
\text { - Helping SI leaders plan sessions. } \\
\text { - SI leaders are still less competent or less committed to their } \\
\text { work. } \\
\text { - SI leaders need to complete menial tasks such as attendance } \\
\text { tracking, submitting payroll, etc. } \\
\text { Coaching Style, which is high directive and high supportive } \\
\text { leadership behaviors, and followers have middling low } \\
\text { competence levels (Blanchard et al., 1985). Potentially useful for } \\
\text { supervisors when: } \\
\text { - Observations particularly early in a semester or for newer SI } \\
\text { leaders. } \\
\text { - Working with a low-committed SI leader that has been on staff } \\
\text { for a while. }\end{array}$ \\
\hline
\end{tabular}




\begin{tabular}{|c|c|}
\hline & $\begin{array}{l}\text { Supporting Style, which is low directive and high supportive } \\
\text { leadership behaviors for followers with middling high } \\
\text { competence levels (Blanchard et al., 1985). Potentially useful for } \\
\text { supervisors when: } \\
\text { - Working with experienced SI leaders that have shown some } \\
\text { competence and higher commitment levels. } \\
\text { - Assisting SI leaders with planning sessions. } \\
\text { - Observing sessions and providing feedback. } \\
\text { - Conducting team-building activities and connecting with others } \\
\text { during training and meetings. } \\
\text { Delegating Style with a low directive and low supportive } \\
\text { leadership behaviors for highly competent followers (Blanchard } \\
\text { et al., 1985). Potentially useful for supervisors when: } \\
\text { - Modeling strategies for SI leaders in training. } \\
\text { - Using SI program assistants to help supervise the program. } \\
\text { - Working with very experienced and competent SI leaders or } \\
\text { possibly when working with SI faculty members on specific } \\
\text { tasks. }\end{array}$ \\
\hline $\begin{array}{l}\quad \frac{\text { Transformational }}{\text { Leadership }} \\
\text { Transformational } \\
\text { leadership tries to } \\
\text { increase the motivation } \\
\text { of followers } \\
\text { (Northouse, 2016). } \\
\text { There are four } \\
\text { components of } \\
\text { transformational } \\
\text { leadership: idealized } \\
\text { influence, inspirational } \\
\text { motivation, intellectual } \\
\text { stimulation, and } \\
\text { individualized } \\
\text { consideration (Bass \& } \\
\text { Riggio, 2006). }\end{array}$ & $\begin{array}{l}\text { Leadership Components } \\
\text { Idealized influence is being a good role model, having a vision, } \\
\text { and being willing to take risks (Bass \& Riggio, 2006). Potentially } \\
\text { useful for supervisors when: } \\
\text { - Modeling SI strategies during training. } \\
\text { - Outlining and creating a shared vision of the SI program in the } \\
\text { institutional context with SI leaders. } \\
\text { - Adapting the SI model to the institutional context. } \\
\text { Inspirational motivation is behaviors that challenge and inspire } \\
\text { followers to perform well (Bass \& Riggio, 2006). Potentially } \\
\text { useful for supervisors when: } \\
\text { - Establishing clear expectations for work processes. } \\
\text { - Motivating SI leaders to improve sessions and to try new } \\
\text { strategies. } \\
\text { - Inspiring SI leader to do their best work, potentially by sharing } \\
\text { a vision of the transformative effect of SI programs. } \\
\text { Intellectual stimulation is where leaders challenge processes, } \\
\text { promote creativity, and encourage innovation (Bass \& Riggio, } \\
\text { 2006). Potentially useful for supervisors when: } \\
\text { - Challenging SI leaders through observation feedback. } \\
\text { - Challenging SI leaders to improve planning for sessions. } \\
\text { - Involving SI leaders in leading program activities. } \\
\text { - Encouraging SI leaders to exchange ideas and strategies. }\end{array}$ \\
\hline
\end{tabular}




\begin{tabular}{|l|l|}
\hline Individualized consideration is when leaders consider follower \\
needs, their ongoing development, and adapt to individual \\
differences (Bass \& Riggio, 2006). Potentially useful for \\
supervisors when: \\
- Developing ongoing training that addresses individual needs \\
- Providing feedback to individual leaders in observations and \\
planning support. \\
- In larger institutional contexts where there is a need for more \\
supervisory support.
\end{tabular}

\section{Organizational Considerations}

When viewing organizations, Bolman and Deal (2013) introduce the concept of framing, which "requires an ability to think about situations in more than one way" (p.5). They suggest that viewing organization through four interrelated frames (structural, human resources, political, and symbol) assist leaders in understanding their organization and problem-solve (Bolman \& Deal, 2013). The table below describes each organizational frame in more detail and provides considerations for leaders of SI programs from that perspective.

\begin{tabular}{|c|c|}
\hline $\begin{array}{c}\text { Organizational Frame } \\
\text { \& Description }\end{array}$ & Considerations for Program Leaders \\
\hline $\begin{array}{l}\quad \text { Structural } \\
\text { The structural view of } \\
\text { organizations suggests } \\
\text { that organizational } \\
\text { performance will be } \\
\text { best through clear roles } \\
\text { and responsibilities } \\
\text { (Bolman \& Deal, } \\
\text { 2013). A key issue of } \\
\text { the structural view of } \\
\text { an organization is how } \\
\text { work is allocated and } \\
\text { how that work is } \\
\text { coordinated (Bolman \& } \\
\text { Deal, 2013). } \\
\text { The structural frame } \\
\text { guides structural } \\
\text { considerations. The } \\
\text { considerations are } \\
\text { based on the structural } \\
\text { imperatives that } \\
\text { Bolman and Deal } \\
\text { (2013) outline. }\end{array}$ & $\begin{array}{l}\text { Consider these structural imperatives when considering the } \\
\text { organization of your SI program: } \\
\text { Bolman and Deal (2013) instruct that an ideal structure and } \\
\text { organization involves several factors and imperatives. Thus, SI } \\
\text { program supervisors need to consider their institutional and } \\
\text { environmental contexts when creating an optimal structure for } \\
\text { their program. } \\
\text { The complexity and rigidity of operations increase with larger } \\
\text { and older organizations (Bolman \& Deal, 2013). } \\
\text { - As you increase the size of your SI program, consider the } \\
\text { coordinating activities and how those will be affected? } \\
\text { Generally, the larger the organization, the more coordinating } \\
\text { activities needed. } \\
\text { - If you are working with an older SI program, consider giving } \\
\text { attention to processes and policies as well as building } \\
\text { flexibility into programming and operations. } \\
\text { - Arendale (2000) found that the age of an SI program was not } \\
\text { significantly related to program outcomes, so longevity does } \\
\text { not necessarily mean a high-quality program. } \\
\text { The structure of the organization should center around its core } \\
\text { process (Bolman \& Deal, 2013). }\end{array}$ \\
\hline
\end{tabular}




\begin{tabular}{|c|c|}
\hline & $\begin{array}{l}\text { - Consider the activities and technology of the SI program and } \\
\text { how they relate to the core functions of SI. Do these items } \\
\text { support the core function or detract from them? What needs to } \\
\text { be refined or changed? } \\
\text { - Arendale (2000) found that SI program structural placement in } \\
\text { either academic affairs or student affairs was not significant to } \\
\text { SI program outcomes. } \\
\text { The structure should align with strategies and goals (Bolman \& } \\
\text { Deal, 2013). } \\
\text { - Consider your organizational activities and your program } \\
\text { goals. Are they aligned? } \\
\text { - Consider how your program's goals and strategies align with } \\
\text { the larger institution's strategies and goals. } \\
\text { Information technology allows organizations to operate with a } \\
\text { flatter and more decentralized structure (Bolman \& Deal, 2013). } \\
\text { - Consider how you use technology to coordinate activities in } \\
\text { your program } \\
\text { - Explore what technology resources are available for your } \\
\text { program. } \\
\text { - Consider how information technology can add efficiencies to } \\
\text { operations and coordinating activities. } \\
\text { Bolman and Deal (2013) suggest that educated and professional } \\
\text { transition of tasks and responsibilities when there is turnover, } \\
\text { - } \text { - } \text { - } \\
\text { ofpecially if you use experienced SI leaders to manage aspects } \\
\text { of program operations. }\end{array}$ \\
\hline $\begin{array}{l}\text { Human Resources } \\
\text { The human resources } \\
\text { (HR) frame indicates } \\
\text { that organizations exist } \\
\text { to serve the people who } \\
\text { work for it and } \\
\text { considers topics such } \\
\text { as fit, motivation, and } \\
\text { development of people } \\
\text { (Bolman \& Deal, } \\
\text { 2013). }\end{array}$ & $\begin{array}{l}\text { Consider these HR strategies when considering your SI program: } \\
\text { Build and implement an HR strategy by creating a vision or } \\
\text { structure to support practices related to managing people (Bolman } \\
\text { \& Deal, 2013). } \\
\text { - Consider your orientation processes for employees and how } \\
\text { these processes are aligned with the organization's vision. } \\
\text { - Consider your compensation strategies and adjust if needed. } \\
\text { - If managing an extensive program, consider how you are } \\
\text { creating teams or training supervisors. }\end{array}$ \\
\hline $\begin{array}{l}\text { In this framework, } \\
\text { Bolman and Deal }\end{array}$ & $\begin{array}{l}\text { Bolman and Deal (2013) discuss clear goals in the hiring process } \\
\text { and maintaining those practices. }\end{array}$ \\
\hline
\end{tabular}




\begin{tabular}{|c|c|}
\hline $\begin{array}{l}\text { (2013) discuss basic } \\
\text { human resource } \\
\text { strategies that } \\
\text { organizations should } \\
\text { employ. Those were } \\
\text { used as a guiding } \\
\text { framework for the } \\
\text { considerations for SI } \\
\text { program leaders. }\end{array}$ & 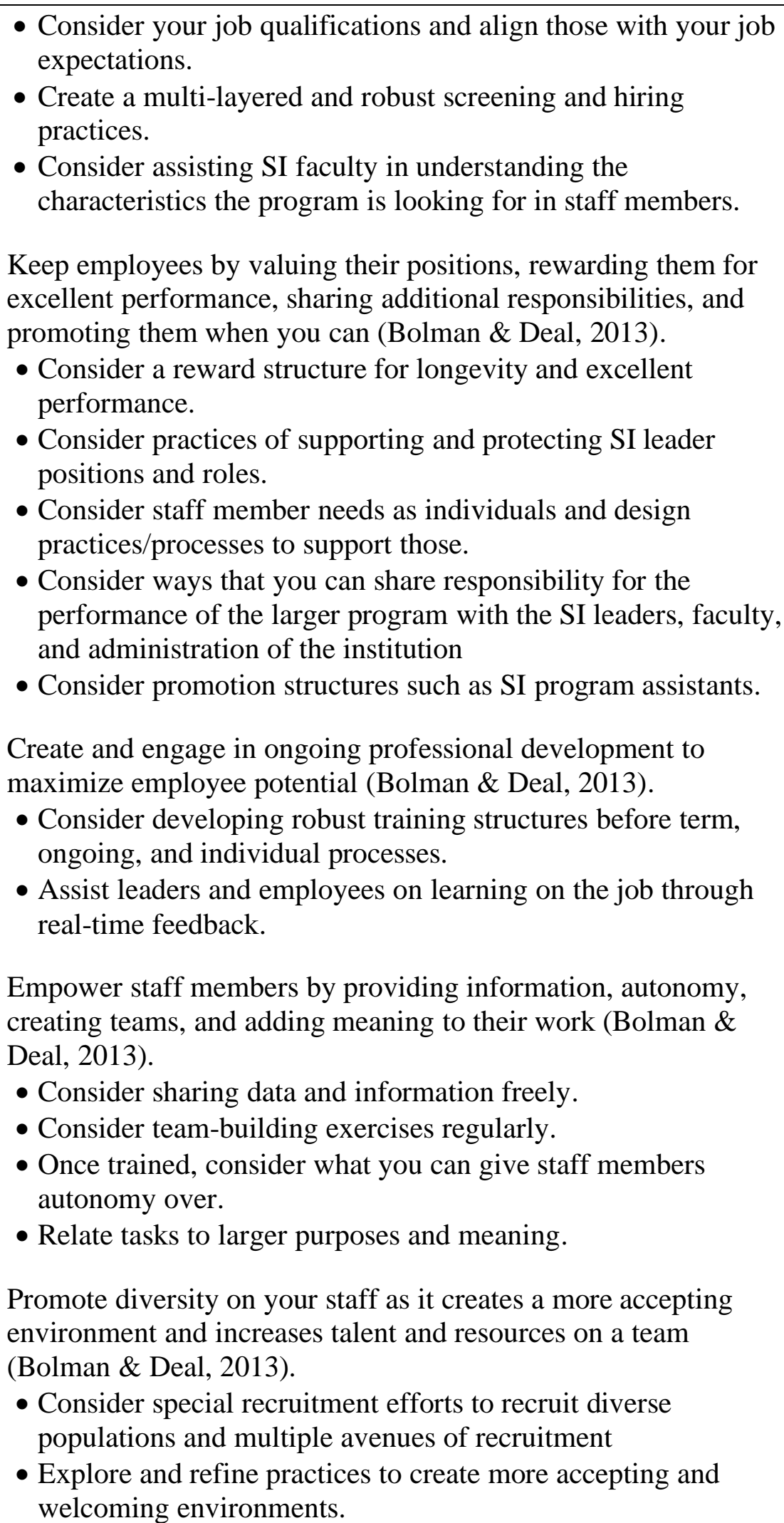 \\
\hline
\end{tabular}




\begin{tabular}{|c|c|}
\hline $\begin{array}{l}\text { Political } \\
\text { The political frame sees } \\
\text { organizations as groups } \\
\text { that represent different } \\
\text { interests that compete } \\
\text { for power and } \\
\text { resources (Bolman \& } \\
\text { Deal, 2013). } \\
\text { Bolman and Deal } \\
\text { (2013) provide a list of } \\
\text { four critical skills for } \\
\text { managers as } \\
\text { politicians, which are } \\
\text { used as the guiding } \\
\text { framework for the } \\
\text { considerations for this } \\
\text { frame. }\end{array}$ & $\begin{array}{l}\text { Consider these political skills for managers when considering } \\
\text { your SI program: } \\
\text { Agenda Setting is a skill for political managers to clarify their } \\
\text { interests and create a plan for achieving them (Bolman \& Deal, } \\
\text { 2013). } \\
\text { - Consider working with SI leaders and within your larger unit } \\
\text { to carve out goals for the organization. } \\
\text { - Consider building a compelling vision that appeals to the } \\
\text { groups around you. } \\
\text { Networking and building coalitions allow leaders and managers } \\
\text { to accomplish tasks and assert their agenda (Bolman \& Deal, } \\
\text { 2013). } \\
\text { - Develop strong relationships with your staff and leaders in } \\
\text { your units/divisions. } \\
\text { - Once identified, build connections and relationships with } \\
\text { influential individuals at your institution. } \\
\text { - Connect with strategic partners inside and outside your } \\
\text { institution that can assist you in achieving your organization's } \\
\text { goals. } \\
\text { Bargaining and negotiation are needed for decision-making } \\
\text { between different interests and coalitions within an organization } \\
\text { (Bolman \& Deal, 2013). } \\
\text { - Develop an understanding of what you need, why you need it, } \\
\text { and on what you can compromise. } \\
\text { - Determine how you can serve others and meet their needs } \\
\text { while accomplishing your goals. } \\
\text { - } \text { - Donstitution, what resources you need to be more effective, and } \\
\text { ading those resources. } \\
\text { influences in the organization, how to communicate with others, } \\
\text { analyzing power structures, and managing political strategies } \\
\text { (Bolman \& Deal, 2013). } \\
\text { administrators are the most influential and why. } \\
\text { - }\end{array}$ \\
\hline $\begin{array}{l}\frac{\text { Symbolic }}{\text { The symbolic frame }} \\
\text { considers how } \\
\text { symbols, cultures, } \\
\text { myths, and stories }\end{array}$ & $\begin{array}{l}\text { Consider these myths, visions, values, stories, and culture affect } \\
\text { the organization of your SI program: }\end{array}$ \\
\hline
\end{tabular}




affect organizational
performance (Bolman
\& Deal, 2013).
In the symbolic frame,
symbols such as myths,
stories, visions, and
values represent an
organization, and it
also describes how
culture affects
organizations (Bolman
\& Deal, 2013). These
were used to provide
considerations for
supervisors.

Myths, vision, and values help organizations communicate plans for the future and values that undergird operations (Bolman \& Deal, 2013).

- Communicate the organization's values and vision and share them with staff, administration, faculty, and students.

- Consider how the values of your program connect and relate to the values of the larger institutions.

- Consider what the vision is of your organization and who was involved in creating that vision.

Stories convey an organization's vision, purpose, and continues traditions (Bolman \& Deal, 2013).

- Consider the use of stories to convey a vision and purpose.

- Consider the use of stories as a way to communicate information and their importance.

Rituals and ceremonies allow individuals to join a group or a new community while continuing the alignment within the organization (Bolman \& Deal, 2013).

- Consider a set of ceremonies and rituals that will communicate belongingness to your program.

- Consider aligning these rituals and ceremonies with the purpose and vision of your organization.

Culture is a set of shared assumptions and learning (Schein, 1993/2005).

- Consider fostering a sense of culture through repeated actions and events.

- Consider how to use members of your staff to share and create a culture.

\section{Supervisory Considerations}

This table provides guidance on key supervisory constructors for SI programs. Benchmarks noted by an "*” and are based on the average value from a sample of approximately 60 SI programs in North America collected during the spring of 2020.

\begin{tabular}{|l|l|}
\hline $\begin{array}{l}\text { Hiring \& } \\
\text { Selection }\end{array}$ & $\begin{array}{l}\text { Time Guidance: No real guidance from the literature on the time needed } \\
\text { for supervisors for hiring and selection processes. }\end{array}$ \\
& $\begin{array}{l}\text { Discussion in the Literature: } \\
\text { Refer to an earlier section in the handbook for hiring } \\
\text { considerations. }\end{array}$ \\
\hline
\end{tabular}




\begin{tabular}{|c|c|}
\hline & $\begin{array}{l}\text { McDaniel (2008) suggests that improving the quality of the SI } \\
\text { session through observations and feedback will reduce the } \\
\text { attrition of SI leaders. } \\
\text { There is little discussion on the time needed for SI program supervisors } \\
\text { when hiring and selecting SI leaders. Mostly, they discuss hiring } \\
\text { qualifications and characteristics of good leaders. Another section in this } \\
\text { handbook discusses qualifications for leaders, so a discussion of that here } \\
\text { would be redundant. Generally, though, SI leader should have } \\
\text { interpersonal skills (Ainsworth et al., 1994; McDaniel, 2008), have higher } \\
\text { grades and strong content knowledge (Ainsworth et al., 1994) and have } \\
\text { the potential for useful instructional techniques and strategies (McDaniel, } \\
\text { 2008). }\end{array}$ \\
\hline Training & $\begin{array}{l}\text { Time Guidance: } \\
\text { - Five to ten hours of preparation for pre-term training (Wilcox, } \\
\text { 2008). } \\
\text { - One to two days of pre-term training (McDaniel, 2008). } \\
\text { - Eight to sixteen hours in total of pre-term training (McDaniel, } \\
\text { 2008). } \\
\text { - Eight hours of ongoing professional development (Curators of the } \\
\text { University of Missouri, 2018). } \\
\text { - Benchmark: } 3.13 \text { hours of training and training preparation time } \\
\text { per SI Leader for the entire semester. * } \\
\text { - Training courses for SI leaders have been options for some } \\
\text { institutions (Lipsky, 2006). } \\
\text { The role of returning SI Leaders in training are mixed. McDaniel } \\
\text { (2008) suggests having SI leaders return for a least a portion of } \\
\text { the training but that it may not be necessary for them to attend all } \\
\text { of it. } \\
\text { - McDaniel (2008) does suggest that it could be useful to use } \\
\text { returning SI leaders for ongoing training to help newer SI leaders. } \\
\text { - SI supervisor involvement was significantly related to the SI } \\
\text { leader training construct in Arendale's (2000) dissertation, which } \\
\text { suggests that SI supervisors are critical for engagement in } \\
\text { training. } \\
\text { For SI program accreditation, the International Center for SI } \\
\text { recommends that training includes mock sessions and at least } \\
\text { eight hours of ongoing professional development (Curators of the } \\
\text { University of Missouri, 2018) } \\
\text { - } \\
\text { - } \\
\text { - }\end{array}$ \\
\hline
\end{tabular}




\begin{tabular}{|c|c|}
\hline & $\begin{array}{l}\text { every additional hour of training/training planning time conducted } \\
\text { per SI leader will net a } 0.65 \% \text { boost in attendance. } \\
\text { Wilcox (2008) and McDaniel (2008) discuss five to sixteen hours of pre- } \\
\text { semester training, and Wilcox (2008) mentions that supervisors would } \\
\text { need around five to ten hours to prepare for the training. McDaniel (2008) } \\
\text { also suggests that training should include good team building, } \\
\text { simulations, and model SI techniques. Lipsky (2006) shares information } \\
\text { about a training course developed for SI leaders that includes topics such } \\
\text { as the role of SI leader and helping SI leaders understand how to plan for } \\
\text { their sessions. The last bullet point above was the key finding from this } \\
\text { dissertation's study. }\end{array}$ \\
\hline Observations & $\begin{array}{l}\text { Time Guidance: } \\
\text { - Observe once a week for the first half of the term, and every other } \\
\text { week for the second half of the term (Wilcox, 2008). } \\
\text { - Two to three hours of observation per course per week for the rest } \\
\text { of the semester after the first few weeks of the semester, which } \\
\text { includes debriefing time (Wilcox, 2008). } \\
\text { - An exemplary level of observation for SI program accreditation } \\
\text { consists of ten or more observations for new SI leaders and at } \\
\text { least eight for returning SI Leaders (Curators of the University of } \\
\text { Missouri, 2018). } \\
\text { Benchmark: } 7.42 \text { hours of observation time per SI leader, } \\
\text { including debriefing time for the entire semester. * } \\
\text { Discussion in the Literature } \\
\text { Observations increase the quality of sessions and allow for } \\
\text { individualized feedback and training (McDaniel, 2008). } \\
\text { Arendale (2000) found that observing and providing feedback to } \\
\text { new and returning SI leaders was significantly related to } \\
\text { participation rate in programs. }\end{array}$ \\
\hline Planning & $\begin{array}{l}\text { Time Guidance: } \\
\text { - Benchmark: } 3.49 \text { planning support hours per SI leader for the } \\
\text { entire semester. * } \\
\text { Discussion in the literature: } \\
\text { - McDaniel (2008) suggests that leaders be expected to plan at least } \\
\text { the first three sessions with a supervisor } \\
\text { - For SI program accreditation, planning sheets should include } \\
\text { opening, middle and closing activities, evidence of collaborative } \\
\text { learning, timing, learning objectives, and additional resources } \\
\text { (Curators of the University of Missouri, 2018) }\end{array}$ \\
\hline
\end{tabular}




\begin{tabular}{|c|c|}
\hline & $\begin{array}{l}\text { - SI supervisors are encouraged to look towards lesson planning in } \\
\text { secondary education as a model for planning sessions (McDaniel, } \\
\text { 2008). }\end{array}$ \\
\hline $\begin{array}{l}\text { Administrative } \\
\text { Responsibilities }\end{array}$ & $\begin{array}{l}\text { Time Guidance: } \\
\text { - Benchmark: } 17.93 \text { hours per SI leader for the entire semester.* } \\
\text { This figure does include hiring and selection processes as well. } \\
\text { Discussion in the Literature: } \\
\text { - Administrative responsibilities include identifying courses, } \\
\text { connecting with faculty, and program evaluation (Martin \& } \\
\text { Arendale, 1992c). } \\
\text { Other administrative responsibilities include the SI program and } \\
\text { program logistics associated with scheduling sessions, tracking } \\
\text { session attendance, and troubleshooting problems (Hurley et al., } \\
\text { 2006). } \\
\text { Arendale (2000) found that the participation rate in an SI program } \\
\text { was correlated with regular program evaluation in the form of } \\
\text { analyzing the difference in grades between SI session attendees } \\
\text { and non-attendees. } \\
\text { This section provides a catch-all for the responsibilities of SI program } \\
\text { supervisors that are not included in the other categories. }\end{array}$ \\
\hline $\begin{array}{l}\text { General } \\
\text { Suggestions }\end{array}$ & $\begin{array}{l}\text { Time Guidance: } \\
\text { - Seven to eight hours per week per course for the first three weeks } \\
\text { due to planning assistance, observations, class presentations, etc. } \\
\text { (Wilcox, 2008). } \\
\text { Discussion in the Literature: } \\
\text { - The ideal ratio of three to four SI leaders per supervisor is } \\
\text { suggested, given the significant job responsibilities (Wilcox, } \\
\text { 2008). } \\
\text { Some researchers, when discussing SI program supervision, provide } \\
\text { overarching guidance to program leaders. Wilcox (2008) suggested that } \\
\text { one supervisor cannot manage more than three to four leaders without } \\
\text { assistance by examining the job responsibilities of supervisors. This } \\
\text { figure is purely based on a description of activities rather than research. }\end{array}$ \\
\hline
\end{tabular}

*These benchmarks are based on an average figure from a sample of approximately 60 SI programs in North America collected during the spring of 2020. 


\section{Funding Considerations}

SI programs are considered efficient due to their group nature (Zerger et al., 2006). The heftiest cost of an SI program comes in terms of the salary and release time for supervisors (Wilcox, 1992).

Often a question for SI program supervisors is how to fund the program or advocate for resources. This sub-section seeks to summarize some of the literature surrounding these questions as it pertains to funding and support of SI programs.

\section{Possible Funding Sources}

1. Reallocating Existing Support. An institution might be able to shift or repurpose existing money to fund an SI program. For example, a program could consider moving some resources from tutoring programs to support SI.

2. Department Support. An institution could ask departments to provide support for SI leader salaries or provide release time for faculty.

3. Grants. There might be grants, such as Title III grants, that could assist with SI program funding.

4. Alternative Compensation. Programs could consider alternative was of paying or compensating SI, such as academic credit or community projects.

5. Work-study funds. Work-study funds, which are provided by the federal government for students who have financial need, might be a way to fund leader salaries.

(Martin \& Arendale, 1992c)

\section{Advocating for Resources}

One common dilemma for SI program supervisors is advocating for resources to start, maintain, or grow their SI program. When advocating for support, here are two key ways to do that:

\section{Return on Investment}

One valuable way of advocating for resources is showing how there is a return on investment for Supplemental Instruction.

One way of conducting a return on investment is showing how the cost of retaining students through SI is more efficient than recruiting additional students to make up for students lost through attrition. Congos (2001) conducted such an analysis and found that it was more costeffective to retain students than recruit students to make up for ones that have been lost through attrition. Congos (2001) provides a model that can be easily replicated at other institutions.

- Congos, D. (2001). How supplemental instruction (SI) generates revenue for colleges and universities. Journal of College Student Retention, 3(3), 301-309.

Another method of showing a return on investment is showing the generated income from a change in the retention of students due to SI is higher than the cost of implementation. If you 
do not have such figures of how SI relates to retention and progression at your institution, consider using data from these sources to justify your calculations:

- Bowles, T. J., \& Jones, J. (2004). The effect of supplemental instruction on retention: A bivariate probit model. Journal of College Student Retention, 5(4), 431-437.

- Bowles, T. J., McCoy, A., \& Bates, S. (2008). The effect of supplemental instruction on timely graduation. College Student Journal, 42(3), 853-859.

- Buchanan, E. M., Valentine, K. D., \& Frizell, M. L. (2019). Supplemental instruction: Understanding academic assistance in underrepresented groups. The Journal of Experimental Education, 87(2), 288-298. doi:10.1080/00220973.2017.1421517

- Kochenour, E. O., Jolley, D. S., Kaup, J. G., Patrick, D. L., Roach, K. D., \& Wenzler, L. A. (1997). Supplemental Instruction: An effective component of student affairs programming. Journal of College Student Development, 38(6), 577-586.

- Ogden, P., Thompson, D., Russell, A., \& Simons, C. (2003). Supplemental instruction: Short- and long-term impact. Journal of Developmental Education, 26(3), $2-8$.

- Oja, M. (2012). Supplemental instruction improves grades but not persistence. College Student Journal, 46(2), 344-350.

- Skoglund, K., Wall, T. J., \& Kiene, D. (2018). Impact of supplemental instruction (SI) participation on college freshman retention. Learning Assistance Review, 23(1), 115-135.

\section{Show How SI Benefits Students}

As described elsewhere in this handbook, regular program evaluation is a critical part of SI program supervisors. Regular program evaluation of your SI program provides evidence of the performance of your SI program and may justify continued program funding.

In this handbook, regular program evaluation is discussed in terms of:

- The difference in the average final grade of the SI attending group versus the nonattending group.

- Comparing the DFW rates of the student who attend the SI session compared to the students who did not attend SI sessions.

In the SI supervisor handbook, the International Center thoroughly notes the process of conducting these analyses, including sample emails/letters to administrators and data collection tables.

Sharing these results every semester can help convey the impact of SI on your campus. Additionally, SI serves to increase graduation rates (SI, 2019b), so, you might consider conducting program evaluation on your campus as it relates to graduation rates. 
If you are unable to conduct regular program evaluation or if you need additional resources to supplement your data, significant research has been conducted on Supplemental Instruction (SI) to support various claims.

Dr. David Arendale regularly maintains an annotated bibliography of research conducted on SI. That bibliography can be accessed here: https://www.arendale.org/peer-learning-bib 


\section{SECTION FIVE - CONTRIBUTION TO SCHOLARSHIP}

The target journal is the Learning Assistance Review (TLAR). TLAR is published by the National College Learning Center Association, which serves professionals, teaching staff, student workers, and administrators associated with Learning Centers (NCLCA, 2015b). Because of the TLAR's focus on learning centers, which is where SI programs are typically housed, this journal is an ideal target for publication of this study. Furthermore, I have personally published work in TLAR on SI programs, and the editors and reviewers indicated that future work related to that study would be welcomed for submission.

The submission guidelines for TLAR indicate that authors should submit manuscripts that conform to APA style guidelines (NCLCA, 2015a). Thus, the major sections that will be included in the manuscript are the following: title page, abstract, introduction, literature review, research questions, methods, findings, discussion, limitations, and references. Additionally, the TLAR guidelines indicate a few other guidelines. Namely the following: a title page with less than 12 words, 100 maximum word abstract, and that all figures are black and white. Manuscript submission involves submitting an altered and one masked transcript for reviewers. The submission process is online and will follow the dissertation defense. 


\begin{abstract}
This study explored the relationship between the Supplemental Instruction (SI) administrative hours and program outcomes (attendance rate, the difference in the average final grades, and the difference in the rate of Ds, Fs, and withdraws). All regression models were insignificant, but training-related hours per SI leader was statistically significant in one model and showed a positive influence on the attendance percentage. This study also explored the relationship between funding and the beforementioned outcomes but netted no significant relationships. These findings were limited by small sample size, so future studies should explore separate administrative constructors and collect larger samples.
\end{abstract}

Keywords: Supplemental instruction, SI, learning assistance, program administration, SI administration, program outcomes, higher education 


\section{Effect of SI Administration Staffing and Support on SI Program Outcomes}

Supplemental Instruction (SI) is an academic assistance program primarily used in postsecondary institutions to support student academic success. Dr. Deanna Martin designed SI at the University of Missouri - Kansas City to decrease attrition rates for courses with high numbers of students who withdraw from specific courses (Hurley et al., 2006). SI provides regularly-scheduled, voluntary study sessions for students enrolled in traditionally challenging courses (Arendale, 1994; Hurley et al., 2006). The purpose of this study is to examine the influence and relationship of SI program administrative tenets and financial support for SI programs on the outcomes of an SI program.

SI programs generally have positive outcomes for high-risk courses. High-risk courses are selected because of a higher rate of students who earn Ds, Fs, or withdraw (DFW rate), a high course enrollment (Arendale, 1994), and a perception of difficulty by the students (Martin \& Arendale, 1992c). When reviewing the literature on SI, Hurley and Gilbert (2008b) describe how utilization of SI programs are positively related to academic outcomes such as reducing attrition, increasing graduation rates, increasing grades, and gains in knowledge. Because of its success in these areas, the SI model has been replicated by institutions all over the world (Arendale, 2010) and verified by the Department of Education as an exemplary educational program (Hurley \& Gilbert, 2008a; Martin \& Arendale, 1992c).

The key feature of SI programs is SI sessions, which are regularly scheduled for the students enrolled in the targeted class (Hurley \& Gilbert, 2008a). Sessions are led by the SI leader, who is usually a student who has taken the targeted course and performed well (Hurley \& Gilbert, 2008a). The SI leader sits in the course again to align their SI sessions with the course content, reinforce their content knowledge, and model good student behavior 
during the class by listening and actively taking notes (Hurley \& Gilbert, 2008a). Another key figure in SI programs is the SI faculty member who assists the program administrators in selecting an SI leader (Martin \& Arendale, 1992c), provides the leader support in planning sessions, and encourages student attendance to SI sessions (Hurley \& Gilbert, 2008a). SI programs are managed by a professional staff member who is responsible for hiring and selecting SI leaders, training leaders, coordinating SI placement in courses, assisting leaders through regular meetings, and ongoing program evaluation (Martin \& Arendale, 1992c).

The optimization and prioritization of supervision in SI programs is not known. Program administrators are given some guidance on the level of supervision needed, but this guidance is might be unrealistic or unsubstantiated with literature. For example, it is claimed that one full-time SI program supervisor cannot adequately supervise more than three or four leaders without some assistance (Wilcox, 2008). This figure is, in practice, often unrealistic due to tight budget climates and is only supported through a description of the supervisor's responsibilities. The International Center for Supplemental Instruction (International Center), based at the University of Missouri - Kanas City, provides additional guidance for an SI program seeking to be accredited, which is seen as the standard of best practice. The International Center suggests that SI programs need to have a clear focus on planning, supervision of SI leaders through observation, significant and ongoing training for leaders, and program evaluation (SI, 2019a). Sometimes, the level of these activities are recommended in the rubric for accreditation (Curators of the University of Missouri, 2018); however, these recommendations do not guide programs on the prioritization of these activities. Thus, there is a gap in our understanding of how SI administrator activities and a program's level of support relates to the outcomes of the program and how to prioritize those 
responsibilities. This study seeks to add to our understanding of the effective administration of SI programs.

\section{Literature Review}

SI was created in the 1970 s to support courses with higher rates of attrition (Hurley \& Gilbert, 2008a). SI focuses support on high-risk courses versus high-risk students to support students in a non-remedial manner, and because of it serves students in groups versus individually, it was cost-effective (Hurley \& Gilbert, 2008a). The creation of SI was timely in higher education, as families were expecting more from postsecondary institutions due to rising costs, and lower student outcomes such as graduation rates increased accountability from the government and accrediting bodies (Cohen \& Kisker, 2010). However, as SI approaches 50 years since its inception, examining its administrative structure for efficiency and effectiveness on promoting student academic outcomes is needed.

There are three main groups of individuals in SI programs: the SI leader, the SI supervisor, and faculty member of the targeted course (Hurley \& Gilbert, 2008a; Martin \& Arendale, 1992c). The SI leader is collaboratively selected for the position by the faculty member and SI supervisor (Martin \& Arendale, 1992c). Once hired, the SI leader attends class again and plans and holds scheduled review sessions outside of class (Hurley \& Gilbert, 2008a). SI faculty members must be willing partners in the SI program and work with their SI leader regularly to assist them with session planning (Hurley \& Gilbert, 2008a). An SI supervisor is generally trained by the International Center (Wilcox, 2008) and, if possible, full-time (Ainsworth et al., 1994). An SI supervisor leads regular programming activities such as training SI leaders, observing SI sessions, planning program logistics, conducting program evaluation, and fostering relationships with stakeholders across campus (Hurley \& 
Gilbert, 2008a). The literature on SI programs provides further guidance on these administrative activities.

Training is vital for all learning assistance professionals (Arendale, 2010), and training is a significant aspect of an SI supervisor's workload (Wilcox, 2008). In general, SI program supervisors are expected to lead approximately eight to sixteen hours of training for SI leaders each semester (Wilcox, 2008). These training sessions cover a wide array of topics such as learning theory, collaborative learning, and how to lead sessions (Lipsky, 2006; Martin \& Arendale, 1992c; Zaritsky \& Toce, 2006). Other writers discuss the importance of ongoing training to help leaders continue to use effective strategies in sessions (Hurley et al., 2006).

Next, SI program supervisors are expected to assist SI leaders through observations and supporting planning for SI sessions. Observations of SI sessions help SI leaders improve their sessions by providing a chance for feedback and individual training (McDaniel, 2008). Bolman and Deal (2013) indicate that effective organizations provide feedback to improve performance as well as on-the-job training. SI program supervisors are recommended to observe the first three SI sessions at the beginning of the term, and then weekly or biweekly for the remainder of the term (Wilcox, 2008). For SI program accreditation, SI program supervisors are encouraged, at the highest level of performance, to observe SI leaders at least ten times if they are new leaders and eight times if they are returning (Curators of the University of Missouri, 2018). Planning support for SI sessions is also a part of supervisor responsibilities. SI leaders are expected to plan each session and work with their supervisor and faculty members to plan SI sessions (Hurley et al., 2006). Wilcox (2008) even suggests that supervisors assist SI leaders in planning their sessions. 
A full range of administrative responsibilities makes up the SI supervisor's time. Supervisors have significant responsibilities in managing the hiring processes and qualification of potential SI leaders (McDaniel, 2008). Assessment and evaluation of the SI program SI is also critical (Hurley et al., 2006) and adds the creditability of the program (Wilcox, 2008). Other administrative responsibilities include determining courses, maintaining faculty relationships, and marketing SI to students (Martin \& Arendale, 1992c; Wilcox, 2008). Lastly, supervisors are responsible for the logistics of the program, such as scheduling sessions and supervision of the daily operations (Hurley et al., 2006).

Beyond the administrative responsibilities, there are the costs associated with running an SI program. Generally, the costliest element of an SI program is the salaries of the SI leaders (Martin \& Arendale, 1992c; Wilcox, 2008). Other costs include supplies (Widmar, 1994) and release time or salaries for administrative personnel (Wilcox, 2008). Some programs use experienced SI leaders to help with the supervision of SI leaders to reduce salary costs for administration (Martin \& Arendale, 1992c). Largely, SI is seen as a low cost and efficient program due to its group-based approach (Wilcox, 1992; Zerger et al., 2006).

SI programs have several measurable outcomes. The first measure of success is the attendance percentage. SI sessions are usually voluntary for students to attend (SI, 2019b); thus, the percentage of students who attend at least one SI session is one indicator of program success. Also, Arendale (2000) studied the influence of SI program constructs on program outcomes, including participation rate, and found that SI supervisor involvement was significantly related to participation rate. Thus, exploring administrative hours and financial support and their relationship with participation is would add to this finding. 
Beyond attendance percentage, there are a couple of standard measures consistent in the program evaluation of SI programs. Hurley et al. (2006) describe examining the difference between the rate of students who earn a D, F, or withdraw from a course between the students who attend at least one SI session and the students who do not attend any SI sessions. Another measure is comparing the average final grade of the students who attend SI sessions compared to the students who do not attend any SI sessions (Hurley \& Gilbert, 2008a). Thus, these would be consistent outcomes to measure SI program success.

Guidance and research on the administration of SI programs and the financial support needed for programs are limited. Wilcox (2008) suggests that one SI program supervisor can only supervise at most four SI leaders before needing assistance, reasoning that between observation, planning, leading training, and managing the program, there is little remaining time. However, they do not cite any empirical research substantiating this ratio. Arendale (2000) explored how aspects of SI programs such as observations, class attendance of the SI leaders, session activities, and training have on program outcomes (the participation rate, the difference in DFW rates, the difference in average grades, and satisfaction of SI program by administrators). In this dissertation, Arendale (2000) found that SI supervisor involvement and SI leader training was significantly related to program success, but did not indicate the optimal level of administration. Similarly, there has been no discussion on how financial support affects SI program outcomes in the literature. Thus, this study seeks to add to our understanding of effective administration and support of SI programs.

\section{Research Questions}

This study uses SI program-level data for a specific semester or term from various institutions. From each program, the percentage of students served, final average grade 
differential between the students who attend SI and those who do not, and the difference in the DFW rates of SI session attendees and non-attendees were collected when available and serve as the dependent variables in this study. The independent variables in this study relate to the supervision and support of the SI program during that specific semester. The independent variables include the average observation hours per SI leader, average hours spent assisting with planning per SI leader, the average training-related hours per SI leader, average supervisory hours per SI leader, and average funding per SI leader. For a complete definition of terminology used, please refer to appendix C. Figure 5.1 visually explores the possible relationships between these variables.

Figure 5.1

\section{SI Administrative Tenets and Program Outcomes}

\section{Supplemental Instruction (SI) Program Adminstration}

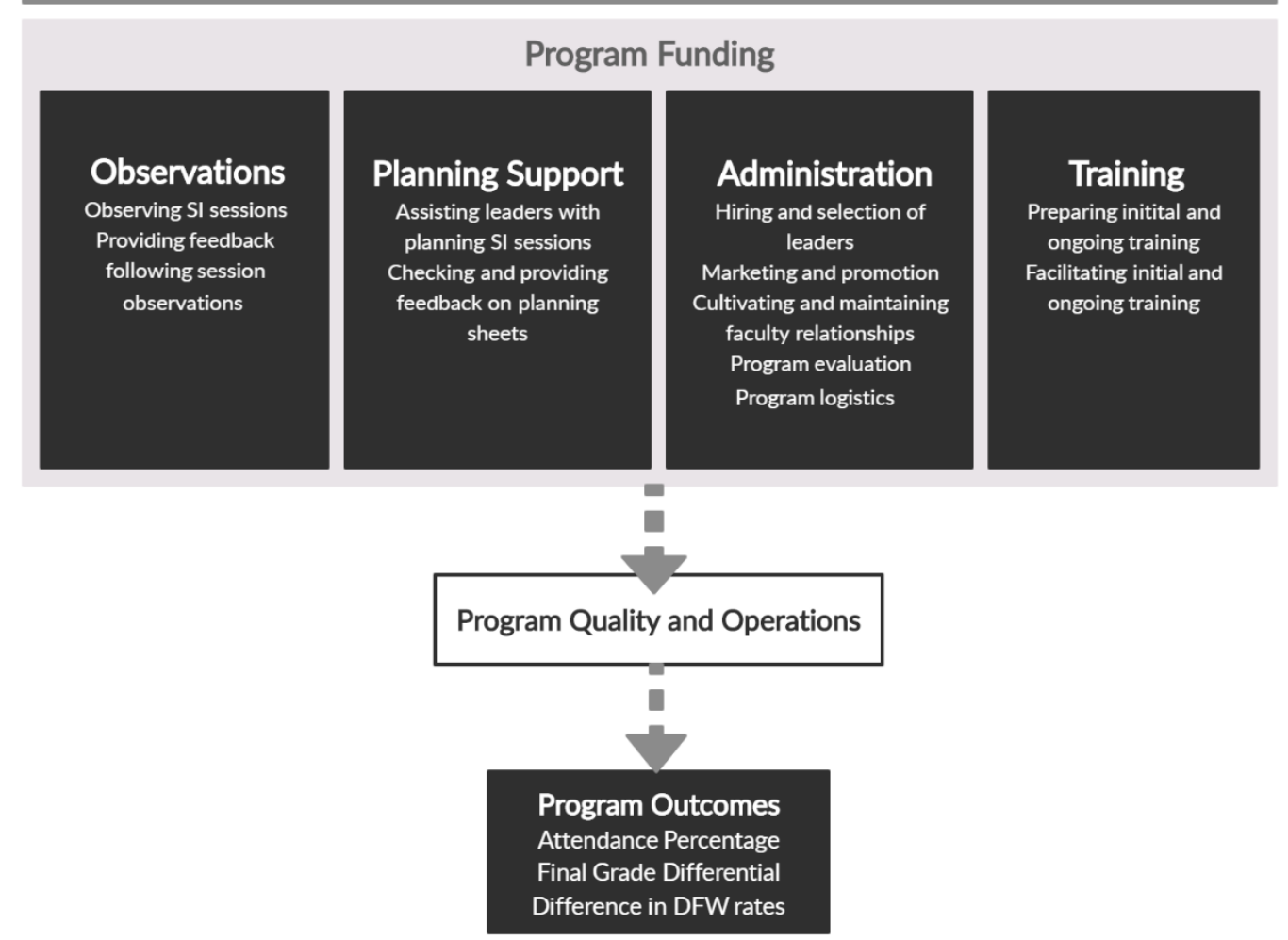


The following research questions guided the study:

1. What is the relationship between the observation hours per SI Leader, planning hours per SI leader, training hours per SI leader, administrative hours per SI leader, and funding per SI leader for an SI program and the percentage of students enrolled in an SI course that attend at least one SI session?

2. What is the relationship between the observation hours per SI Leader, planning hours per SI leader, training hours per SI leader, administrative hours per SI leader, and funding per SI leader for an SI program and the final grade differential between the students who attended SI sessions and the students who did not?

3. What is the relationship between the observation hours per SI Leader, planning hours per SI leader, training hours per SI leader, administrative hours per SI leader, and funding per SI leader for an SI program and the difference in DFW rates of the students who attend SI sessions and those who did not?

\section{Methodology}

\section{Setting}

This study took place during the first few months of 2020. The target audience was higher education institutions with an SI program in North America. SI programs in North America exist at all types of postsecondary institutions, so data could be from a two- or fouryear school as well as public or private entities. At the time of writing, there are over 1,000 institutions with an SI program in North America.

\section{Survey Design and Implementation}

Significant care was used when designing and implementing the survey. The initial survey was designed with good practices of survey design, such as avoiding biased phrasing, 
focusing questions on a single thought, and placing easy-to-answer questions at the end (Fink, 2017). Additionally, Fink (2017) and Newcomer and Triplett (2015) recommend pilot testing a survey to gather feedback on the design and clarity of questions. Thus, the initial draft of the survey was sent to two SI program supervisors for initial review and feedback. Their suggestions were incorporated, and they were asked to review the survey again to provide additional feedback.

A final pilot testing round included experts at the International Center, four former or current SI program supervisors trained in the SI model, and two higher-level administrators whose units include SI programs. Using experts in the field to examine the survey can increase the validity of the results (Creswell, 2014), so these processes added validity to the instrument. The feedback from these pilot testing processes was incorporated before distribution. See appendix A for the final version of the survey.

The International Center has a website with institutions that have a trained SI supervisor and a list of programs that are accredited. These websites were mined to create a list of institutions that could potentially have SI programs. In addition, a list of higher education institutions in several states was generated to explore for potential SI programs. The websites of each institution were examined for evidence of an SI program or SI-like program for contact information. If there was an SI program, the email and phone number were added to a list, if found, to use for contact.

Initial emails and follow-up emails were sent to the list of program contacts and inviting them to fill out the survey. In total, most programs had about a month to respond to the survey. The survey and reminders were also posted on two listservs commonly used by SI 
professionals, which provided another way to reach potential SI programs. Sample and template messages that were sent to programs are in appendix B.

\section{Participants}

Approximately 575 individuals were emailed from over 550 institutions and 36 of those that completed the survey (roughly a $6.3 \%$ response rate). From the listservs or other means, approximately 12 additional SI programs responded to the survey. If institutions replied to the survey invitation email to indicate that they could not fill out the survey, the typical reasons included being new to SI program administration, that the institution does not really have an SI program, they did not have time to complete the survey, or that they did not have access to data needed to complete the survey. Table 5.1 shows the frequency of institutions and the demographic characteristics of the institutions that responded to the survey. One institution was Canadian, while the rest were located in the US.

\section{Table 5.1}

Institutional Characteristics of the Survey Respondents

\begin{tabular}{ccc}
\hline & & Frequency \\
\hline \multirow{2}{*}{ Was the institution public or private? } & Private & 9 \\
& Public & 53 \\
& Unknown & 1 \\
\hline \multirow{2}{*}{ Was the institution a 2-Year or 4-Year } & 2-Year & 14 \\
Institution? & 4-Year & 48 \\
& Unknown & 1 \\
\hline \multirow{2}{*}{ Was the SI program accredited by the } & No & 38 \\
International Center? & Unsure & 4 \\
& Yes & 21 \\
\hline
\end{tabular}

A majority of the SI programs that responded to the survey were from public, fouryear institutions. However, these frequencies appear to be relatively representative or at least 
not biased towards any particular institution type. Not all of the responses were complete, and others provided information that would suggest that their data would be skewed or unusable. Thus, the program responses were reviewed, and responses were removed if the program used different attendance criteria to classify SI attendees (e.g., SI attendees needed to attend three times before being counted in that group), or if there was evidence of extra credit or required attendance to SI sessions that were included in the program's data. These institutions would have influenced the analysis as these criteria would have affected the program outcomes directly. Additionally, responses were checked for reasonableness and adjusted if needed. For example, a program with 70 SI leaders suggested their funding level was 20 dollars, which did not make sense, so the funding level was removed from that program's response and left blank. After removing these responses and adjusting for specific values, 47 institutions remained in the study.

\section{Data Analysis}

To control for SI program size, all the independent variables (observation hours, planning support hours, training-related hours, administration hours, and program funding) were divided by the number of SI leaders actively working that term for that program. Table 5.2 shows the descriptive statistics of the variables and outcomes in this study. Linear regression was the primary method of analysis. Linear regression is an analysis method to measure the linear relationship between at least two predictor variables (Miles \& Shevlin, 2001). Field (2018) outlines several assumptions of regression models, including additivity and linearity, independence of errors, homoscedasticity, normal distribution of errors. Of these assumptions, one possible concern is program funding and the assumption of independence. The values for observation hours, training-related hours, planning support 
hours, and administrative hours likely depend on program funding because funding dictates how much administrative time is spent on these areas. Several programs also indicated that calculating funding was a challenge when responding to the survey. Given this and the violation of the independence assumption, program funding was examined separately with each dependent variable. For the remaining four independent variables, other possible concerns for multiple linear regression include multicollinearity and outliers (Field, 2018). All these assumptions were met with the exception of some possible outliers which are addressed later. Moreover, the sample size played a significant role in this study.

Table 5.2

Descriptive Statistics of the Variables and SI Leaders

\begin{tabular}{|c|c|c|c|c|c|}
\hline & $\mathrm{N}$ & Mean & SD & Minimum & Maximum \\
\hline $\begin{array}{l}\text { Average Final Grade } \\
\text { Differential* }\end{array}$ & 46 & 0.62 & 0.40 & 0.03 & 2.00 \\
\hline $\begin{array}{c}\text { Difference in the DFW } \\
\text { Rates }(\%)\end{array}$ & 45 & 16.38 & 10.28 & 0.12 & 55.00 \\
\hline $\begin{array}{c}\text { Attendance Percentage } \\
(\%)\end{array}$ & 46 & 37.91 & 15.03 & 7.84 & 71.10 \\
\hline $\begin{array}{l}\text { Observation Hours Per SI } \\
\text { Leader }\end{array}$ & 48 & 7.42 & 7.05 & 0.36 & 30.30 \\
\hline $\begin{array}{c}\text { Training Hours Per SI } \\
\text { Leader }\end{array}$ & 48 & 3.13 & 3.86 & 0.29 & 20.45 \\
\hline $\begin{array}{c}\text { Planning Hours Per SI } \\
\text { Leader }\end{array}$ & 48 & 3.49 & 4.98 & 0.00 & 22.50 \\
\hline $\begin{array}{l}\text { Administration Hours Per } \\
\text { SI Leader }\end{array}$ & 46 & 17.93 & 20.62 & 0.64 & 104.17 \\
\hline Funding Per SI Leader & 43 & $\$ 3,091.26$ & $\$ 1,648.05$ & $\$ 93.75$ & $\$ 8,333.33$ \\
\hline Number of SI Leaders & 48 & 25.67 & 19.945 & 3 & 83 \\
\hline
\end{tabular}

*Values are presented in GPA format using a 4 point scale $(4=\mathrm{A}, \mathrm{B}=3$, etc.)

The sample size needed for a study depends on several factors. Miles and Shevlin (2001) suggest using a power analysis for determining the appropriate sample sizes for any study or experiment. This process uses the significance level, desired effect size in the population, and desired power level (Miles \& Shevlin, 2001). In this study, the significance 
level is set at 0.05 , and the study seeks to uncover large effect sizes. Lastly, the power level was set to 0.8, which Cohen (1988), as cited by Miles and Shevlin (2001) suggests is conventional. Additionally, the needed sample size for the study is affected by the number of predictors in the regression model (Miles \& Shevlin, 2001), which in this study is four. With four predictors variables, a significance level of 0.05 , a power level of 0.8 , and the ability to detect large effect sizes, this analysis needs a sample size of at least 40 . Thus, this study has a sufficient sample to detect large effects for the four predictor variables. Next, the assumptions of multiple liner regression are explored.

As mentioned earlier, there were potential concerns related to outliers. Outliers were uncovered using residual plots, as recommended by Miles and Shevlin (2001). For the model examining attendance percentage as the dependent variable, two outliers were discovered through inspection of the residual plots. For the model examining DFW rates, there was one outlier, while in the model examining differences in final grades, three outliers were identified. Miles and Shevlin (2001) suggests determining why an outlier occurs. With these responses, there was insufficient evidence to suggest that there was a measurement error. Thus, Miles and Shevlin (2001) present a dilemma: including the outlier might influence the model, but excluding it might be inappropriate. Therefore, Miles and Shevlin (2001) recommend running the analysis twice and reporting the results with the outliers included and not included. This strategy was used in this study. It should be noted that the new datasets with the outliers removed were also checked for assumptions related to multiple linear regression, and no additional concerns were noted.

As funding was separated from the other predictor variables, a separate analysis was conducted using that variable with the dependent variables. Correlations measure the linear 
relationship between two variables (Miles \& Shevlin, 2001). Thus, the correlation would be an effective way of measuring the potential relationship between program funding and program outcomes. According to the Field (2018), there are two assumptions to be considered when calculating a correlation: linearity and normality. Both assumptions were checked before proceeding, and no concerns arose. Thus, the correlation was used to analyze the funding of the SI program as it relates to the outcomes of the SI program.

\section{Findings}

The findings in this section are organized by research questions. However, since the analysis related to funding was separated out, it is addressed in a separate subsection.

\section{Attendance Percentage}

Multiple linear regression was used to determine if there was a relationship between the attendance percentage of an SI program and the hours spent observing, assisting SI leader with planning sessions, conducting and preparing training, and completing other administrative tasks per SI leader in the program. As addressed in the previous section, there were two outliers in the dataset, and the following results included those outliers in this analysis. A non-significant regression equation was found, $\mathrm{F}(4,39)=2.573, p=.053$, with an $R^{2}=.209$, which suggests the model accounted for approximately $20.9 \%$ of the variance in the sample. None of the model variables are statistically significant at $\alpha=0.05$ except for training hours per SI leader, $p=0.27$. Table 5.3 gives the regression coefficients and standardized beta values.

For the next analysis, the two outliers were removed from the dataset, and the regression equation calculated again with attendance percentage as the dependent variable. In this new analysis, a significant regression equation was not found, $\mathrm{F}(4,37)=1.296, p=.289$, 
with an $R^{2}=.123$, which suggests the model accounted for approximately $12.3 \%$ of the variance in the sample. Additionally, none of the model variables were statistically significant at $\alpha=0.05$. Table 5.4 gives the regression coefficients and the standardized beta values for this new model.

Table 5.3

Coefficients for Regression Model for Attendance Percentage with Outliers Included

\begin{tabular}{ccccccc}
\hline & \multicolumn{2}{c}{$\begin{array}{c}\text { Unstandardized } \\
\text { Coefficients }\end{array}$} & $\begin{array}{c}\text { Standardized } \\
\text { Coefficients }\end{array}$ & & \\
\cline { 2 - 4 } & B & Std. Error & $\beta$ & & Sig. \\
\hline $\begin{array}{c}\text { Constant } \\
\text { Observation Hours Per SI } \\
\text { Leader }\end{array}$ & 39.850 & 3.904 & & 10.208 & $<.001^{*}$ \\
$\begin{array}{c}\text { Training Hours Per SI } \\
\text { Leader }\end{array}$ & -0.040 & 0.320 & -0.019 & -0.126 & 0.900 \\
$\begin{array}{c}\text { Planning Hours Per SI } \\
\text { Leader }\end{array}$ & -0.611 & 0.449 & -0.207 & -1.359 & 0.182 \\
$\begin{array}{c}\text { Administration Hours Per } \\
\text { SI Leader }\end{array}$ & -0.160 & 0.105 & -0.220 & -1.531 & 0.134 \\
\hline
\end{tabular}

*Significant at $\alpha=0.05$

Table 5.4

Coefficients for Regression Model for Attendance Percentage with Outliers Excluded

\begin{tabular}{|c|c|c|c|c|c|}
\hline & \multicolumn{2}{|c|}{$\begin{array}{c}\text { Unstandardized } \\
\text { Coefficients }\end{array}$} & \multirow{2}{*}{$\begin{array}{c}\text { Standardized } \\
\text { Coefficients }\end{array}$} & \multirow[b]{2}{*}{$t$} & \multirow[b]{2}{*}{ Sig. } \\
\hline & $\mathrm{B}$ & Std. Error & & & \\
\hline Constant & 40.947 & 4.429 & & 9.245 & $<.001 *$ \\
\hline $\begin{array}{c}\text { Observation Hours Per SI } \\
\text { Leader }\end{array}$ & 0.022 & 0.348 & 0.011 & 0.062 & 0.951 \\
\hline $\begin{array}{l}\text { Training Hours Per SI } \\
\text { Leader }\end{array}$ & 0.653 & 1.231 & 0.088 & 0.531 & 0.599 \\
\hline $\begin{array}{c}\text { Planning Hours Per SI } \\
\text { Leader }\end{array}$ & -0.656 & 0.464 & -0.234 & -1.415 & 0.165 \\
\hline $\begin{array}{l}\text { Administration Hours Per } \\
\text { SI Leader }\end{array}$ & -0.161 & 0.107 & -0.233 & -1.502 & 0.142 \\
\hline
\end{tabular}

*Significant at $\alpha=0.05$ 


\section{Average Final Grade Differential}

A similar process was conducted using the average final grade differential as the dependent variable instead of the attendance percentage. The same impendent variables were included. Also, similar to the models created with the attendance percentage, there were three outliers discovered when checking the assumptions. This model was conducted with those outliers included. The regression equation was not statistically significant, $\mathrm{F}(4,39)=1.480, p$ $=.227$ with an $R^{2}=.132$. This model accounted for roughly $13.2 \%$ of the variance. None of the variables included in the model were statistically significant at $\alpha=0.05$ as well. Table 5.5 gives the regression coefficients and the standardized beta values for this model.

Table 5.5

Coefficients for Regression Model for the Average Final Grade Differential with Outliers Included.

\begin{tabular}{|c|c|c|c|c|c|}
\hline & \multicolumn{2}{|c|}{$\begin{array}{l}\text { Unstandardized } \\
\text { Coefficients }\end{array}$} & \multirow{2}{*}{$\begin{array}{c}\begin{array}{c}\text { Standardized } \\
\text { Coefficients }\end{array} \\
\beta\end{array}$} & \multirow[b]{2}{*}{$t$} & \multirow[b]{2}{*}{ Sig. } \\
\hline & $\mathrm{B}$ & Std. Error & & & \\
\hline Constant & 0.605 & 0.108 & & 5.585 & $<.001 *$ \\
\hline $\begin{array}{c}\text { Observation Hours Per SI } \\
\text { Leader }\end{array}$ & -0.015 & 0.009 & -0.272 & -1.690 & 0.099 \\
\hline $\begin{array}{c}\text { Training Hours Per SI } \\
\text { Leader }\end{array}$ & -0.005 & 0.015 & -0.053 & -0.351 & 0.728 \\
\hline $\begin{array}{c}\text { Planning Hours Per SI } \\
\text { Leader }\end{array}$ & 0.022 & 0.012 & 0.287 & 1.803 & 0.079 \\
\hline $\begin{array}{c}\text { Administration Hours Per } \\
\text { SI Leader }\end{array}$ & 0.003 & 0.003 & 0.156 & 1.038 & 0.306 \\
\hline
\end{tabular}

*Significant at $\alpha=0.05$

The three outliers were removed from the dataset, and the regression model was created again. Again, the regression model was not significant, $\mathrm{F}(4,36)=.914, p=.466$, with an $R^{2}=.092$ which is about $9.2 \%$ of the variance. Additionally, none of the variables were significant in the model at $\alpha=0.05$. Table 5.6 gives the regression coefficients and the standardized beta values for this new model. 
Table 5.6

Coefficients for Regression Model for the Average Final Grade Differential with Outliers Excluded

\begin{tabular}{cccccc}
\hline & \multicolumn{2}{c}{$\begin{array}{c}\text { Unstandardized } \\
\text { Coefficients }\end{array}$} & $\begin{array}{c}\text { Standardized } \\
\text { Coefficients }\end{array}$ & $t$ & Sig. \\
\cline { 2 - 6 } & B & Std. Error & $\beta$ & & \\
\hline $\begin{array}{c}\text { Constant } \\
\text { Observation Hours Per SI } \\
\text { Leader }\end{array}$ & 0.605 & 0.078 & & 7.771 & $<.001^{*}$ \\
$\begin{array}{c}\text { Training Hours Per SI } \\
\text { Leader }\end{array}$ & -0.012 & 0.008 & -0.302 & -1.546 & 0.131 \\
$\begin{array}{c}\text { Planning Hours Per SI } \\
\quad \text { Leader }\end{array}$ & 0.005 & 0.012 & 0.082 & 0.425 & 0.673 \\
$\begin{array}{c}\text { Administration Hours Per } \\
\text { SI Leader }\end{array}$ & 0.002 & 0.002 & 0.172 & 1.061 & 0.296 \\
\hline
\end{tabular}

*Significant at $\alpha=0.05$

\section{Difference in the DFW Rates}

Lastly, a regression analysis was run using the difference in the DFW rates between the students who attended at least one session and the students who did not attend any SI sessions as the dependent variable with the same independent variables used for the attendance percentage and average final grade differential models. In this model, only one outlier existed, and it was included for this first model. A non-significant regression equation was the result, $\mathrm{F}(4,38)=.902, p=.472$, with an $R^{2}=.087$. This model accounted for about $8.7 \%$ of the variance in the data. Additionally, none of the independent variables in the model were significant at $\alpha=0.05$. Table 5.7 gives the regression coefficients and the standardized beta values for this new model.

For the last regression analysis, the sole outlier was removed from the dataset, and the regression model created using the difference in the DFW rates as the dependent variable with the same independent variables. This model was not significant, $\mathrm{F}(4,37)=.721, p=$ .583 , with an $R^{2}=.072$ which is approximately $7.2 \%$ of the variance in the sample. Again, 
none of the independent variables were statistically significant at $\alpha=0.05$. Table 5.8 gives the regression coefficients and the standardized beta values for this model.

Table 5.7

Coefficients for Regression Model for the Difference in the DFW Rates with Outliers Included

\begin{tabular}{ccccccc}
\hline & \multicolumn{2}{c}{$\begin{array}{c}\text { Unstandardized } \\
\text { Coefficients }\end{array}$} & $\begin{array}{c}\text { Standardized } \\
\text { Coefficients }\end{array}$ & & \\
\cline { 2 - 4 } & $\mathrm{B}$ & Std. Error & $\beta$ & & \multirow{2}{*}{ Sig. } \\
\hline $\begin{array}{c}\text { Constant } \\
\text { Observation Hours Per }\end{array}$ & 19.024 & 2.658 & & 7.158 & $<.001^{*}$ \\
$\begin{array}{c}\text { SI Leader } \\
\text { Training Hours Per SI }\end{array}$ & -0.028 & 0.214 & -0.022 & -0.133 & 0.895 \\
$\begin{array}{c}\text { Leader } \\
\text { Planning Hours Per SI }\end{array}$ & -0.031 & 0.370 & -0.013 & -0.084 & 0.934 \\
$\begin{array}{c}\text { Leader } \\
\text { Administration Hours } \\
\text { Per SI Leader }\end{array}$ & -0.357 & 0.301 & -0.196 & -1.186 & 0.243 \\
\cline { 1 - 3 } & -0.091 & 0.070 & -0.202 & -1.293 & 0.204 \\
\hline
\end{tabular}

*Significant at $\alpha=0.05$

Table 5.8

Coefficients for Regression Model for the Difference in the DFW Rates with Outliers Excluded

\begin{tabular}{|c|c|c|c|c|c|}
\hline & \multicolumn{2}{|c|}{$\begin{array}{l}\text { Unstandardized } \\
\text { Coefficients }\end{array}$} & \multirow{2}{*}{$\begin{array}{c}\text { Standardized } \\
\text { Coefficients }\end{array}$} & \multirow[b]{2}{*}{$t$} & \multirow[b]{2}{*}{ Sig. } \\
\hline & B & Std. Error & & & \\
\hline Constant & 16.211 & 2.126 & & 7.626 & $0 *$ \\
\hline $\begin{array}{l}\text { Observation Hours Per } \\
\text { SI Leader }\end{array}$ & 0.059 & 0.166 & 0.061 & 0.358 & 0.722 \\
\hline $\begin{array}{l}\text { Training Hours Per SI } \\
\text { Leader }\end{array}$ & 0.086 & 0.287 & 0.048 & 0.299 & 0.766 \\
\hline $\begin{array}{l}\text { Planning Hours Per SI } \\
\text { Leader }\end{array}$ & -0.283 & 0.233 & -0.204 & -1.211 & 0.234 \\
\hline $\begin{array}{l}\text { Administration Hours } \\
\text { Per SI Leader }\end{array}$ & -0.061 & 0.055 & -0.178 & -1.116 & 0.272 \\
\hline
\end{tabular}

*Significant at $\alpha=0.05$ 


\section{SI Program Funding}

SI program funding and its potential relationship with the attendance percentage of the SI program, the average final grade differential, and the difference in the DFW rates were examined via Pearson correlation. None of these relationships were statistically significant at $\alpha=0.05$. Both of the correlation coefficients for the relationship with per SI leader funding and the average final grade differential and a difference in DFW rates were positive while the correlation coefficient with attendance percentage was negative. Table 5.9 shows the correlations of these values with the corresponding $p$-values.

Table 5.9

Pearson Correlations with Per SI leader Funding by Program Outcome

\begin{tabular}{cccc}
\hline & $r$ & Sig. & $N$ \\
\hline Average Final Grade Differential & 0.257 & 0.105 & 41 \\
Difference in DFW Rates & 0.032 & 0.844 & 40 \\
Attendance Percentage & -0.220 & 0.167 & 41 \\
\hline
\end{tabular}

\section{Discussion}

None of these models were statistically significant, suggesting that there are other factors that explain the variance in SI program outcomes. In his dissertation, Arendale (2000) learned that there were significant relationships between participation rate in SI sessions and the program constructs, which included SI supervisor involvement, SI leader involvement, SI leader training, and institutional involvement. When drilling that down further, SI supervisor involvement was significantly related to higher participation rates. Because this study focused on SI supervisor activities and did not involve the other constructs, it is possible these other areas explain some of the variances in the model. Moreover, Arendale (2000) recommended that further research include national studies of SI programs with constructs 
such as institutional or student characteristics that were not incorporated in this study.

Finally, this research only had a sufficient sample size to detect large effects according to a power analysis based on Miles and Shevlin's (2001) work. Therefore, it is possible that medium or small effects of the constructs exist, but the sample size was insufficient to detect those effects. Nonetheless, there are some results to explore further from this study and possible areas of future research.

\section{Attendance Percentage}

Neither regression model using the attendance rate as the dependent variable was statistically significant; however, the model including the outlier showed that training hours per SI leader was significant. This result suggests that for every additional hour of training/training planning time conducted per SI leader will net a $0.65 \%$ boost in attendance rate for the SI sessions across the program. This result should be treated with caution, however, as the model itself was not significant. If significant, the model accounted for approximately $21 \%$ of the variance in the data. It should also be noted that the model including the outliers was approaching statistical significance with $p=.053$, which might suggest this model's variables have the potential to be influential with more data to detect smaller effects. With the outliers removed, both of those effects were erased, suggesting that the outliers were influential on the model.

Given the prevalence of training in the literature on leading SI programs, it is perhaps, unsurprising that training time per SI leader showed up as a significant result in one of the models. In the supervisor manual handed out by the International Center, attendance strategies are addressed with supervisors (Curators of the University of Missouri, 2019). McDaniel (2008) discusses scheduling ongoing training for SI leaders to provide support for 
each other. Such support might be influencing the SI leader's performance and thereby increasing attendance percentages. This result might also be a result of better attendance tracking. McDaniel (2008) recommends discussing data collection, such as attendance at sessions as part of pre-term training. That emphasis in training might result in better tracking of attendance; consequently, attendance percentages would go up. Lastly, Bolman and Deal (2013) discuss training in the context of effective organizations. Thus, training might result in better organizational outcomes, in the case of this study, attendance rates. Perhaps surprising that was that administrative hours per SI leader was not significant in either model related to attendance. Arendale (2000) found that participation rates were significantly related to the specific SI program supervisor constructs questions on conducting program evaluation. Administrative hours in this study captured the time spent conducting program evaluation, so the insignificant results of this study somewhat run contrary to Arendale's (2000) findings.

\section{Difference in Average Final Grade}

Neither model — the one with or without outliers — was statistically significant. This finding suggests that there are other factors that influence the average final grade differential. It is worth noting that observation hours per SI and planning hours per SI were approaching significance in the model that included outliers with $p=.099$ and $p=.079$, respectively. As these results also approached statistical significance, so it might suggest that these variables have a medium or small effect on the average final grade differential. However, observation hours per SI leader showed a negative effect on the difference in average grades, while planning hours per SI leader showed a positive effect. 
Stout and McDaniel (2006) describe observations and debriefing as part of a performance evaluation process for SI leaders. Even though observations are described as developmental (Stout \& McDaniel, 2006), it is possible that SI supervisors conduct more observations when performance is lagging. This type of coaching or supporting relationship is recommended by the coaching and directive leadership styles when follower competence is low (Blanchard et al., 1985). Additionally, the rubric for accreditation of SI programs recommends a greater number of observations for newer SI leaders (Curators of the University of Missouri, 2018), who are likely of less competent than their more experienced peers. Thus, the number of observations would be weighted for less competent leaders and could skew results in a negative direction. Nonetheless, this finding merits additional study and future studies should explore the relationships between observation hours of sessions and measures of program performance.

In contrast, planning support for SI sessions might result in higher quality sessions. McDaniel (2008) suggests that supervisors assist SI leaders in planning that uses effective pedagogy and encourages the use of lesson plan formats. Thus, these planning processes may influence the quality of SI sessions and the performance of the students who attend sessions and thereby increase the difference in the average grades between the students who attend SI sessions and those who do not. Similar to observations, further research should explore planning support systems. In the second model, outliers were removed, and the near significant effect was removed for these variables; subsequently, there is insufficient evidence to suggest that these two constructs truly had an effect on the difference in average grades. Nonetheless, future research should explore these constructs to see if there is an effect. 


\section{Difference in the DFW Rates}

Neither regression model was significant when exploring the relationships between administrator activities and the difference in the DFW rates of the students who attend SI sessions compared to the students who do not attend SI sessions. Hurley and Gilbert (2008a) describe SI program evaluation processes, which include examining the difference in the average final grade between the SI session attendees and non-attendees as a measure of student learning while examining the differences in DFW rates as a measure of attrition for that course. The results in these models suggest that SI administrator activities do not have a large effect on the attrition in these high-risk courses. As suggested earlier, the sample size was sufficient to detect large effects, but not small or medium effects; thus, supervisory activities may have a medium effect or small effect on attrition for these courses.

\section{Program Funding}

When examining the correlations of the program outcomes (average final grade differential, the difference in the DFW rates, and attendance percentage) with SI program funding per SI leader, there were no significant correlations. The relationship between funding and both the average final grade differential and difference DFW rates were positive, $r=0.257$, and $r=0.032$, respectively. According to Field (2018), we can calculate the effect size of each of these by squaring them; thus, $R^{2}=.066$ for the relationship between the average final grade differential and per SI leader funding, and $R^{2}=.001$ for the relationship between the difference in the DFW rates and per SI leader funding. Cohen (1988), as cited in Miles and Shevlin (2001), suggests that $R^{2}=0.02$ is a small effect size while $R^{2}=0.13$ is a medium effect size. Thus, the effect size for the relationship between per SI leader funding and average grade differential is small, while the relationship between per SI leader funding 
and the difference in the DFW rates is extremely small if it exists at all. Similarly, the relationship between per SI leader funding and attendance percentage was negative, $r=$ $.220, \mathrm{R}^{2}=.048$ which is a small effect size. These effects should be treated cautiously, as there were no statistically significant correlations in the analysis.

Understanding these relationships is challenging. Bolman and Deal (2013) describe organizations as groups advocating for limited resources. One would suspect that being able to advocate for program resources successfully would improve the program outcomes. This result is modestly true for the relationship between per SI leader funding and the difference in average grade, but not for attendance percentage. Hurley and Gilbert (2008a) describe that SI faculty involvement is critical to the success of the program. Faculty have the ability to easily refer students to an SI program (Martin \& Arendale, 1992c); thus, attendance percentage as an outcome might be more related to faculty involvement than program funding. Bolman and Deal (2013) suggest that an organization's structure is influenced by its size, so it is possible that attendance percentages are affected more by institutional size rather than funding. Possibly, large institutions have more resources while smaller institutions have less, but larger institutions would have larger class sizes, while smaller institutions with smaller class sizes would be able to refer students to SI sessions easier. Regardless, more research should be conducted into funding and program outcomes. Before conducting this study, the International Center was consulted and suggested the inclusion of funding in the study (J. Collins \& M. Cross, personal communication, August 8, 2019). This vein of research should be continued as it has significant implications for the field. 


\section{Limitations}

There are several limitations to this study. The first set relates to the quality of the data collected. First, the data collected was from a convenience sample. "A convenience sample is one that you get because people who are willing to complete the survey are also available when you need them" (Fink, 2017, p. 99). This type of sampling has the potential to introduce bias in the results because the sample may not be representative of the population. The demographic characteristics of the institutions appeared to be relatively representative (see table 5.1), but it is possible there was bias in the sample of institutions collected. Second, although the survey was vetted by experts as suggested by Creswell (2014) and piloted tested as suggested by Fink (2017), there was room for misinterpretation of the questions, so it is possible that the respondents misinterpreted the questions when responding. While there was insufficient evidence to remove the outliers mentioned earlier, they may be outliers because the respondents misinterpreted the question and responded accordingly. Third, several programs responded via email or within the context of the survey to indicate that they tracked their data differently, such as classifying SI attendance as those who attend three or more sessions versus one or more. Those results were excluded when it was known. Still, some of the respondents may have included their data without sharing those differences in their calculations, which could have introduced bias into the data. Lastly, as mentioned several times, the sample size is a possible limitation. With a larger sample size, multiple linear regression may have been able to detect small and medium effect sizes (Miles \& Shevlin, 2001). It should also be noted that data collection for this study was interrupted by international events that disrupted educational operations, which affected the total number of respondents, specifically the COVID-19 pandemic of 2020. 
The second set of limitations is characteristics or qualities outside the data collection process. For example, institutional size or classification was not included in the analysis. There is a possible relationship between the characteristics of the institution and SI program outcomes. Additionally, as funding for SI programs is primarily salaries (Wilcox, 2008), the funding might be contingent on the cost of living in the areas surrounding the institution rather than a marker of institutional support. Besides those, there were also differences in institutional practices at it pertains to their SI program. Wilcox (2008) recommends flexibility in the model for newer SI programs as they adapt SI to their institution. Several institutions included in the study were different in ways they adapted the SI model, such as the number of SI leaders per enrollment, number of sessions offered each week, differences in class attendance, and others. If any of those differences had a direct effect on the outcomes of program, the response would have been excluded, otherwise the response was included. Thus, these differences could be related to SI program outcomes more than this study's constructs.

\section{Delimitations}

There are a few of delimitations of the study. The first was the assumption that supervisory characteristics would be related to outcomes of SI programs while not including other aspects of SI programs. For example, faculty involvement is seen as critical to the success of an SI program (Hurley et al., 2006), but this study did not include a measure of that involvement. Some of the recommendations from Arendale's (2000) dissertation included national studies involving student characteristics or institutional characteristics. Thus, these are possible future areas of study but were also delimitations of this study. Second, the institutions in this data set were collected from North American institutions. Any 
institutions that filled out the survey as part of other international contexts were excluded. Third, in the survey, hours reported included paraprofessional staff, such as experienced SI leaders who serve to mentor or assist in program management. Respondents were asked to lump the hours of professional and paraprofessional staff together, implying no difference in the quality of those hours. There may be a difference between professional and paraprofessional staff, but there is a lack of research to determine what, if any, differences exist and the impact on program outcomes.

\section{Recommendations for Practice}

Because of the lack of statistical significance within the variables studied, this study does not offer many recommendations for practice. The findings around training hours per SI and attendance percentage provide one recommendation. Based on the findings of this study, SI program supervisors should consider prioritizing training-related activities when trying to boost SI attendance percentage. As McDaniel (2008) suggests, spending time discussing data collection during training is essential. This emphasis in training makes sure that leaders collect accurate attendance data. Spending time discussing the important role of SI leaders in attendance and working on strategies during training to promote session attendance is another recommendation. For example, the SI supervisor manual discusses SI marketing strategies to boost attendance and includes strategies such as distributing handouts, offering sample tests, and writing SI times on the board every class period (Curators of the University of Missouri, 2019). Reviewing these strategies with SI leaders during training could be a valuable method of boosting session attendance. Besides the focus on attendance strategies, SI supervisors could focus on other aspects of training that could produce higher quality sessions or processes that would boost attendance. One example might be creating a welcoming and 
inclusive environment in sessions to help students feel comfortable. Besides using training to boost attendance, there also might be some considerations for SI programs to insert more planning support processes in the program in order to support SI leaders and promoting program outcomes, but that finding was not substantiated by this research.

\section{Further Areas of Study}

This research provides multiple opportunities for additional areas of study. The first area of exploration would be exploring the supervisory constructs individually and possibly controlling for other characteristics or constructs. For example, exploring the relationship of planning support or observations with course outcomes when controlling for training, funding, and administrative support at one institution could control for outside variances that were present in this study. Studies such as these would help refine what practices are critical to the success and efficiency of an SI program. Additionally, future research should explore what aspects of training-related activities are associated with attendance percentage to help supervisors prioritize their work. Given the near significance of planning support and observation hours on the difference in average final grades, future research should explore these constructs further. In particular, research should investigate the potential negative relationship between observation hours and the difference in average final grades.

The second area of recommended further study would be to explore mixed-method approaches of program effectiveness. Creswell (2014) suggests three possible mixed-method designs, convergent parallel mixed methods (qualitative and quantitative research are conducted at the same time and compared), explanatory sequential mixed methods (quantitative analysis informs qualitative data collection), and exploratory (qualitative analysis informs quantitative data collection). Any of these three approaches might help 
explore supervisory constructs more deeply and inform additional studies on how they influence program outcomes. Such approaches might produce informative findings through sequential research methodologies.

Lastly, future studies should continue to collect data on a national or international level. For example, this study analyzed data in North American contexts, but a similar study could be conducted with SI programs in Australia. Additionally, these studies could include other important characteristics, such as institutional characteristics, faculty involvement, and other important factors that are theoretically linked to the success of an SI program. With such studies, a longer and more robust data collection process is likely warranted to ensure sufficient sample sizes to detect small and medium effects as well as a representative sample.

\section{Conclusion}

This study explored the relationships between SI program supervisory constructs and financial support with program outcomes through the use of multiple linear regression and correlation. While no significant models or correlations were detected, the training hours per SI leader was significantly related to attendance percentage for the program. Every hour added of training-related activities per SI leader will net an increase of slightly more than a $1 / 2$ of a percent in the attendance percentage of the program. This finding suggests that trainingrelated hours should be a critical component of an SI program supervisor's activities. Supervisors should focus on attendance strategies and creating high-quality sessions during training to boost attendance for the program. This study was limited by several factors but mainly sample size, measurement of constructs, and the exclusion of other potential factors that may influence an SI program's success. Future areas of study should focus on the 
individual supervisory constructs and design studies that are longitudinal and consist of various research methodologies.

The cost of higher education has been increasing, and the accountability from governments and individual families for student success is increasing as well (Cohen \& Kisker, 2010). Huisman and Currie (2004) suggest that the accountability of higher education is also related to how funds are used efficiently. As SI programs look to expand or justify their continued funding, additional research is needed to evaluate program impact, support continued operational efficiency, and continuously improve program quality. Studies such as these lead conversations around effectiveness and efficiency in hopes to provide the best possible programming for student success. 


\section{SECTION SIX - SCHOLARLY REFLECTION}

In this section, I discuss how the dissertation-in-practice process has affected my development as a scholar and practitioner. This process has influenced my growth as a scholar and confidence in my ability to conduct research, solve more significant problems of practice, and connect with scholars in my community. Additionally, the connections made and reflective skills gained have helped me as a practitioner in my organization and furthered my leadership development. This section discusses my development in more detail as a result of this dissertation-in-practice process.

\section{Scholarly Development}

There are several ways in which I have developed as a scholar throughout this process. The first is how understanding and using literature to support a study is an iterative process. I gained skills in using statistical techniques and strategies, particularly multiple linear regression. Third, I developed my ability to visualize data and represent information. Fourth, I now see problems of practice as potential scholarly endeavors and opportunities to help the field of learning assistance make positive changes to increase efficiency and effectiveness.

The first area of growth as a scholar was writing literature reviews and understanding the roles of theoretical and conceptual frameworks. In the coursework of summer two, I learned that the theory and conceptual framework should support and justify the methods and variables of a quantitative study. Creswell (2014) describes the role of literature in helping understand the relationships between ideas, and that theory often can organize the methods and hypotheses of the study. Ravitch and Riggan (2012) discuss how literature reviews point out gaps in knowledge and how conceptual frameworks relate different aspects of a study 
together. When writing my literature review and creating a framework for the study, I used these to support the methods and organization of my research. A conceptual framework should provide the reason for the study to be completed (Ravitch \& Riggan, 2012). Thus, one of the key areas of literature I reviewed was higher education and learning assistance programs, which provided context for the study and understanding of the need for the research to be completed. The other two conceptual pillars, SI program foundations and staffing considerations and support, shed light on how the independent variables could be related to the outcomes of the program. What surprised me about this process of alignment with the methods and variables of the study is how the process is iterative.

Checking the conceptual framework for alignment with the study has been an ongoing process. When discussing writing literature reviews, Galvan and Galvan (2017) suggests, "check[ing] the flow of your arrangement for coherence" (p.130). This process of checking the flow has occurred multiple times throughout the dissertation process, mainly as aspects of the study have changed over time. I have learned to write, and then come back and examine the flow and argument of my writing to see if it is not only coherent but aligns well with the arguments I am making with the conceptual framework. Galvan and Galvan (2017) also suggest how researchers should be able to describe how the literature connects to another. This process is also iterative as more connections are found with other scholarly work. It seems like I am continually finding new sources and new links between new work and what I studied.

This process has helped me understand the importance of visualization. The first realization is providing a visual of a conceptual framework. Ravitch and Riggan (2012) suggest that one view of conceptual frameworks is a visual of the organization or theory 
used. I think this is an excellent suggestion as it helps a reader understand the parts of the study, and furthers the alignment of the literature review with the framework. Beyond conceptual framework visualization, I am now more inclined to use visualizations of numbers. My undergraduate and graduate degrees were in mathematics education. Given this background, I generally can interpret and use numbers easily. However, I am learning that it can help others without such inclinations to have a visual of the numerical relationships and findings to be able to interpret that information more easily. Evergreen (2017) describes data visualization as a way to communicate information. When determining an appropriate visualization of the data, it is essential to consider what you are trying to communicate (Evergreen, 2017). This lesson of being clear on my purpose is critical for me as a practitioner. Evergreen (2017) also describes how to help others consider how to make visualizations more appealing and understandable. Information that I have gleaned from Evergreen's (2017) work includes colorization, selecting the most appropriate chart or graph, and clarifying scales, titles, and labels. Evergreen (2017) also cautions about how data visualization can provide misleading information; thus, I think it is critical to think about the fairest and most accurate way to represent the information I am trying to convey to promote ethical research practices.

The next area of scholarly development that I have gained throughout the dissertation-in-practice process is more familiarity with multiple linear regression. Most notably, I have learned more about power and appropriate sample sizes for multiple linear regression. Field (2018) and Miles and Shevlin (2001) give treatment to sample size concerns and how many samples are needed for a given number of predictors and the level of power. These considerations were used when designing the study and determining which variables to 
include. Additionally, both Field (2018) and Miles and Shevlin (2001) discuss assumptions of multiple linear models that were used in this study and will help me when I apply this method in the future.

Finally, this dissertation-in-practice process has helped me learn to treat problems in practice as potential scholarly endeavors. The idea for this study was inspired by a listserv post that discussed the need for scholarly literature on the structure and organization of tutoring programs. Before this process, my focus was on analyzing program effectiveness. Now I see so much potential in studying organizational effectiveness and efficiency of learning assistance programs and other higher education programs. When folks in learning assistance conduct research, we are often just studying how our programs impact or influence student success, but we also need to examine the effectiveness and efficiency of that work. Now when colleagues pose questions about issues or concerns in their practice, I think about how I might be able to study the issue. Learning assistance practices need additional research to support them (Arendale, 2010), so the field of learning assistance desperately needs this type of research. I now feel empowered to do that work in a scholarly way.

\section{Practitioner Development}

The dissertation-in-practice process has developed me significantly as a practitioner. First, the use and design of a survey will be useful in my work. Often, survey questions are critical for assessing programs and services in higher education. Second, this dissertation has allowed me to see and examine the value of practitioner and scholarly connections. Since implementing my survey, I have seen the value of networking with others by their responses to my survey and creating an even tighter group of professional and scholarly colleagues. Third, section two of the dissertation-in-practice was an extremely beneficial process that 
helped me reflect on my work as a leader and the organizations in which I work.

Furthermore, this type of analysis will aid me in other areas of my work and leadership in higher education, such as my role leading tutoring programs or if I took a leadership role in another area in higher education.

\section{Survey Design}

Survey design has been an enlightening process. When designing the survey, I had to consider several factors. "The appropriate analysis methods for survey data depends on sample size, the survey's research design, and the characteristics and quality of the data" (Fink, 2017, p. 153). Furthermore, Newcomer and Triplett (2015) discuss determining an analysis plan before designing a survey to collect the data you need. Thus, I considered all of these before designing my survey to determine the most effective way to collect and analyze the data. This lesson is vital for me to remember as a practitioner, as I often do not think ahead to the analysis method when designing a survey. Another aspect of planning the survey that was a useful lesson was giving time for pilot testing. Taking the time to get several rounds of feedback was extremely helpful for me to add clarity and add validity to my process. Fink (2017) and Newcomer and Triplett (2015) claim that pilot testing surveys are essential processes. I can see why, and it makes me want to be sure to include a pilot testing process in every survey I implement.

The second way that I have grown as far as survey development is the structure of a survey. Fink (2017) provides several recommendations for survey structure, such as including definitions, a progress bar, and having easy-to-answer questions at the end. This process of survey structure is useful, and I plan to use Fink's (2017) work when designing surveys in the future. Newcomer and Triplett (2015) discuss having an introduction to the 
survey that also describes the purpose. I attempted to do that as well in both my survey and email to participants. Some of the suggestions, such as leaving demographic questions at the end, are counter-intuitive, but I can see how it assisted people in completing a survey.

I have also learned methods of follow-up and implementation. When conducting a survey, sending regular reminders and tracking responses is needed for an improved response rate (Newcomer \& Triplett, 2015). In my dissertation process, I had several follow-up emails and phone calls. Newcomer and Triplett (2015) suggest adding the purpose to a survey introduction, which would add context, but I found that adding even more relevancy to the study's findings helped response rates. For example, I responded to a listserv post that was discussing the research I was trying to conduct and included my survey as part of my response. Several people filled it out after that email response. Second, phone calls helped tremendously, as it added a human connection and allowed program leaders to ask and receive clarification on questions about the survey. Newcomer and Triplett (2015) discuss the benefit of follow-up contacts in boosting response rates.

\section{Connections in the Field}

Another way that this dissertation-in-practice has helped me grow is through connections with others in the field. This process has allowed me to connect with others across the US and world. For example, I have a meeting set up with a Learning Center coordinator in May and an email exchange with an Australian about conducting a similar study in the Australian context. This study has been an opportunity to connect with likeminded colleagues and a chance to engage and make connections with others that I would not have done otherwise. This realization echos Baxter Magolda's (2009) description of connecting with supportive partners both personally and professionally as a method of 
growing a stronger sense of self. Additionally, the ability to use my knowledge and understanding to support my colleagues across the world and conduct research that is needed has been motivating to me professionally.

\section{Reflective Practices}

Section two of this dissertation-in-practice included a leadership and organizational analysis of our program of study. This analysis of both the leadership and organization of SI programs allowed me to engage in reflective practices that led to new perspectives in both of those areas. Merriam and Bierema (2014) describe the reflective practice as a method of learning where the individual reflects on experiences and make decisions based on that information. This section and its analysis provided this reflective experience for me. For example, situational leadership helped me understand how different leadership styles could be used to support SI leaders in different ways and build organizational structures to do that. Another example of how the leadership analysis affected my development was the discussion of transformational leadership, which made me realize that SI program administrators need to spend more time discussing the vision of the SI program to inspire and engage followers. This leadership analysis provided helpful and practical suggestions for me as a program supervisor. Thus, I hope to continue to engage in this leadership analysis as I progress in my professional career.

Similarly, the organizational analysis provided new perspectives on the organization of SI programs and their effectiveness. Bolman and Deal (2013) discuss the process of reframing in the field of organizational analysis, which "requires an ability to think about situations in more than one way, which lets you develop alternative diagnoses and strategies" (p. 5). For example, using the symbolic frame of organizational analysis helped me 
understand the importance of using stories and building a culture in an SI program. Analyzing programs and services through an organizational lens provides new perspectives on operations and effectiveness. Thus, I think this process of analyzing my work through organizational lenses is essential for me as a professional.

\section{Assessment Work}

Lastly, this process has helped me in my work in assessment. One critical competency of student affairs professionals is assessment, evaluation, and research (Johnson Eanes et al., 2015). This dissertation-in-practice process has helped me improve my understanding of quality assessment practices and given me greater abilities and confidence in designing assessments for different programs and student learning outcomes through wellhoned and specific, measurable research questions.

\section{Conclusion}

The dissertation-in-practice has been a valuable process that has helped me grow as a scholar and as a leader. As a scholar, I better understand statistical techniques and visualization strategies that will help me analyze problems more in-depth. I also have a better understanding of the process of developing and supporting scholarly work with bodies of literature, theories, and a conceptual framework. Finally, as a scholar, I have a better sense of how to see problems of practice as potential scholarly work that could help fellow practitioners. As a practitioner, I have seen the value of being able to develop better surveys as well as use surveys as assessment tools. This dissertation-in-practice process has also shown me the importance of connections between practitioners in the field. Being able to connect with others, share ideas, and support each other in research has provided valuable insights and relationships in the field. The process of analyzing an organization or leadership 
for this study has been a helpful reflective process. As my role changes in the future, I hope to periodically engage in leadership and organizational reflection to add new insights into my roles and responsibilities. Lastly, this work has been useful to apply to program evaluation and assessment in my work. It has given me additional skills to not only analyze the work I do but also the design of assessment activities. 


\section{References}

Ainsworth, L., Garnett, D., Phelps, D., Shannon, S., \& Ripperger-Suhler, K. (1994). Steps in starting supplemental instruction. New Directions for Teaching and Learning, 1994(60), 23-29.

Alexander, F. K. (2000). The changing face of accountability: Monitoring and assessing institutional performance in higher education. The Journal of Higher Education, 71(4), 411. doi:10.2307/2649146

Arendale, D. R. (1994). Understanding the supplemental instruction model. New Directions for Teaching and Learning, 1994(60), 11-21.

Arendale, D. R. (2000). Effect of administrative placement and fidelity of implementation of the model on effectiveness of supplemental instruction (Doctoral Dissertation). Retrieved from the ERIC database. (ED480590).

Arendale, D. R. (2004). Mainstreamed academic assistance and enrichment for all students: The historical origins of learning assistance centers. Research for Educational Reform, 9(4), 3-21.

Arendale, D. R. (2010). Access at the crossroads-Learning assistance in higher education. ASHE Higher Education Report, 35(6), 1-145.

Astin, A. W. (1985). Achieving educational excellence. San Francisco, CA: Jossey-Bass. Bass, B. M., \& Riggio, R. E. (2006). Transformational leadership (2nd ed.). Mahwah, NJ: Lawrence Erlbaum Associates, Inc.

Baum, S., Ma, J., \& Payea, K. (2013). Education pays, 2013: The benefits of higher education for individuals and society. College Board Retrieved from https://files.eric.ed.gov/fulltext/ED572537.pdf 
Baxter Magolda, M. (2009). Authoring your life: Developing your INTERNAL VOICE to navigate life's challenges. Sterling, VA: Stylus.

Bell, G. D. (1967). Determinants of span of control. American Journal of Sociology, 73(1), 100-109. doi: 10.1086/224439

Blanc, R. A., DeBuhr, L. E., \& Martin, D. C. (1983). Breaking the attrition cycle: The effects of supplemental instruction on undergraduate performance and attrition. Journal of Higher Education, 54(1), 80-90.

Blanchard, K. H., Zigarmi, P., \& Zigarmi, D. (1985). Leadership and the one minute manager: Increasing effectiveness through situational leadership. New York, NY: Morrow.

Bolman, L. G., \& Deal, T. E. (2013). Reframing organizations: Artistry, choice, \& leadership (5th ed.). San Francisco, CA: Jossey-Bass.

Bowles, T. J., \& Jones, J. (2004). The effect of supplemental instruction on retention: A bivariate probit model. Journal of College Student Retention, 5(4), 431-437.

Bowles, T. J., McCoy, A., \& Bates, S. (2008). The effect of supplemental instruction on timely graduation. College Student Journal, 42(3), 853-859.

Brubacher, J. S., \& Rudy, W. (1997). Changes and increases in administrative personnel. In L. F. Goodchild \& H. S. Wechsler (Eds.), The history of higher education (2nd ed., pp. 315-317). Needham Heights, MA: Simon \& Schuster Custom Publishing.

Buchanan, E. M., Valentine, K. D., \& Frizell, M. L. (2019). Supplemental instruction: Understanding academic assistance in underrepresented groups. The Journal of Experimental Education, 87(2), 288-298. doi: 10.1080/00220973.2017.1421517 
Butler, D. (2016). College access and opportunity. In C.P. Loss \& P. J. McGuinn (eds.), The Convergence of K-12 and higher education: Policies and programs in a changing era (pp. 137-163). Cambridge, MA: Harvard Education Press.

Carzo, R. Jr., \& Yanouzas, J. N. (1969). Effects of flat and tall organization structure. Administrative Science Quarterly, 14(2), 178-191.

Chickering, A. W., \& Reisser, L. (1993). Education and identity (2nd ed). San Francisco, CA: Jossey-Bass.

Church, R. L., \& Sedlak, M. W. (1997). The antebellum college and academy. In L. F. Goodchild \& H. S. Wechsler (Eds.), The history of higher education (2nd ed., pp. 131-148). Needham Heights, MA: Simon \& Schuster Custom Publishing.

Cohen, A. M., \& Kisker, C. B. (2010). The shaping of American higher education: Emergence and growth of the contemporary system (2nd ed.). San Francisco, CA: Jossey-Bass.

Collins, J. C. (2001). Good to great: Why some companies make the leap--and others don't. New York, NY: HarperCollins Publishers.

Collins, J., \& Cross, M. (2019, August 8). SI research meeting [Personal communication]. Congos, D. (2001). How supplemental instruction (SI) generates revenue for colleges and universities. Journal of College Student Retention, 3(3), 301-309.

Congos, D. H. (2002). How supplemental instruction stacks up against Arthur Chickering's 7 principles for good practice in undergraduate education. Research \& Teaching in Developmental Education, 19(1), 75-83. 
Congos, D. H., \& Mack, A. (2005). Supplemental instruction's impact in two freshman chemistry classes: Research, modes of operation, and anecdotes. Research \& Teaching in Developmental Education, 21(1), 43-64.

Congos, D. H., \& Schoeps, N. (1993). Does supplemental instruction really work and what is it anyway? Studies in Higher Education, 18(2), 165-176. doi:

$10.1080 / 03075079312331382349$

Creswell, J. W. (2014). Research design: Qualitative, quantitative, and mixed methods approaches. Thousand Oaks, CA: Sage.

Curators of the University of Missouri. (2018). SI program certification rubric [PDF file] Retrieved from https://info.umkc.edu/si/wp-content/uploads/2019/09/SI-programcertification-Rubric-Revised-Nov-2018.pdf

Curators of the University of Missouri. (2019). Supervisor manual. [Handbook]. Kansas City, Mo: University of Missouri - Kansas City

Dar, L. (2016). Institutional assessment and accountability. In C. P. Loss, \& P. J. McGuinn (Eds.), The convergence of $K-12$ and higher education: Policies and programs in a changing era (pp. 103-113). Cambridge, Ma: Harvard Education Press.

Etter, E. R., Burmeister, S. L., \& Elder, R. J. (2001). Improving student performance and retention via supplemental instruction. Journal of Accounting Education, 18(4), 355368.

Evergreen, S. D. H. (2017). Effective data visualization: The right chart for the right data. Thousand Oaks, CA: Sage.

Field, A. (2018). Discovering statistics using IBM SPSS statistics: North American edition (5th ed.). Thousand Oaks, CA: Sage 
Fink, A. (2017). How to conduct surveys: A step-by-step guide $\left(6^{\text {th }}\right.$ ed.). Thousand Oaks, CA: Sage.

Freeland, R. M. (1997). The world transformed: A golden age for American universities, 1945-1970. In L. F. Goodchild \& H. S. Wechsler (Eds.), The history of higher education (2nd ed., pp. 587-609). Needham Heights, MA: Simon \& Schuster Custom Publishing.

French, J. R., \& Raven, B. (2005). The bases of social power. In J. M. Shafritz, J. S. Ott, \& Y. S. Jang (Eds.), Classics of organization theory (6th ed., pp. 311-320). Belmont, CA: Wadsworth. (Reprinted from Studies in social power, pp. 150-167, by D.P. Cartwright, Ed., 1959, Ann Arbor, MI: Institute for Social Research, University of Michigan)

Galvan, J. L., \& Galvan, M. (2017). Writing literature reviews: A guide for students of the social and behavioral sciences ( $7^{\text {th }}$ ed.). New York, NY: Routledge.

Gattis, K. W. (2000). Long-term knowledge gains due to supplemental instruction in college chemistry courses. Journal of Research and Development in Education, 33(2), 118126.

Greenleaf, R. K. (1996). On becoming a servant-leader (D. M. Frick \& L. C. Spears, Eds.; 1st ed). San Francisco, CA: Jossey-Bass.

Guarcello, M. A., Levine, R. A., Beemer, J., Frazee, J. P., Laumakis, M. A., \& Schellenberg, S. A. (2017). Balancing Student Success: Assessing Supplemental Instruction Through Coarsened Exact Matching. Technology, Knowledge and Learning, 22(3), 335-352. doi: 10.1007/s10758-017-9317-0 
Haveman, R., \& Smeeding, T. (2006). The role of higher education in social mobility. Future of Children, 16(2), 125-150.

House, R. J. (1996). Path-goal theory of leadership: Lessons, legacy, and a reformatted theory. Leadership Quarterly, 7(3), 323-352.

House, R. J., \& Mitchell, T. R. (1974). Path-goal theory of leadership. Journal of Contemporary Business, 3(4), 81-97.

Huisman, J., \& Currie, J. (2004). Accountability in higher education: Bridge over troubled water? Higher Education, 48(4), 529-551. doi:

10.1023/B:HIGH.0000046725.16936.4c

Hurley, M., \& Gilbert, M. (2008a). Basic supplemental instruction model. In M. E. Stone \& G. Jacobs (Eds.), Supplemental instruction: Improving first-year student success in high-risk courses (Monograph No. 7) (3rd ed., pp. 1-9). Columbia, SC: University of South Carolina, National Resource Center for The First-Year Experience and Students in Transition.

Hurley, M., \& Gilbert, M. (2008b). Effectiveness of Supplemental Instruction. In M. E. Stone \& G. Jacobs (Eds.), Supplemental instruction: Improving first-year student success in high-risk courses (Monograph No. 7) (3rd ed., pp. 11-19). Columbia, SC: University of South Carolina, National Resource Center for The First-Year Experience and Students in Transition.

Hurley, M., Jacobs, G., \& Gilbert, M. (2006). The basic SI model. New Directions for Teaching and Learning, 2006(106), 11-22.

Jacobs, G., \& Stone, M. E. (2008). Foreword. In M. E. Stone \& G. Jacobs (Eds.), Supplemental instruction: Improving first-year student success in high-risk courses 
(Monograph No. 7) (3rd ed., pp. v-vi). Columbia, SC: University of South Carolina, National Resource Center for The First-Year Experience and Students in Transition. Jacobs, G., Stout, M. L., \& Stone, M. E. (2008). Supplemental instruction: International adaptations and future directions. In M. E. Stone \& G. Jacobs (Eds.), Supplemental instruction: Improving first-year student success in high-risk courses (Monograph No. 7) (3rd ed., pp. 81-90). Columbia, SC: University of South Carolina, National Resource Center for The First-Year Experience and Students in Transition.

Johnson, E. L. (1997). Misconceptions about early land-grant colleges. In L. F. Goodchild \& H. S. Wechsler (Eds.), The history of higher education (2nd ed., pp. 222-233). Needham Heights, MA: Simon \& Schuster Custom Publishing.

Johnson Eanes, B., Perillo, P. A., Fechter, T., Gordon, S. A., Harper, S., Havice, P., Hoffman, J. L., Martin, Q. I., Osteen, L., Pina, J. B., Simpkins, W., Tran, V. T., Turner Kelly, B., \& Willoughby, C. (2015). Professional competency areas for student affairs educators. Washington, DC: American College Personnel Association (ACPA) and National Association of Student Personnel Administrators (NASPA).

Jones, J. P. (2013). The impact of the Supplemental Instruction leader on student performance in introductory accounting. American Journal of Business Education, 6(2), 247-254.

Kathman, J. M., \& Kathman, M. D. (2000). Training student employees for quality service. The Journal of Academic Librarianship, 26(3), 176-182.

Kochenour, E. O., Jolley, D. S., Kaup, J. G., Patrick, D. L., Roach, K. D., \& Wenzler, L. A. (1997). Supplemental Instruction: An effective component of student affairs programming. Journal of College Student Development, 38(6), 577-586. 
Kouzes, J. M., \& Posner, B. Z. (2012). The leadership challenge: How to make extraordinary things happen in organizations (5th ed). San Francisco, CA: Jossey-Bass.

Levi, D. (2017). Group dynamics for teams (5th ed.). Thousand Oaks, CA: Sage.

Liden, R. C., Panaccio, A., Meuser, J. D., Hu, J., \& Wayne, S. J. (2014). Servant Leadership. In D. V. Day (Ed.), The Oxford Handbook of Leadership and Organizations (pp. 357-379). New York, NY: Oxford University Press.

Lipsky, S. A. (2006). A credit-bearing course for training SI leaders. New Directions for Teaching and Learning, 2006(106), 33-41.

Lozada, N., \& Johnson, A. T. (2019). Perspective transformation in the supplemental instruction (SI) leader. Journal of Transformative Education, 17(2), 112-132. doi: $10.1177 / 1541344618774544$

Manning, K. (2009). Organization theory in higher education. New York, NY: Routledge. Martin, D. C., \& Arendale, D. R. (1992a). Review of research on supplemental instruction. In J. N. Gardner, B. O. Barefoot, D. S. Fidler, \& S. M. Jennings (Eds.), Supplemental Instruction: Improving first-year student success in high-risk courses. (pp. 19-26). Columbia, SC: The National Resource Center for the Freshman Year Experience. Martin, D. C., \& Arendale, D. R. (1992b). Supplemental instruction in the first college year. In J. N. Gardner, B. O. Barefoot, D. S. Fidler, \& S. M. Jennings (Eds.), Supplemental Instruction: Improving first-year student success in high-risk courses. (pp. 11-18). Columbia, SC: The National Resource Center for the Freshman Year Experience. Martin, D. C., \& Arendale, D. R. (1992c). Understanding the SI model. In J. N. Gardner, B. O. Barefoot, D. S. Fidler, \& S. M. Jennings (Eds.), Supplemental Instruction: 
Improving first-year student success in high-risk courses. (pp. 3-10). Columbia, SC: The National Resource Center for the Freshman Year Experience.

Martin, D. C., \& Blanc, R. (1981). The learning center's role in retention: Integrating student support services with departmental instruction. Journal of Developmental \& Remedial Education, 4(3), 2-23.

Maxwell, M. (1997). What are the functions of a college learning assistance center?. Kensington, MD: MM Associates. Retrieved from ERIC database (ED413031).

McDaniel, A. (2008). Recruiting and training supplemental instruction leaders. In M. E. Stone \& G. Jacobs (Eds.), Supplemental instruction: Improving first-year student success in high-risk courses (Monograph No. 7) (3rd ed., pp. 39-56). Columbia, SC: University of South Carolina, National Resource Center for The First-Year Experience and Students in Transition.

McGuire, S. Y. (2006). The impact of Supplemental Instruction on teaching students how to learn. New Directions for Teaching and Learning, 2006(106), 3-10.

Meier, K. J., \& Bohte, J. (2000). Ode to Luther Gulick: Span of control and organizational Performance. Administration \& Society, 32(2), 115-137. doi: $10.1177 / 00953990022019371$

Meling, V. B., Mundy, M., Kupczynski, L., \& Green, M. E. (2013). Supplemental instruction and academic success and retention in science courses at a hispanic-serving institution. World Journal of Education, 3(3), 11-23. doi: 10.5430/wje.v3n3p11

Merriam, S. B., \& Bierema, L. L. (2014). Adult learning: Linking theory and practice. San Francisco, CA: Jossey-Bass. 
Meyer, M. W. (1968). Expertness and the span of control. American Sociological Review, 33(6), 944-951. doi: 10.2307/2092685

Miles, J., \& Shevlin, M. (2001). Applying regression \& correlation: A guide for students and researchers. London: Sage.

Mintzberg, H. (2005). The five basic parts of the organization. In J. M. Shafritz, J. S. Ott, \& Y. S. Jang (Eds.), Classics of organizational theory (6th ed., pp. 219-230). Belmont, CA: Wadsworth. (Reprinted from The structure of organization: A synthesis of research, pp. 18-24, 1979, Upper Saddle River, NJ: Prentice Hall)

NCLCA. (2015a). Pertinent Publishing Parameters [PDF]. Retrieved from https://nclca.wildapricot.org/resources/Documents/Publications/TLAR/Pertinent_Publ ishing_Parameters_6th_Edition_APA.pdf

NCLCA. (2015b). The Learning Assistance Review [webpage]. Retrieved from https://nclca.wildapricot.org/tlar

Newcomer, K. E., \& Triplett, T. (2015). Using surveys. In K. E. Newcomer, H. P. Hatry, \& J. S. Wholey (Eds.), Handbook of practical program evaluation (4th ed., pp. 344-382). Hoboken, NJ: Jossey-Bass.

Ning, H. K., \& Downing, K. (2010). The impact of supplemental instruction on learning competence and academic performance. Studies in Higher Education, 35(8), 921939. doi: 10.1080/03075070903390786

Northouse, P. G. (2016). Leadership: Theory and practice. Thousand Oaks, CA: Sage.

Ogden, P., Thompson, D., Russell, A., \& Simons, C. (2003). Supplemental instruction: Short- and long-term impact. Journal of Developmental Education, 26(3), 2-8. 
Oja, M. (2012). Supplemental instruction improves grades but not persistence. College Student Journal, 46(2), 344-350.

Painter, S. L., Bailey, R., Gilbert, M., \& Prior, J. (2006). New directions for supplemental instruction. New Directions for Teaching and Learning, 2006(106), 73-84.

Price, J., Lumpkin, A. G., Seemann, E. A., \& Bell, D. C. (2012). Evaluating the Impact of Supplemental Instruction on Short- and Long-Term Retention of Course Content. Journal of College Reading and Learning, 42(2), 19.

Ramirez, G. M. (1997). Supplemental Instruction: The long-term impact. Journal of Developmental Education, 21(1), 2-10.

Ravitch, S. M., \& Riggan, M. (2012). Reason \& rigor: How conceptual frameworks guide research. Thousand Oaks, CA: Sage.

Schein, E. H. (2005). Defining organizational culture. In J. M. Shafritz, J. S. Ott, \& Y. S. Jang (Eds.), Classics of organization theory (6th ed., pp. 360-367). Belmont, CA: Wadsworth. (Reprinted from Organizational culture and leadership (2nd ed.), pp.315, 1993, San Francisco: Jossey-Bass)

SI. (2019a). Certification Overview [webpage]. Retrieved from https://info.umkc.edu/si/certification/

SI. (2019b). What Is Supplemental Instruction [webpage]. Retrieved from https://info.umkc.edu/si/

Skoglund, K., Wall, T. J., \& Kiene, D. (2018). Impact of supplemental instruction (SI) participation on college freshman retention. Learning Assistance Review, 23(1), 115135. 
Stout, M. L., \& McDaniel, A. J. (2006). Benefits to supplemental instruction leaders. New Directions for Teaching and Learning, 2006(106), 55-62.

Thelin, J. R. (2011). A history of American higher education (2nd ed.). Baltimore, MY: John Hopkins University Press.

Tinto, V. (1987). Leaving college: Rethinking the causes and cures of student attrition.

Chicago, IL: University of Chicago Press.

Tinto, V. (2012). Completing college: Rethinking institutional action. Chicago, IL: University of Chicago Press.

Truschel, J., \& Reedy, D. L. (2009). National Survey - What is a Learning Center in the 21st Century? The Learning Assistance Review, 1, 9-22.

Udell, J. G. (1967). An empirical test of hypotheses relating to span of control. Administrative Science Quarterly, 12(3), 420-439. doi: 10.2307/2391313

UMKC SI. (2019). FAQ [webpage]. Retrieved from https://info.umkc.edu/si/faq/ Vygotsky, L.S. (1978). Mind in society: The development of higher psychological processes. Cambridge, MA: Harvard University Press.

Weick, K. (1983). Educational organizations as loosely coupled systems. In J. V. Baldridge \& T. Deal (Eds.), The dynamics of organizational change in education (pp. 15-37). Berkley, CA: McCutchan Publishing Corporation. (Reprinted from Administrative Science Quarterly, 23, pp. 541-552, 1978)

Widmar, G. E. (1994). Supplemental instruction: From small beginnings to a national program. New Directions for Teaching and Learning, 1994(60), 3-10.

Wilcox, F. K. (1992). Reasons educators and students choose SI. In J. N. Gardner, B. O. Barefoot, D. S. Fidler, \& S. M. Jennings (Eds.), Supplemental Instruction: Improving 
first-year student success in high-risk courses. (pp. 27-30). Columbia, SC: The National Resource Center for the Freshman Year Experience.

Wilcox, F. K. (2008). Implementing a new supplemental instruction program. In M. E. Stone \& G. Jacobs (Eds.), Supplemental instruction: Improving first-year student success in high-risk courses (Monograph No. 7) (3rd ed., pp. 29-38). Columbia, SC: University of South Carolina, National Resource Center for The First-Year Experience and Students in Transition.

Wilcox, F. K., \& Jacobs, G. (2008). Thirty-five years of Supplemental Instruction: Reflection on study groups and student learning. In M. E. Stone \& G. Jacobs (Eds.), Supplemental instruction: Improving first-year student success in high-risk courses (Monograph No. 7) (3rd ed., pp. vii-x). Columbia, SC: University of South Carolina, National Resource Center for The First-Year Experience and Students in Transition. Zaritsky, J. S., \& Toce, A. (2006). Supplemental instruction at a community college: The four pillars. New Directions for Teaching and Learning, 2006(106), 23-31.

Zerger, S. (2008). Theoretical frameworks that inform the supplemental instruction model. In M. E. Stone \& G. Jacobs (Eds.), Supplemental instruction: Improving first-year student success in high-risk courses (Monograph No. 7) (3rd ed., pp. 21-28). Columbia, SC: University of South Carolina, National Resource Center for The FirstYear Experience and Students in Transition.

Zerger, S., Clark-Unite, C., \& Smith, L. (2006). New directions for Supplemental Instruction. New Directions for Teaching and Learning, 2006(106), 63-72. 


\section{Appendix A}

\section{SI Program Survey}

This survey is designed to collect data for a research study about the effect of SI program administrator activities and funding on program outcomes. We are conducting this study to determine what SI program supervisory activities are the most critical for program outcomes, the optimal level of those activities, and to assist in prioritizing these tenets. The research is conducted as part of a dissertation at the University of Missouri - Columbia.

We invite you to take part in this research study because of your potential affiliation with an SI program. If you do not feel you can answer the following questions or do not feel you are the appropriate person, please pass this survey along to the current SI supervisor at your institution.

Anyone who leads a Supplemental Instruction (SI) in North America based on the model created at the University of Missouri - Kansas City are invited to complete this study. You are assisting SI program administrators in learning how their activities affect program outcomes. By participating in this research, the results of the research will help SI program administrators lead their programs. The results of the study could help administrators find gaps in their current practice and subsequently advocate for resources. If SI programs are seeking to expand or implement new SI programs, the findings will help them do that.

Your participation in this research should only take approximately 10-15 minutes if your data is readily available. Your participation in this survey is entirely voluntary. You may stop at any time and decide not to complete the survey, and your responses will not be recorded. Only one survey response per program per semester/term is needed.

Participants who choose to include their email when completing this survey will receive a copy of the findings. There are no other known benefits to participate in the study.

The information we collect about your SI program will be kept anonymous, and no identifiable information for the institution or program will be present in the results of the study. Additionally, the data will be stored on the researcher's computer behind password protection.

If you have any questions or concerns, please contact Kirk Skoglund at kaskhn@mail.missouri.edu or the dissertation advisor, Dr. Timothy Wall, at timwall@nwmissouri.edu.

If you have questions about your rights as a research participant, please contact the University of Missouri - Columbia Institutional Review Board (IRB) by phone 573-8823181 or email irb@missouri.edu.

Definition of Terms: 
- Administrative staff - any personnel associated with an SI program who assists in the program administration, including training, observations, session planning, program evaluation, data collection, and logistics. These personnel include SI mentors, graduate assistants, professional staff, and clerical staff.

- SI Mentors - program assistants that may assist with a variety of SI program tasks, including observations, assisting SI leaders with planning, assisting with training, data collection and evaluation.

To complete this survey, you will need access to the following information:

For a given semester or term, the following data points:

- Average grade differential* defined as the difference in the average final course grade of the entire SI program for a given semester using a four-point scale ( $4=\mathrm{A}$, $\mathrm{B}=3$, etc.) between the students who attended at least one SI session compared to the students who did not attend any SI sessions.

- The difference in DFW rates* for the entire SI program defined as the difference between the rate of students who earn a D, F, or withdrew from a course and attended at least one SI session and the students who earned a D, F, or withdrew from a course and did not attend any SI sessions

- Percentage of students who attended at least one SI session* for the entire SI program for SI-supported courses.

- Approximate number of training hours, number of SI Leaders, number of observation hours, administration hours (see guided questions below for more details.)

- Approximate amount of funding devoted to the SI program for a given semester (see the guided questions below for more detail.)

- *If you are missing this data point and cannot calculate it, you may leave it blank.

\section{Guided Questions}

For these questions, consider a specific semester or term for which you have the data listed above for your entire SI program.

1. What term or semester are you using? (e.g. Fall 2019 or Winter/Spring 2018)

2. What is the average final grade differential for your SI program during the designated semester or term? Calculate by taking the average final course grade of all the students who did not attend any SI sessions using a four-point scale ( $4=\mathrm{A}, 3=\mathrm{B}$, etc.) and subtract it from the average final grade using a four-point scale $(4=\mathrm{A}, 3=\mathrm{B}$, etc.) for all the students attended at least one SI session. For example, if the average final grade of the SI attendees was 2.00 and the average final grade of the students who did not attend SI sessions was a 1.50 , the difference would be $2.00-1.50=0.50$, and you would enter 0.50 .

3. What is the difference in DFW rates for the institution's entire SI program during the designated semester or term? Calculate by subtracting the rate of students who earned 
a D, F, or withdrew from a class who attended at least one SI session from the rate of the students who earned a D, F, or withdrew from a class of the students who did not attend any SI sessions. For example, if the DFW rate of the student who attended SI sessions was $15 \%$ and the DFW rate of the students who did not attend SI sessions was $33 \%$, the calculation should be $33-15=18 \%$ and that should be entered for this question.

4. What is the percentage of students who attended at least one SI session for the entire SI program for the given semester or term? Calculate by taking the total number of students who attended at least one SI session divided by the total number of students enrolled in SI supported courses.

Please estimate how many administrative hours were spent in total on the following activities in a given semester or term:

5. Total Observation Hours: The approximate number of hours spent observing, preparing to observe, and debriefing with SI leaders following observations. These hours can include peer observations, observations by SI mentors or program assistants, and observations by professional or paraprofessional staff.

6. Total Training Hours: Any administrative hours planning and delivering training, including initial or pre-semester and any ongoing training. This figure includes the actual training time. Do not duplicate planning time. Occasionally, staff members work together to plan training, only double that time if each staff member is working on separate tasks.

7. Total Planning Support Hours: All administrative hours devoted to assisting SI leaders with planning SI sessions. This figure does not include faculty members' assistance with planning or an SI leader's individual planning time, only administrative time dedicated to assisting SI leaders with planning.

8. Total Administrative Hours: Any hours by office staff, SI leader, SI Mentors, graduate assistants, or professional staff devoted to SI program evaluation, faculty meetings, data collection, and tracking, report writing, room scheduling, emailing, etc. These hours should not include training, observations, or planning activities.

9. Total Funding for the SI program for a specific semester and term: The approximate total amount of funding, including the salaries of all SI leaders and administrative staff, and operational costs of the SI program. If administrative staff have multiple roles, account only for the portions working for the SI program. For example, if $25 \%$ of an administrator's time goes to the SI program, only $25 \%$ of his/her salary should be used in this calculation. Additionally, if it makes sense to divide your annual budget by the number of terms/semesters to calculate the cost for a semester, please feel free to do that.

\section{Other Questions}

10. How many SI Leaders were employed and actively holding sessions by your institution's program during the given semester/term?

11. Was your institution's SI program accredited/certified by the International Center for Supplemental Instruction during that semester/term? (Yes/No) 
12. Which adaptations, if any, differentiate your implementation of SI from the model presented by the International Center for Supplemental Instruction at UMKC? Please elaborate on them here.

13. Your institution's name?

14. Is your institution considered...? (public or private)

15. Is your institution considered....? (4-year or 2-year?

16. What is your name (if provided will only be used for follow-up/clarification purposes)?

17. What is your preferred email (if provided will only be used for follow-up/clarification purposes)?

18. What is your phone number (if provided will only be used for follow-up/clarification purposes)?

Thank you for completing the survey questions. Please click the arrow key to submit your responses. 


\title{
Appendix B
}

\section{Initial Email to Contacts}

Colleagues,

I am completing my Doctorate in Education in Educational Leadership and Policy Analysis at the University of Missouri, and I am seeking your assistance in a research study about the effect of Supplemental Instruction (SI) program administrator activities and funding on program outcomes.

I am conducting this study as part of my doctoral dissertation and hope to determine which SI program activities are the most critical for program outcomes, the optimal level of those activities, and prioritizing these tenets.

You are invited to take part in this research study because of your potential affiliation with an SI program. The SI program should be based on the model presented by the International Center for Supplemental Instruction at the University of Missouri - Kansas City model, but institutional adaptations are expected. If you no longer supervise an SI program, please pass this survey along to the current SI supervisor at your institution. Only one survey response per program per semester/term is needed.

Your participation in this research should only take approximately 10-15 minutes if your data is readily available and is entirely voluntary. If you plan on completing this survey, please do so by <INSERT DATE>.

To access the survey, please click the following link:

\section{$<$ INSERT LINK>}

Participants who complete this survey will receive a copy of the findings if they choose to provide an email. There are no other known benefits to participate in the study.

The information we collect about your SI program will be kept anonymous, and no personal identifying information will be present in the results. Additionally, the data will be stored on the researcher's computer behind password protection.

If you have any questions, please feel free to contact me or my dissertation advisor, Dr. Timothy Wall (timwall@nwmissouri.edu).

I hope you consider participating.

Thank you,

\author{
Kirk Skoglund \\ Doctoral Candidate \\ University of Missouri - Columbia \\ kaskhn@mail.missouri.edu
}




\section{$\underline{\text { Reminder Email to Contacts }}$}

Colleagues,

This email is a friendly reminder regarding the SI program survey in the email below. If you have a moment to fill out the survey, it would be greatly appreciated. This data is critical for my dissertation.

If you plan to fill out the survey, please do so by <INSERT DATE >

If you have any questions, please feel free to contact me or my dissertation advisor, Dr. Timothy Wall (timwall@nwmissouri.edu).

I hope you consider participating.

Thank you,

Kirk Skoglund

Doctoral Candidate

University of Missouri - Columbia

kaskhn@mail.missouri.edu

Colleagues,

I am completing my Doctorate in Education in Educational Leadership and Policy Analysis at the University of Missouri, and I am seeking your assistance in a research study about the effect of Supplemental Instruction (SI) program administrator activities and funding on program outcomes.

I am conducting this study as part of my doctoral dissertation and hope to determine which SI program activities are the most critical for program outcomes, the optimal level of those activities, and prioritizing these tenets.

You are invited to take part in this research study because of your potential affiliation with an SI program. The SI program should be located in North America and based on the model presented by the International Center for Supplemental Instruction at the University of Missouri - Kansas City model, but institutional adaptations are expected. If you no longer supervise an SI program, please pass this survey along to the current SI supervisor at your institution. Only one survey response per program per semester/term is needed.

Your participation in this research should only take approximately 10-15 minutes if your data is readily available and is entirely voluntary. If you plan on completing this survey, please do so by <INSERT DATE>. 
To access the survey, please click the following link:

$<$ INSERT LINK>

Participants who complete this survey will receive a copy of the findings if they choose to provide an email. There are no other known benefits to participate in the study.

The information we collect about your SI program will be kept anonymous, and no personal identifying information will be present in the results. Additionally, the data will be stored on the researcher's computer behind password protection.

If you have any questions, please feel free to contact me or my dissertation advisor, Dr. Timothy Wall (timwall@nwmissouri.edu).

I hope you consider participating.

Thank you,

Kirk Skoglund

Doctoral Candidate

University of Missouri - Columbia

kaskhn@mail.missouri.edu

\section{Email to Listservs:}

Colleagues,

I am completing my Doctorate in Education in Educational Leadership and Policy Analysis at the University of Missouri, and I am seeking your assistance in a research study about the effect of Supplemental Instruction (SI) program administrator activities and funding on program outcomes.

I am conducting this study as part of my doctoral dissertation and hope to determine which SI program activities are the most critical for program outcomes, the optimal level of those activities, and prioritizing these tenets.

Given that members of this list are often affiliated with an SI program, I am asking many of you to take this survey. If you no longer supervise or are affiliated with an SI program, please pass this survey along to the current SI supervisor at your institution. Only one survey response per program per semester/term is needed.

Your participation in this research should only take approximately 10-15 minutes if your data is readily available and is entirely voluntary. If you plan on completing this survey, please do so by <INSERT DATE>

To access the survey, please click the following link: 


\section{$<$ INSERT LINK>}

Participants who complete this survey will receive a copy of the findings if they choose to provide an email. There are no other known benefits to participate in the study.

The information we collect about your SI program will be kept anonymous, and no personal identifying information will be present in the results. Additionally, the data will be stored on the researcher's computer behind password protection.

If you have any questions, please feel free to contact me or my dissertation advisor, Dr. Timothy Wall (timwall@nwmissouri.edu).

I hope you consider participating.

Thank you,

Kirk Skoglund

Doctoral Candidate

University of Missouri - Columbia

kaskhn@mail.missouri.edu 


\section{Appendix C}

These terms and definitions will be included in the appendix of the journal article when submitted.

1. Administrative hours - any hours by office staff, SI leader, SI program assistants or SI mentors, graduate assistants, or professional staff that are dedicated to SI program evaluation, faculty meetings, data collection, and tracking, report writing, room scheduling, emailing, etc. This figure does not include training, observations, or planning activities.

2. Difference in DFW rates - the difference between the rate of students who earn a D, $\mathrm{F}$, or withdrew (DFW) from a course and attended at least one SI session and the DFW rate of the students who did not attend any SI sessions

3. Grade differential - the difference in the average final grade of the entire SI program across all their courses for a given semester using a four-point scale $(4=\mathrm{A}, \mathrm{B}=3$, etc.) between the students who attend at least one SI session compared to the students who did not attend any SI sessions.

4. Observation hours - the approximate number of hours spent observing, preparing to observe, and debriefing with SI leaders following observations. These hours can include peer observations, observations by SI mentors or program assistants, and observations by professional or paraprofessional staff.

5. Planning hours - all administrative hours devoted to assisting SI leaders with planning SI sessions.

6. Total Funding - the approximate total amount of funding, including the salaries of all SI leaders and administrative staff and operational costs of the SI program.

7. Training hours - administrative hours planning and delivering training and/or professional development, including initial and any ongoing training. This figure includes the actual training time as well as time planning it. 


\section{VITA}

Kirk Skoglund entered the field of learning assistance during his undergraduate degree as a math tutor with the desire to follow most of his family in the world of K-12 education as a high school math teacher. After discovering a passion for helping students learn and the excitement of supporting students in higher education, Kirk pursued and attained a myriad of student employment roles during his undergraduate degree, including such positions as a tour guide, orientation leader, peer advisor, and office assistant. After graduating, Kirk was offered a short-term position conducting research at his alma mater in collaboration with Birmingham City University, conducting research on peer academic support systems in the context of international higher education. What was designed to be short-term ended up not being short, and Kirk continued working at his alma mater. While working, Kirk attained a master's degree in teaching: Mathematics with what is now recognized as the foolish hope of escaping higher education to be a math teacher. After working in leadership roles in higher education, Kirk decided that further education in educational leadership was necessitated. Besides school, Kirk is an avid runner, cook, and reader. This doctorate will not likely be the end of Kirk's educational pursuits, but will likely be the only doctorate. 